\title{
AN EVALUATION OF ONTARIO PUBLIC HEALTH UNITS' PRACTICES IN THE REDEVELOPMENT OF BROWNFIELDS
}

\author{
By \\ Barbara Lachapelle, BASc \\ Toronto, Ontario \\ May 6, 2013 \\ A thesis presented to Ryerson University \\ In partial fulfillment of the \\ Requirements for the degree of \\ Master of Applied Science \\ In the Program of \\ Environmental Applied Science and Management \\ Toronto, Ontario, Canada, 2013 \\ (C) Barbara Lachapelle 2013
}




\section{Author's Declaration}

I hereby declare that I am the sole author of this thesis. This is a true copy of the thesis, including any required final revisions, as accepted by my examiners.

I authorize Ryerson University to lend this thesis to other institutions or individuals for the purpose of scholarly research.

I further authorize Ryerson University to reproduce this thesis by photocopying or by other means, in total or in part, at the request of other institutions or individuals for the purpose of scholarly research.

I understand that my thesis may be made electronically available to the public. 


\begin{abstract}
An Evaluation of Ontario Public Health Units' Practices in the Redevelopment of Brownfields

Master of Applied Science, 2013

Barbara Lachapelle, Environmental Applied Science and Management

Ryerson University

The revitalization of brownfields provides many health benefits. Revitalization addresses historical contamination and it allows to re-design the community with health in mind. It is recognized that public health units (PHUs) have an important role to play on brownfield sites. Information suggests that Ontario PHUs often become involved on brownfield sites but the extent of that involvement is not known.

Ontario PHUs were surveyed about their involvement on brownfield sites. The results indicate that most Ontario PHUs engage in brownfield redevelopment to some extent. Public health units identified inadequate resources, expertise, and lack of training as the most critical factors affecting their response.

Results of the survey were further compared with the ATSDR Brownfields/Land Revitalization Action Model. This critical analysis helped to identify key gaps and weaknesses in the current Ontario practices. The results are used to propose recommendations to enhance public health practice and to maximize community health benefits.
\end{abstract}




\section{Acknowledgments}

It would not have been possible to write this Masters thesis without the help and support of many people around me.

This thesis would not have been possible without the help, support, and encouragement of my supervisor, Dr. Timothy Sly. Furthermore, I would like to thank the members of my examining committee, Dr. Michal Bardecki, Dr. Ron Pushchak, and Mr. Rod Adams, for their time, consideration, and excellent feedback.

Many of my colleagues provided support and shared their enthusiasm for this work, thank you Reg Ayre, Melissa Simone, Andrea Fernando, Melanie Azeff, and Josephine Archbold. Your patience, support and feedback were always appreciated and welcomed.

I would also like to thank my loving friends Jordan Tustin and Elizabeth MacDougall. Your guidance, patience, support, and the ability to tolerate many long conversations on the topic of brownfields were invaluable to my success.

Thank you to my parents, Irena and Daniel, for your love and encouragement during the long years of my education. This thesis would not have been possible without your support.

And finally, I would like to thank my husband, Trevor Lachapelle, for being my dearest friend, support system, sounding board, coach, and cheerleader. Thank you for always being there for me. 


\section{Table of Contents}

Author's Declaration $\quad$ ii

Abstract

Acknowledgements

Table of Contents $\quad v$

List of Tables, Figures and Appendices vii

1.0 Introduction $\quad 1$

1.1 The Need for Assessing the Current Level of Involvement 2

1.2 Background $\quad 2$

2.0 Environmental Public Health and Contaminated Sites 5

2.1 Environmental Burden of Disease $\quad 5$

$\begin{array}{ll}2.2 & \text { Environmental Risk Factors at Contaminated Sites }\end{array}$

2.3 Review of Environmental Exposures and Health Outcomes 12

$\begin{array}{ll}2.4 \text { Limitations of the Current Body of Research } & 18\end{array}$

2.5 Spatial Distribution of Brownfields 21

2.6 Health Risks and Contaminated Sites: Summary of Evidence 25

3.0 Assessing Public Health Units' Involvement in Brownfield Activities $\quad 27$

$\begin{array}{ll}3.1 \text { Purpose } & 27\end{array}$

3.2 Measuring Involvement: Methods $\quad 28$

3.3 Results - Univariate Analysis $\quad 35$

3.4 Results - Bivariate Analysis $\quad 52$

$\begin{array}{ll}3.5 \text { Discussion } & 57\end{array}$

3.6 Study Limitations $\quad 66$

4.0 Integrating Brownfield Redevelopment with Health 69

4.1 Community Design and Health 69 
$\begin{array}{ll}\text { 4.2 Revitalization of Brownfields and Health } & 70\end{array}$

$\begin{array}{ll}\text { 4.3 Best Practices and Health Focused Brownfield Revitalization } & 71\end{array}$

4.4 Rationale for Choosing the ATSDR Model as Best Practices in Health-Based

Brownfield Redevelopment

4.5 Overview of the ATSDR Land Reuse Revitalization Process

4.6 Examples of Development Communities and Improvements in Measurable Health Outcomes

4.7 Critical Analysis of PHUs Activities on Brownfield Sites in Comparison to the ATSDR Action Model

4.8 Conclusions

5.0 Recommendations

5.1 Proposed Federal Initiatives

5.2 Provincial Level Support

5.3 Changes at the Municipal Level

6.0 Conclusions

Appendix A

References 


\section{List of Tables}

Table 2.1 Distribution of Contaminants at Brownfield Sites 8

Table 2.2 Potential Exposure Pathways 10

Table 2.3 Potentially Contaminated Sites in Canada 22

Table 3.1 Spatial Distribution of Public Health Units in Ontario 30

Table 3.2 Characteristics of Ontario Public Health Units (N=36) 35

Table 3.3 PHUs Involvement in Activities Related to Brownfields Between 2000 and 36

$2010(N=32)$

Table 3.4 PHUs Change in Involvement in Brownfield Activities Since 2004 (N=32) 37

Table 3.5 Process for PHUs Involvement in Brownfield Activities ( $\mathrm{N}=32)$

Table 3.6 Initiation of PHUs Involvement in Brownfield Activities (N=32) 38

Table 3.7 Stage at Which PHUs Initiate Involvement in Brownfields ( $N=32)$

Table 3.8 Public Health Units' Activities at Brownfield Sites ( $N=32)$

Table 3.9 Engagement of Community Members in Brownfield Activities ( $N=32)$

Table 3.10 Importance of Brownfields as a Public Health Issue Within PHUs (N=32) 42

Table 3.11 Importance of Engagement in Brownfield Activities Within PHUs (N=32) 43

Table 3.12 Involvement in Brownfields as Part of the Current Scope of Work (N=32) 44

Table 3.13 Awareness of Brownfields Within PHUs Jurisdiction ( $N=32)$

Table 3.14 Need for Involvement in Brownfields Within PHUs Jurisdiction (N=32) 45

Table 3.15 Perceived Benefits Related to PHUs Involvement in Brownfields ( $N=32)$

Table 3.16 Perceived Benefits Gained from PHUs Involvement in Brownfield Activities 46

$(\mathrm{N}=32)$

Table 3.17 Skills and Expertise Within Ontario Health Units (N=32) 47

Table 3.18 Professional Development Opportunities Within PHUs ( $\mathrm{N}=32)$

Table 3.19 Access to Resources Within PHUs (N=32) 49

Table 3.20 Need for Additional Resources and Training ( $N=32)$

Table 3.21 Stakeholder Collaboration in Brownfield Activities $(N=32)$

Table 3.22 Communication Tools Used by PHUs ( $\mathrm{N}=32)$ 
Table 3.23 The Need for Engagement as Reported by PHU's Involvement in Brownfield

Activities ( $\mathrm{N}=27)$

Table 3.24 Awareness of Existing Brownfields within PHU's Jurisdiction and

Involvement in Brownfield Activities ( $N=27)$

Table 3.25 Involvement in Brownfield Activities and Importance of Brownfields as a

Public Health Issue $(\mathrm{N}=28)$

Table 3.26 Involvement in Brownfield Activities and Benefits from PHUs Involvement

on Brownfield Sites ( $\mathrm{N}=26)$

Table 3.27 Involvement in Quantitative Risk Analysis on Brownfield Sites and PHUs'

Current Expertise in Quantitative Risk Analysis ( $N=23)$

Table 4.1 Community Health Evaluation Example

Table 4.2 Examples of ATSDR Development Communities

\section{List of Figures}

Figure 4.1 Steps in Developing a Healthy Community

\section{List of Appendices}

Appendix A: Key Informant Questionnaire: Public Health Practice 


\subsection{Introduction}

Current provincial and municipal policies encourage brownfield redevelopment throughout Ontario (Ontario Ministry of Public Infrastructure Renewal, 2006; 2008; Great Lakes Commission, 2001). Revitalization of brownfield sites provides opportunities to improve the health of communities by cleaning up historically contaminated lands and thereby reducing the public's potential exposure to toxic chemicals (Archbold \& Lachapelle, 2008; NACCHO, 2000; TPH, 2009). Furthermore, brownfield revitalization allows an opportunity for an integration of health promotion principles into community design, thereby leading to the creation of healthy built environments and the overall well-being of neighbourhoods (ATSDR, 2010; NACCHO, 2000).

It is well established that public health units (PHUs) have an important role to play in the redevelopment of brownfields (Archbold \& Lachapelle, 2008; TPH 2009; ATSDR, 2010 \& 2011; NACCHO, 2000). In Ontario, although they do not have the primary jurisdictional responsibility in the redevelopment process, PHUs are often engaged by communities to evaluate health risks associated with exposures to site contaminants. The demand for public health intervention is often driven by communities' perception of local health authorities as being credible and trustworthy (Sly, 2000; NACCHO, 2000).

PHUs involvement in brownfield redevelopment can enhance levels of community trust, maximization of public health benefits, minimization of risk (real and perceived), and minimization of unnecessary cost overruns and delays. Furthermore, if the involvement is facilitated early in the redevelopment process, it allows public health officials to address health disparities and broader determinants of health. 


\subsection{The Need for Assessing the Current Level of Involvement}

Although the need for and benefits of public health involvement in brownfield redevelopment are well documented, the actual extent to which Ontario PHUs engage in redevelopment activities is not known. Anecdotal data suggest that Ontario PHUs display a large variability in the processes, policies, and tools they utilize during the redevelopment process. At a 2009 meeting between the Ministry of the Environment (MOE) and Greater Toronto Area (GTA) health units to discuss implications of brownfield regulatory reforms, it became evident that PHUs involvement in brownfields ranged from being highly engaged to providing minimal input (Archbold, 2009). As such, it was hypothesized that an analysis of the extent of PHUs involvement in brownfield activities would help to identify the barriers influencing such involvement and opportunities to enhance it. The results would be useful in identifying best practices, enhancing consistency and standardization throughout jurisdictions, and optimizing targeting of interventions to improve health outcomes.

\subsection{Background}

The Ontario Ministry of the Environment (MOE) (2008) defines Brownfields as "abandoned, idle, or under-utilized industrial and commercial properties where the previous property use caused environmental contamination". As many sites are often impacted by toxic substances, they can pose significant health risks to the surrounding communities.

Risks of adverse health effects on such sites depends on the nature of the contaminant and the site-specific physicochemical conditions, combined with the magnitude and duration of exposure and the individual characteristics of the receptor. Although there is a substantial body of toxicological and epidemiological evidence regarding specific environmental hazards, 
causal relationships between exposure at Brownfield sites and adverse health outcomes are often difficult to correlate due to small sample sizes, long latency periods, difficulties in characterizing exposure, and population migration (Vrijheid, 2000). Current data, though not scientifically robust, suggest an association between physical proximity to contaminated sites and increased incidence of respiratory illness, various cancers, adverse reproductive outcomes, low birth weights, birth defects, abnormal liver function, renal disease, and increases in total mortality (Litt et al., 2002; Griffith et al., 1989; Vrijheid, 2000; Litt \& Burke, 2002; Ofungwu \& Eget, 2005).

Due to the lack of a comprehensive provincial brownfield inventory, little is known about the actual numbers of such sites in Ontario. A study published by ECO Canada (2007) suggests there could be as many as 25,000 potentially contaminated sites located throughout the province. Many are located in desirable and strategic locations - in the hearts of urban communities, on scenic waterfronts, in or near downtown cores, and often in close proximity to residential areas (Ontario Brownfields Advisory Panel, 2000).

\section{Ontario Public Health Brownfields Policy}

Public health involvement in the brownfield redevelopment process is not clearly defined, but rather implied. Under the current regulatory regime, local health agencies have a clear duty to prevent, decrease, or eliminate health hazards, and specifically to investigate all environmental and occupational health hazards (HPPA, 1990). Under the current Ontario Public Health Standards (MHLTC, 2008), the Environmental Health Program Standards specify that health units assess environmental health risks, reduce the incidence of adverse health outcomes from exposure to environmental agents, and reduce the burden of illness from 
environmental hazards. Although involvement with Brownfields redevelopment is not explicitly defined, the response to the hazards and risks associated with these sites is well within each health unit's mandatory program mandates.

The Ontario Ministry of the Environment (MOE) has the primary jurisdiction over the Brownfields redevelopment process. The MOE enforces the Record of Site Condition regulation, sets and enforces soil and groundwater standards, and issues regulatory control instruments for contaminated sites (MOE, 2009). The major limitation within the current brownfields regulation is that it only applies to sites that are changing use from less sensitive to more sensitive land use leaving many contaminated sites outside of the MOE jurisdiction and without any regulatory oversight (Archbold \& Lachapelle, 2008). As a result, Ontario public health units often become engaged in the brownfields process to assess and interpret human health risks, communicate those risks with affected communities, and propose solutions to mitigate those risks (NACCHO, 2000; ATSDR, 2010). As such, it is necessary that health units have the necessary response capacity to effectively participate in the redevelopment process to maximize public health benefits on brownfield sites. Furthermore, health units' activities on these sites should be aligned with best practices established by other credible public health agencies (NACCHO, 2000; ATSDR, 2010). 


\subsection{Environmental Public Health and Contaminated Sites}

\subsection{Environmental Burden of Disease}

It has been widely recognized that exposure to environmental pollution remains a major source of health risk throughout the world (e.g. Briggs, 2003; WHO, 2000; McLaughlin Centre, 2007; Boyd \& Genuis, 2007; Landrigan et al., 2002). For a number of years, the World Health Organization (WHO) had set out to measure the environmental burden of disease (EBD), the proportion of the human disease burden that is attributed to environmental causes (WHO, 2006). In their seminal work, Preventing Disease Through Healthy Environments, Towards an estimate of the environmental burden of disease, the WHO environmental working group had estimated the contribution of various environmental factors to human disease worldwide (WHO, 2006; Thomas, 2009). By focusing on disease endpoints, rather than risk factors, they estimated how much morbidity and mortality could realistically be avoided each year as a result of reduced exposures to environmental hazards. They have concluded that $24 \%$ of the global disease burden and $23 \%$ of all deaths can be attributed to environmental factors. Amongst many risk factors, urban air pollution and exposure to lead carried some of the largest absolute burden and contributed to 799,000 and 234,000 excess deaths per year, respectively (WHO, 2006; Thomas, 2009).

Empirical data indicate significant environmental body burdens amongst the Canadian population as well. It has been well documented that Canadian adults and children bare heavy body burdens of dozens of toxic chemicals, including heavy metals, pesticides, dioxins, flame retardants and other pollutants (Neumann et al., 2006, Health Canada, 2009). In their recent 
review, Boyd and Genuis (2007) evaluated the EBD in Canada for respiratory disease, cardiovascular disease, cancer, and congenital affliction. They utilized the environmentally attributable fractions (EAF) method developed by the WHO and the data from Canadian public health institutions to provide an estimate of the environmental burden of disease for the four major categories of disease. They have concluded that as many as 25,000 deaths, 194,000 hospitalizations, 1.5 million hospital days, 24,000 new cancer cases, and 2500 low birth weight babies were associated with environmental exposures. Smith et al. (1999) estimated that children under 5 years of age seem to bear the largest environmental burden.

That is consistent with conclusion reached by others, that the biggest environmental impact is largely experienced by children. The WHO estimated that as much at $36 \%$ of all deaths amongst children could be attributed to environmental factors. In general, children experience higher relative food intake, water and soil consumption per kilogram of body weight. They have increased ventilation rates relative to adults, and often exhibit behavioural factors such as hand-to-mouth contact that increases their contact with the ground (Tyshenko et al., 2007). Landrigan and colleagues (2002) set out to estimate the relative contribution of environmental pollutants to the morbidity, mortality, and costs for lead poisoning, asthma, cancer, and developmental disabilities in American children. Utilizing the EAF approach they have determined that environmental factors to contribute $100 \%$ of lead poisoning, $30 \%$ of asthma, $5 \%$ of cancers, and $10 \%$ of neurobehavioural disorders. The total annual costs were estimated to be $\$ 54.9$ billion, $2.8 \%$ of the total U.S. health care cost. As the body burden of environmental pollutants appears to be similar between American and Canadian children, it is reasonable to expect similar contributions of environmental exposures to the incidence, 
prevalence, mortality and costs of pediatric disease in the Canadian population (Boyd \& Genuis, 2007).

\subsection{Environmental Risk Factors at Contaminated Sites}

\section{Brownfields and contaminants of concern}

The Ontario Ministry of the Environment (MOE) defines brownfields as "abandoned, idle, or under-utilized industrial and commercial properties where the previous property use caused environmental contamination" (MOE, 2008). They include sites that are both vacant or are actively used, and can range from former water ports to railway lines, from industrial and manufacturing sites to auto-body shops and gas stations. They may even include neighbourhood dry cleaner operations.

Published empirical research indicates that brownfields are often contaminated by toxic substances, which can pose significant health risks (Litt et al., 2002; Syms, 2004; Colten, 1990). Hundreds of chemicals associated with industrial and manufacturing processes - delivery, storage and handling of raw materials, manufacturing, and disposal of waste products - can impact sites as a result in soil, groundwater, or air contamination (Syms, 2002; Leigh \& Hise, 1997; Colten, 1990; MOE, 2011). The potential for the chemical to have an impact on human health will depend, amongst other things, on its concentration and inherent toxicity. Although there are hundreds of potential chemicals on any given site, they can be broadly classified into categories based on their physical and chemical properties. Most commonly encountered categories include heavy metals, petroleum hydrocarbons, polycyclic aromatic hydrocarbons, volatile organic compounds and polychlorinated biphenyls. Their physicochemical characteristics, e.g. solubility in water, partition coefficient, hydrolysis, ionization, and vapour 
pressure, are critical in predicting the environmental fate, its persistence, and its toxicity (McKinney, 1981).

Data from the United States reported by Johnson (1995) indicate that the most frequently encountered contaminants include: volatile organic compounds (VOC) $(74 \%$ of all assessed sites), metals (71\%), halogenated pesticides (37\%), polycyclic aromatic hydrocarbons (25\%), phenol/phenoxy acids (23\%), phthalates (22\%), nitrosamines/ethers/alcohols (15\%), and organophosphates (14\%). Furthermore, at nearly half of federally registered brownfield sites, contaminants such as metals and volatile organic compounds are associated with off-site migration and contamination of adjacent properties (NRC, 1991). When in proximity to residential dwellings, off-site migration of chemicals can pose a significant risk to health.

Table 2.1. Distribution of Contaminants at Brownfield Sites

\begin{tabular}{|c|c|c|c|c|c|c|c|c|c|}
\hline Substance & $\begin{array}{l}\text { ATSDR } \\
\text { Priority } \\
\text { Group }\end{array}$ & No. & $\%$ & $\begin{array}{l}\text { Sites with } \\
\text { Migration }\end{array}$ & $\begin{array}{l}\text { Ground- } \\
\text { water }\end{array}$ & $\begin{array}{l}\text { Surface } \\
\text { water }\end{array}$ & Soil & Air & Food \\
\hline \multicolumn{2}{|c|}{ Metallic Elements } & 564 & 59 & 327 & 234 & 138 & 122 & 37 & 50 \\
\hline Lead & 1 & 404 & 43 & 224 & 159 & 84 & 88 & 28 & 39 \\
\hline Chromium & 1 & 329 & 35 & 142 & 93 & 55 & 48 & 12 & 15 \\
\hline Arsenic & 1 & 262 & 28 & 36 & 92 & 46 & 54 & 16 & 19 \\
\hline Cadmium & 1 & 232 & 24 & 112 & 72 & 49 & 45 & 18 & 21 \\
\hline \multicolumn{10}{|c|}{ Volatile Organic } \\
\hline TCE & 1 & 402 & 42 & 231 & 204 & 63 & 41 & 44 & 19 \\
\hline $\begin{array}{l}\text { Benzene } \\
\text { Vinyl }\end{array}$ & 1 & 323 & 34 & 139 & 115 & 41 & 27 & 29 & 9 \\
\hline Chloride & 1 & 187 & 20 & 87 & 80 & 16 & 14 & 18 & 7 \\
\hline PCBs & & 162 & 17 & 86 & 43 & 25 & 40 & 11 & 25 \\
\hline PAHs & & 187 & 20 & 75 & 32 & 22 & 31 & 4 & 6 \\
\hline Phthalates & & 106 & 11 & 35 & 22 & 13 & 17 & 5 & 5 \\
\hline Pesticides & & 82 & 9 & 25 & 13 & 8 & 17 & 6 & 7 \\
\hline
\end{tabular}

Source: NRC, 1991. 
Data from Ontario are not as readily available. Although hundreds of Phase I and Phase II Environmental Site Assessments (ESA) are completed each year in support of applications for the MOE Record of Site Condition, the actual reports are not available for review - only the summary reports are posted on the World Wide Web (MOE, 2011b). A cursory review of the available reports indicates that the contaminant profile and distribution is similar to that reported by Johnson (1995). This is further supported by research completed by Toronto Public Health (TPH, 2011) in support of the Urban Gardening Soil Assessment Protocol initiative.

\section{Potential pathways of exposure}

For populations to be affected at brownfield sites, an established complete exposure pathway must be present. The mere presence of a contaminant will not result in adverse effects in the population if a receptor does not have a contact with the contaminant. Exposure pathway analysis helps to identify how site receptors are exposed to the contaminants. Furthermore, the route of exposure is toxicologically significant as it identifies how the contaminant makes physical contact with the body (Health Canada, 1996). As illustrated in Table 2.3, exposure pathways most often of concerns at contaminated sites include: ingestion, inhalation, and dermal contact. 


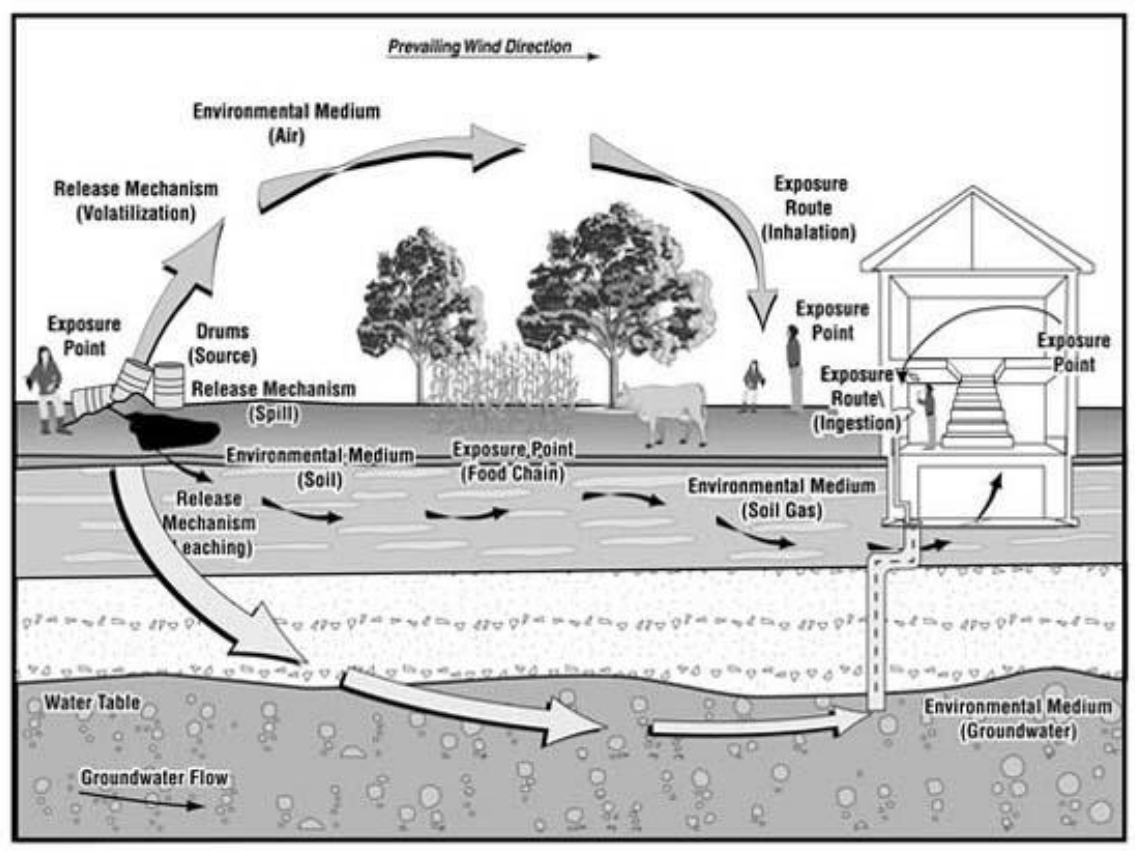

Source: ATSDR, 2005.

Sever (1998) noted that in order for an individual to be exposed at a contaminated site, a completed exposure pathway must exist through the five criteria of exposure (Sever, 1998):

- Identified source of contamination

- Environmental media and transport pathways

- Geographic point of exposure or contact

- Biologic route of exposure

- Presence of receptor population

Although any incidental site user can come in contact with contaminants, soil contamination from past industrial activities is one of the more significant exposure pathways for several receptors in particular: children, construction, remediation and utility workers, gardeners, 
individuals residing on brownfield sites (Litt, Tran \& Burke, 2002; MOE, 2009; Ott et al., 2007; Toronto Public Health, 2011):

Children. Because their bodies are still developing, children are more prone to experience adverse health effects as a result of exposure to site contaminants. They consume more food and water per body weight than adults and their digestive system can absorb some contaminants such as lead more readily than an adult's system. Children are also prone to hand-to-mouth behavior leading to higher ingestion rates of contaminated soils. It has been estimated that children can ingest approximately $200 \mathrm{mg}$ of soil per day, ingest $100 \mathrm{mg}$ of dust per day, and have dermal contact with 400 mg of dust per day (MOE, 2009; Ott et al., 2007).

Construction, remedial and utility workers. They are at an increased risk of contact with site contaminants. As they may spend a significant amount of time directly on the brownfield sites, they might come in direct contact with site contaminant through touching soils, inhaling contaminated dust or ingesting dust. If they do not change clothing, they might carry contaminated dust on their persons potentially depositing it into their indoor environment (MOE, 2009).

Gardeners. Gardeners are at an increased risk of contact with contaminants due to their direct dermal contact with soils and high potential for breathing contaminated dust. In addition, they might be exposed through consuming produce with uptake of contaminants from and groundwater (Toronto Public Health, 2011).

Individuals residing at brownfield sites. Exposure to site contaminants can occur through ingestion of contaminated water and produce, ingestion of contaminated dust on food 
products, inhalation of contaminated dust and ambient air, and inhalation of contaminated indoor air as a result of vapour vitalization and intrusion into the home (MOE, 2009).

In conclusion, risk of adverse health effects will depend on the nature of the contaminant encountered and its site-specific physicochemical conditions, combined with the magnitude and duration of exposure and the individual characteristics of the receptor.

\subsection{Review of Environmental Exposures and Health Outcomes}

In recent years there has been a wealth of research directed at quantifying the relationship between environmental exposures and various health outcomes. In general, the research can be grouped into two major categories: study of health effects resulting from exposure to mixtures of various chemicals at contaminated sites, and study of health outcomes associated with exposure to specific chemicals that are commonly encountered in the environment, but not necessarily at a site that is traditionally defined as a brownfield. It is outside the scope of this paper to critically review all studies published on the topic of environmental exposures and associated health outcomes, however, this section identifies the main themes identified in the peer reviewed literature.

\section{Literature pertaining to brownfield sites and health outcomes}

There is limited literature on exposure to contaminants at brownfield sites and associated health outcomes however, it is suspected that is due to the use of the term brownfield rather than lack of studies on the subject matter. Most literature can be located by searching by environmental media, (i.e. soil, groundwater or air contamination), by specific health outcomes (e.g. cancer or birth effects), by specific property uses (e.g. hazardous waste sites or industrial facilities), or by a specific substance (e.g. lead). This is a representative 
summary of the current literature on the topic. It covers most common health endpoints of concern, contaminants of concern, and specific property uses.

\section{$\underline{\text { Cancer }}$}

One of the most commonly explored environmental health outcomes in peer reviewed literature. It is estimated that in Ontario, by 2020 , there will be 91,000 newly diagnosed cancer cases (Cancer and the Environment Stakeholder Group, 2007). Furthermore, there is a rising incidence of cancer among young adults, and over half (56\%) of new cancers occurs among those under 70 years of age. Although the percentage of cancers related to environmental exposures is not well understood, cancers of the bladder, breast, pancreas, prostate, kidney, ovary and lung have been linked to environmental carcinogens, and some childhood cancers, (i.e. thyroid, brain and childhood leukemia) have been linked to environmental exposures (Cancer and the Environment Stakeholder Group, 2007).

Russi et al. (2007) reviewed nineteen peer reviewed studies published between 1980 and 2006 to explore cancer incidence or mortality in the vicinity of toxic waste sites. Sixteen of the nineteen studies were ecological surveys and thus provided little insight into individual exposures. Authors often failed to characterize the contamination or include transport pathways or modeling. Russi et al. concluded that studies have generated hypotheses, but lacked the necessary robustness to assess cancer risk in the exposed populations.

Wild et al. (2009) explored the association between lung cancer and exposure to carcinogenic metals, i.e. chromium, nickel, beryllium, cadmium, arsenic, and silicon. Furthermore, they also reviewed the existing literature for metals for which the evidence is less clear: lead, titanium, iron and cobalt. As expected, they found strong evidence for metals such 
as cadmium and chromium, but weaker associations between metals such as lead and cancer risk. They acknowledge that factors inherent to some metals, i.e. speciation, physical structure, and solubility, and the challenges they bring into the epidemiological studies.

Brody et al. (2007) explored exposure to several environmental pollutants and the incidence of breast cancer. They reviewed several studies with varied study designs and sample sizes. They found that evidence to date generally supports an association between breast cancer and exposure to PAHs (Analysis from three studies that were reviewed - OR=1.92, 95\% $\mathrm{Cl}: 1.21-3.07 ; \mathrm{OR}=1.9,95 \% \mathrm{Cl}: 1.15-3.15 ; \mathrm{OR}=1.32,95 \% \mathrm{Cl}: 1.00-1.74)$ as well as breast cancer and exposure to $\mathrm{PCBs}(\mathrm{OR}=2.9,95 \% \mathrm{Cl}: 1.02-8.2 ; \mathrm{OR}=2.5,95 \% \mathrm{Cl}: 1.1-5.7)$. They found much weaker evidence for cancer outcomes and exposure to pesticides, organic solvents, DDT, dioxins, and organochlorine.

Hoar Zahm \& Ward (1998) reviewed the association between exposure to various pesticides and childhood cancer. Although Ontario has had a cosmetic pesticides ban in effect since April 22, 2009 (MOE, 2011a), much of the empirical literature indicates that pesticides can be persistent in soil and groundwater, representing an important potential exposure pathway for children (Arias-Estevez et al., 2007; Grant, 2011; Hoar Zahm \& Ward, 1998). In their review the authors considered various routes and timings of exposure, including maternal and paternal exposures, and also the direct exposure of the child; the timing of exposure included most of the childhood life stages ranging from pregnancy through the childhood. In terms of health outcomes the authors considered leukemia, brain cancer, neuroblastoma, non-Hodgkin's lymphoma, Wilm's tumor, Ewing's sarcoma, and other malignancies. They reported positive association between most cancers and childhood exposures to pesticides noting a similar trend 
amongst adult receptors as well. They have acknowledged typical challenges that are common to environmental epidemiologic investigations: case definition, choice of controls, exposure assessment, genetic-environmental interactions, statistical power and the required strength of association.

\section{Congenital abnormalities}

Are a common health endpoint often explored in epidemiologic studies of environmental contamination. It has been suggested that birth outcomes, such as birth weights, are particularly sensitive to environmental influences (Sever, 1998). Furthermore, data on live and stillbirths are routinely collected through regular surveillance activities and generally considered to be reliable and of good quality (Dodds \& Seviour, 2001). Dodds and Seviour (2001) examined adverse birth outcomes in residents residing in Sydney, Nova Scotia, in proximity to one of the largest hazardous waste sites in North America. The site is a result of approximately 80 years of coke oven operations and had documented multi-media contamination with PAHs, PCBs, benzene, and heavy metals. Investigators compared birth outcomes of Sydney residents to those of Cape Breton County and rest of Nova Scotia. They observed a small, but statistically significant increase in the rate of congenital anomalies in Sydney versus the rest of Nova Scotia (adjusted RR=1.25; 95\% Cl=1.04-1.51).

In 2006, Buchynska and Tarkowski explored various environmental exposures and its impact on birth outcomes. They examined several epidemiological studies of exposures to commonly encountered brownfield contaminants and the associated health outcomes such as low birth weights, preterm births, and birth defects. Although they acknowledged methodological limitations in many of the studies, they concluded that exposure to 
environmental pollutants may significantly affect the prevalence of adverse health outcomes. Based on the results of their review, they called for a precautionary approach and preventive measures aimed at reduction of environmental exposures. Similar conclusions were drawn by Dolk and Vrijheid (2003). Although they also recognized many similar design limitations in the studies they examined, they acknowledged there is enough empirical evidence to warrant a precautionary approach and reduction in exposures to environmental pollutants.

\section{$\underline{\text { Psychosocial distress }}$}

Although not as commonly associated with exposures to chemical hazards as physical health outcomes, psychosocial distress associated with contaminated sites has also been explored in the peer-reviewed literature. Vandermoere (2008) examined psychosocial health of residents exposed to soil pollution in a Flemish neighbourhood. He examined several major covariates of mental health among residents living on soil polluted with heavy metals and PAHs. After comparing 109 exposed residents with a quasi-control group ( $n=161)$ he concluded the mental health of exposed residents was much worse than that of the non-exposed group. The major distress factors were the perceived lack of participation in the brownfields process and the perceived need for soil remediation and clean up.

Boardman et al. (2008) examined proximity to industrial activity, the role of gender, occupational status and family status, and its association with psychosocial distress. Using a spatial assessment of industrial activity coupled with demographic data from the U.S. Census, he found that residents living in close proximity to industrial activity reported elevated levels of psychological distress. He concluded these stressors were more pronounced amongst women versus man however, in both cases they were strongly conditioned by occupational and 
parental status. Although Burger (2005) did not look at indicators of psychosocial stress but rather at attitudes of residents living near contaminated sites, she observed the residents were highly concerned about human health and pollution. Specifically, concerns about accidents/spills and loss of public health were ranked the highest.

\section{Exposure to lead}

Environmental exposure factors contribute to $100 \%$ of lead poisonings. Lead is one of the most abundant of the heavy metals in the Earth's crust and it has been widely used since prehistoric times, as a result, it is widely distributed in the environmental media (Tong et al., 2000). Overwhelmingly, exposure to lead has been associated with a wide array of adverse health impacts. At high concentrations, human exposure results in damage to most organ and organ systems, including the central nervous system, kidneys and blood, often culminating in death. At low levels, lead exposure impacts biochemical processes, as well as psychological and neurobehavioural function (Gasana et al., 2006; Lorenzana et al., 2003; Tong et al., 2000; Mostafa et al., 2009). Empirical data show that lead is one of the most commonly encountered contaminants on brownfield sites, with elevated levels being detected at $55 \%$ of all U.S. Superfund sites (Lorenzana et al., 2003; Toronto Public Health, 2011). Many have noted that residing near contaminated sites impacted with lead has been positively correlated with elevated childhood lead blood levels and the associated adverse health impacts (Gasana et al., 2006; Lorenzana et al., 2003; Tong et al., 2000; Mostafa et al., 2009).

\section{$\underline{\text { Hazardous waste sites }}$}

Association between exposure at the Love Canal, a hazardous waste site in New York, US, and adverse health outcomes has been extensively explored in the epidemiologic literature. 
NRC (1991) and Sever (1998) reviewed numerous epidemiologic studies that explored the association between exposure to hazardous waste at Love Canal and adverse health outcomes. In their review they note the different study designs (e.g. cohort, cross-sectional, ecological), different exposure classifications, different study populations, and different selection criteria. They note the studies also examined a wide array of health outcomes, e.g. cancer, chromosomal aberrations, low birth weight, seizures, hyperactivity, skin conditions, anthropometric measures and others. NRC (1991) and Sever (1998) concluded that although many of the studies reported significant association between exposures and reported outcomes, all were subject to common challenges encountered in environmental epidemiologic research and failed to establish causality.

\subsection{Limitations of the Current Body of Research}

Although there is a substantial body of toxicological and epidemiological evidence regarding specific environmental hazards, evidence presented in this paper indicates that causal relationships between exposure at brownfield sites and adverse health outcomes are often difficult to correlate. Most often cited challenges pertain to study design and include small sample sizes, long latency periods, difficulties in characterizing exposure, and population migration (Vrijheid, 2000). However, current data, though not scientifically robust, do suggest an association between physical proximity to contaminated sites and increased incidence of respiratory illness, various cancers, adverse reproductive outcomes, low birth weights, birth defects, abnormal liver function, renal disease, and increases in total mortality (Litt et al., 2002; Griffith et al., 1989; Vrijheid, 2000; Litt \& Burke, 2002; Ofungwu \& Eget, 2005). Evidence 
presented earlier in this paper shows that most studies have focused on former landfills or hazardous waste sites, and have used proximity to sites as a proxy for measuring exposure. In their respective publications, the National Research Council (1991), Baker and Nieuwenhuijsen (2008), and the US EPA (2009) have extensively reviewed the most common challenges related to environmental epidemiologic and toxicological research.

Exposure assessment. An exposure to a specific environmental chemical is often extremely difficult to accurately characterize. It can be very costly to conduct the necessary environmental sampling to fully characterize the chemical in the various environmental compartments. Most chemicals are present as mixtures of various concentrations that can change over time and as such, their effects are not always fully understood. It is almost impossible to assess how much of a given chemical a person has actually been exposed to. Residing near contaminated sites is often used as an exposure proxy, regardless of whether an exposure pathway is actually present. Lastly, many epidemiologic studies are often retrospective in nature and rely on participants' recollection of the events.

Toxicity studies. Most of our knowledge regarding the hazard potential of various chemicals stems from animal model toxicological studies. Although there are many strong qualities associated with animal studies, e.g. the ability to test a single chemical at a specific dose and for a pre-determined duration of exposure, there are also many negatives. Animal models often differ significantly from human subjects in how they absorb, distribute and metabolize chemicals. Laboratory animals are often dosed with high concentrations of chemicals and are exposed for short durations of time, described as the "high dose phenomena". In order to use the animal data to predict impacts to humans, smaller doses and 
chronic exposure duration are extrapolated from the dose-response curves (US EPA, 2009). Safety factors are then applied to account for the uncertainty.

Human studies. As the majority of experimental human studies for toxicology are highly unethical, the majority of the current knowledge on human health risks from direct exposures to chemicals stems from observational studies in occupational settings. This makes it a challenge for extrapolation of risk to the general public, as subjects in occupational studies tend to be healthy, young, and usually exposed for shorter duration of time. Furthermore, they are usually exposed to chemicals at concentrations that are not environmentally relevant. As many chemicals have specific effect threshold, that could either overestimate the risk or preclude from observing more sensitive health outcomes occurring at lower concentrations (Hallenbeck \& Cunningham, 1986).

Causal inference. Environmental epidemiologic studies are rarely robust enough to meet the standard requirements for demonstrating causality (NRC, 1991). Strength of association is often difficult to document and many of the relevant health outcomes, e.g. cancer and spontaneous abortions, are prevalent in the unexposed population. Specificity of association is difficult to prove as one agent disease model often does not apply to the health outcomes under observations and multiple factors (e.g. genetics and lifestyle factors) are often implicated in disease formation. Consistency of association is also a challenge as the exposed populations are heterogeneous and often exposed to mixtures that might vary from those encountered at other sites. Biologic gradient of the dose-response relationship can be highly affected by the timing of exposure and health condition of the subjects. Often the removal of suspected cause to prove causal relationship is unfeasible as many contaminants are now 
ubiquitous in the environment. And lastly, biological plausibility is often questioned due to the inherent reliance on animal toxicity data.

\subsection{Spatial Distribution of Brownfields}

The environmental impacts on brownfield sites usually stem from myriad historical industrial and manufacturing activities that resulted in improper storage, handling, and disposal of chemicals and the resulting intentional or unintentional releases to soil, groundwater and air. Brownfield sites can range from neighbourhood gas stations and dry cleaners to urban waterfronts and rain lands, through large scale mines and coal tar sites. Environmental Careers Organization Canada (ECO, 2007) Canada estimated that in Ontario there are approximately 25,611 potentially contaminated sites. Ontario has by far the highest number of contaminated sites in Canada - out of a total of 64,046 federally distributed sites Ontario houses $39 \%$ of them. Ontario is followed by Quebec with 14,820 sites and British Columbia with 7,905 potentially contaminated sites. 
Table 2.3 Potentially Contaminated Sites in Canada

\begin{tabular}{|c|c|c|c|c|c|c|c|}
\hline \multirow{2}{*}{$\begin{array}{l}\text { PROVINCE/ } \\
\text { TERRITORY }\end{array}$} & \multicolumn{6}{|c|}{ TYPE OF PROPERTIES } & \multirow{2}{*}{$\begin{array}{l}\text { POTENTIALLY } \\
\text { CONTAMINATED } \\
\text { STITES }\end{array}$} \\
\hline & $\begin{array}{l}\text { Manufacturing } \\
\text { industries } \\
(2003)\end{array}$ & $\begin{array}{c}\text { Gas } \\
\text { Stations } \\
(2004)\end{array}$ & $\begin{array}{l}\text { Recycling } \\
\text { Industries } \\
\text { (2005) }\end{array}$ & $\begin{array}{l}\text { Operating } \\
\text { Mines } \\
(2005)\end{array}$ & $\begin{array}{l}\text { Abandoned } \\
\text { Mines (nd) }\end{array}$ & $\begin{array}{c}\text { Coal } \\
\text { Tar } \\
\text { Sites }\end{array}$ & \\
\hline AB & 3,189 & 1,580 & 80 & 46 & 2,100 & - & 6,995 \\
\hline BC & 4,196 & 1,550 & 175 & 70 & 1,887 & 27 & 7,905 \\
\hline MB & 1,141 & 610 & 69 & 41 & 237 & - & 2,098 \\
\hline NB & 741 & 504 & 25 & 36 & 60 & - & 1,366 \\
\hline NL & 365 & 511 & 15 & 27 & 100 & - & 1,018 \\
\hline NS & 881 & 502 & 19 & 28 & 300 & - & 1,730 \\
\hline ON & 15,014 & 3,788 & 389 & 297 & 6,015 & 108 & 25,611 \\
\hline PEI & 166 & 106 & 7 & 3 & - & - & 282 \\
\hline $\mathbf{Q C}$ & 9,340 & 4,018 & 142 & 320 & 1,000 & - & 14,820 \\
\hline SK & 702 & 775 & 65 & 37 & 505 & - & 2,084 \\
\hline NWT & 17 & 30 & 1 & 3 & Federal & - & 51 \\
\hline $\mathbf{N U}$ & 7 & - & - & - & Federal & - & 7 \\
\hline $\mathrm{YT}$ & 15 & 60 & 4 & - & Federal & - & 79 \\
\hline TOTAL & 35,774 & 14,034 & 991 & 908 & 12,204 & 135 & 64,046 \\
\hline
\end{tabular}

Source: Eco Canada, 2007.

It is important to note that these numbers are an approximation and are likely underestimating the number of potential sites. As there is no federal or provincial inventory of brownfield sites, the numbers were largely derived from published sources on the distribution of manufacturing facilities, waste processing, recycling, and disposal facilities, operating and abandoned mines, gasoline stations, abandoned or vacant residential buildings and warehouses, and old railway yards and waterfronts. This does not capture potential sites such as residential properties and sites surrounding transportation zones, nor does it capture sites located on federal lands. 
It is important to note that many brownfield sites are often located in desirable and strategic locations: in the heart of urban communities, on scenic waterfronts, in or near downtown cores, and often in close proximity to residential areas (Ontario Brownfields Advisory Panel, 2000). This heightens the potential for incidental exposures in the community, thereby increasing the risk of adverse health outcomes.

\section{Brownfield site activities}

The type of industrial or commercial site activities is an important indicator of the environmental impact the property might have sustained. Past historical activities can inform about potential chemicals of concerns, the type of environmental media affected, and the likelihood of human exposure, allowing to screen for hazards and potential risks. As such, many agencies and researchers have tabulated extensive land use classification guides to aid environmental professionals in assessing site risks based on different land uses (Syms, 1999; Syms, 2004; Leigh \& Hise, 1997). These screening tools allow risk assessors to identify sites with potential impacts and prioritize them with respect to human health. In addition, in jurisdictions lacking centralized brownfield inventories they can serve as useful tools for estimating and identifying impacted sites.

There are several methods of classifying and ranking sites based on site activity and land use. The methods range from simple application of standard industrial classification codes to census tracks, through desk-top screening exercises that identify chemicals associated with various industrial and manufacturing processes, finally to complex assessments that integrate chemical specific toxicity with environmental fate and persistence and human activity patterns (Syms, 1999; Syms, 2004; Leigh \& Hise, 1997, Litt \& Burke 2002; Litt et al. 2002). The type of 
process employed is largely driven by resources and the availability of site-specific information and data.

\section{Examples of Land Use Classification Systems}

The Desk Reference Guide to Potentially Contaminative Land Uses (Syms, 1999) is a good example of such a tool. In the Guide the author identifies 39 industrial activity groups that are most likely to have resulted in soil contamination and ranked them according to the Index of Perceived Risk. The index was based on the potential for substances to be present at concentrations that would require remedial action and in turn allowed various industrial activities to be grouped into perceived risk categories and ranked according to hazard. For example, the highest hazard ranked industrial activity was asbestos manufacture and use, followed by organic and inorganic chemicals production. Also in the high perceived risk category were waste disposal sites, oil refining, petrochemicals production and storage, metal smelting and refining, iron and steel works, and scrap yards. In the medium risk category there were concrete, ceramics, cement and plaster works, film and photographic processing, and railway lands. In the low end it was food processing and airports.

A similar, albeit a more complex approach, was developed by Litt et al. (2002). The riskbased Brownfields Scoring Algorithm was based on the integration of a chemical-specific hazard score with a chemical persistence weight. The hazard scoring method utilized a semiquantitative approach using weight of evidence information related to the toxicity and quality of data for a given chemical and a quantitative weighting scheme. As multiple recognized or suspected health effects are associated with each substance, each health effect was assigned a weight. By summing the weights associated with each effect the authors were able to derive a 
hazard score for each substance. The second critical factor in the scoring algorithm was the chemical persistence. The authors chose the octanol-water partition coefficient (Koc) - the measure of a chemical's tendency to sorb to soil or sediment organic matter - as a proxy for substance's fate in the environment. They argued that a chemical with a high adsorptive capacity is less likely to volatilize to air and will be much more persistent in the environmental media. The final site specific score was calculated by summing all substances ( $n$ ) found at each site with information such as duration of operation for each facility and its area.

As it was noted earlier, land use classification systems are extremely useful in identifying potentially contaminated sites when lacking brownfield inventories or site specific data.

Historical site activities such as industrial processes and manufacturing activities provide insight into the types of chemical contamination likely to be encountered. More complex classification applications allow sites to be ranked with respect to hazard and risk thus allowing sites to be prioritized based on potential impacts to human health.

\subsection{Health Risks and Contaminated Sites - Summary of Evidence}

In conclusion, it is apparent that exposure at brownfield sites can pose a risk to human health. Brownfields are very common in Ontario and often located in densely populated urban environments where exposure to contaminants is more likely. Empirical data show that brownfields are often impacted with a mixture of various chemicals, many with well documented toxicity and carcinogenicity. Although causal relationships between exposure at contaminated sites and health outcomes are often difficult to establish, that is largely due to the inadequacy of epidemiologic methods and study design, rather than to the evidence that it does not exists. 
In light of such evidence, it becomes imperative that public health agencies mandated with reduction of health hazards and protection of human health play an active role with regards to brownfield redevelopment. In addition to traditional roles centered on hazard identification, risk assessment and risk mitigation, public health units can engage in revitalization activities that reduce blight and promote development of parkland, safe transportation corridors, and safe and vibrant communities. 


\subsection{Assessing Public Health Units' Involvement in Brownfield Activities}

\subsection{Purpose}

The purpose of this research is to examine the involvement of Ontario public health units (PHUs) in brownfield activities and to evaluate the key factors which limit or impede the process. Results are used to determine the extent to which Ontario PHUs get involved in brownfield activities. Furthermore, comparisons are made between the Ontario PHUs involvement and the Agency for Toxic Substances and Disease Registry Land Revitalization model, the existing "gold standard" of health agencies' involvement in brownfields.

\section{Research Question}

What is the level of Ontario public health units' involvement in brownfield

redevelopment?

\section{Sub-Questions}

\section{Question 1}

Since 2004, have Ontario public health units been called upon to investigate and respond to brownfields concerns within their jurisdiction?

\section{Question 2}

If yes, were they able to respond adequately?

\section{Question 2b}

If Ontario public health units were not able to respond adequately, what were the limiting factors?

\section{Question 3}


Are Ontario public health units currently involved in brownfield redevelopment within their jurisdiction?

\section{Question 4}

What are the variables that enhance or restrict Ontario public health units' involvement in brownfield redevelopment?

\section{Question 5}

What are the resources needed now to facilitate Ontario public health units' involvement in brownfield activities?

\section{Question 6}

How does Ontario public health units' involvement in brownfield activities compare to the framework developed by the Agency for Toxic Substances and Disease Registry Land Revitalization program?

The aim of this research study is to assess the involvement of Ontario PHUs in brownfield activities and to critically evaluate the adequacy of that involvement. The results are used to formulate conclusions and propose recommendations to inform public health practice and policy. The gathered data is used to identify needs, gaps, and opportunities in the current approach through direct comparison with the components of the "best practices" framework developed by the ATSDR Land Revitalization program. Furthermore, the results are utilized to propose recommendations aimed at optimizing PHUs engagement in the revitalization of brownfields.

\subsection{Measuring Involvement: Methods}

\section{Ethical Review Process}


The cross-sectional survey research design required data collection from human subjects. A copy of the survey tool (Appendix A) and the Evaluation And Research Application was submitted to the Professional Practice Unit, Planning \& Policy, Toronto Public Health (TPH), for review and appraisal. All components of the submission were evaluated by two reviewers. Several minor methodological issues were identified through the process requiring questionnaire adjustments and clarification. All reviewers' comments were satisfactorily addressed and the application was approved. Once the proposed research was accepted by TPH, the application was submitted to, and accepted by, the Ryerson University Research Ethics Board.

\section{Participants}

The participants in this study are the 36 Ontario PHUs. Each Ontario PHU was asked to participate in the study, thus eliminating the need for sampling. The $36 \mathrm{PHUs}$ are located throughout the province of Ontario, Canada. 
Table 3.1 Spatial Distribution of Public Health Units in Ontario

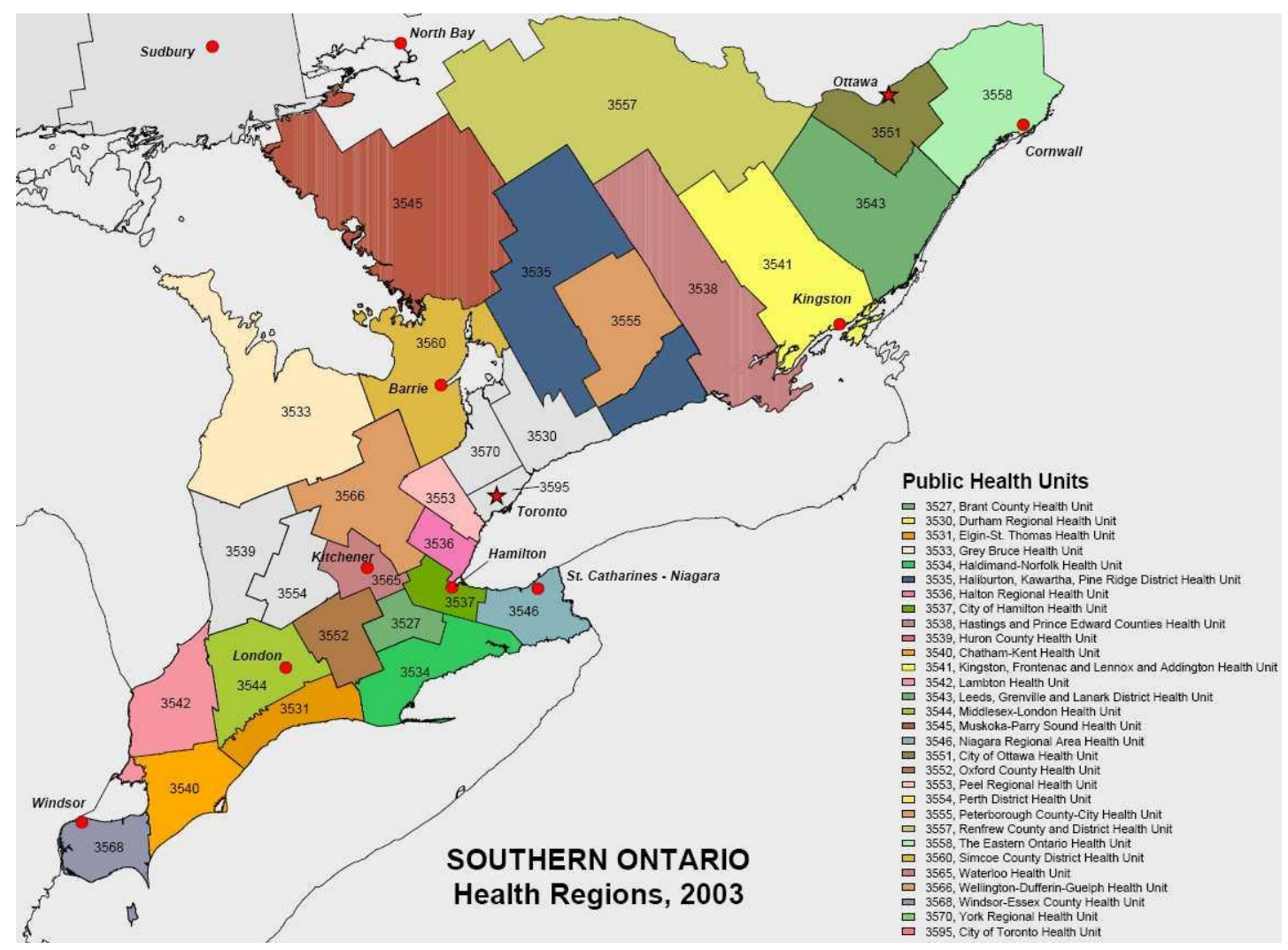

Source: www.pophealthmetrics.com

\section{Population}

The study population is the 36 Ontario PHUs. All Ontario PHUs were asked to participate in this research study. As such, the entire study population was represented and inferential analysis was not required. Furthermore, the study focused solely on the province of Ontario, its unique brownfield and public health policies and its regulatory structure. Although the results are compared to the best practices framework established by the ATSDR to determine the adequacy of PHUs involvement, inferences of results to other provinces were not made, as each province operates under different regulatory framework. The findings of this study are applicable only to the Ontario public health units. 


\section{Recruitment}

Each public health unit was asked to identify a key informant deemed to have the most local experience in the area of brownfields. The key informant was identified by each health unit's Medical Officer of Health (or their designate). If several key informants were identified at a PHU, all were encouraged to participate in completing the questionnaire by combining their responses and submitting only one completed survey that best reflects that PHUs policies and practices.

\section{Data Collection: Demographic and primary data}

1. Demographic data. Data regarding the demographics of each PHU such as size of region, population, population growth rate, population density, etc., was obtained from the Ontario Ministry of Health and Long Term Care (MHLTC). The Ontario MHLTC generates demographic data by obtaining raw data from Statistics Canada and grouping data points by health unit boundaries, information not routinely available from Statistics Canada.

2. Primary data (i.e. professional practices, capacity, knowledge, opinions, attitudes).

One questionnaire was administered to each of the 36 Ontario PHUs, soliciting a single response from each.

\section{Pilot Testing of the Survey Instrument}

Prior to data collection, pilot testing was conducted by administering the survey to establish face validity and reliability of the instrument, and to improve questions, clarity, format, and scales. To minimize error, the questionnaire was pilot tested by selected individuals that were both familiar and not familiar with brownfield practices, and those that 
have or do not have expert knowledge in survey design methods. Minor changes were made to the survey instrument as a result of the pilot testing.

\section{Instructions to Participants}

In the survey tool (Appendix A), participants were provided with the purpose of the study, the background, directions, acronyms, and the confidentiality clause. Furthermore, several terms were defined to ensure uniform comprehension amongst the study participants. Involved . For the purpose of the study "involved" was defined as: responsible for responding to complaints or inquiries, evaluation and interpretation of human health risk, evaluation of remediation methods, and risk communication.

Brownfields. Definition of brownfields was based on the MOE terminology "Brownfields are abandoned, idle, or under-utilized industrial and commercial properties where the previous property use caused environmental contamination" (MOE, 2008). For the purpose of the study the definition was further refined to include:

- Properties that are both vacant and those that are being actively used

- Where contamination may be the result of current activities or related to historical use

- Brownfield sites may include, but are not limited to: former water ports and railway lines, former and current industrial and manufacturing sites, auto-body shops and gas stations, or even neighbourhood dry cleaner operations.

Furthermore, as the study sought answers at the health unit level, participants were instructed to answer the questions from a PHUs' perspective, not based on a personal opinion or belief. As such, each answer is believed to reflect the PHUs' official position on involvement in brownfields. 


\section{Data Collection}

The survey instrument was distributed electronically and data were collected between June 2011 and September 2011. All participants were asked to complete the questionnaire in a manner they were most comfortable with, e.g. by providing either written or typed answers to specific questions. All participants were asked to return the completed survey instrument to the principal investigator by mail, electronically, or by fax. The purpose of providing several options was to ensure a higher response rate. The initial data collection period was set for three weeks however, only 8 out of 36 health units had responded during that period. The deadline for response was extended to achieve a higher response rate and to allow for completion of a more representative data set. The non-responding health units were contacted and asked once again to participate. The final response rate was 32 out of 36 health units (88.9\%, $\mathrm{N}=36)$. All data were collected, recorded and coded by the principal investigator.

\section{Data storage}

All electronic data were stored on an encrypted USB memory device as well as on a password-protected hard drive of a desktop computer. Only the principal investigator had access to those data. All physical data (i.e. completed surveys) were stored in a locked desk drawer. Once again, only the principal investigator had access to those data.

\section{Data Analysis}

Once collected, the survey responses were compiled for aggregate analysis to assess various study variables, their distribution amongst health units, and the potential influence of various factors and relationships on that distribution. Descriptive statistics, i.e. frequency distribution, measures of central tendency, and measures of dispersion, were utilized to 
qualitatively display data and to determine the distribution of variables. Bivariate analysis was utilized to test for relationships between selected variables in the study.

The overall purpose of the study was to examine the practices of Ontario PHUs with respect to brownfields activities. The use of descriptive statistics allowed for the analysis of the distribution of various behaviours, attitudes, and beliefs throughout the province. By using bivariate analysis such as cross-tabulations, it was possible to determine which variables appeared to modify health units' involvement in brownfield activities.

\section{Disposition of Data}

Both electronic and hard copies of the completed questionnaires will be kept for one year after the publication of the study in anticipation of any inquiries following the publication of the study results. One year after the publication of study results all completed questionnaires will be destroyed. 


\subsection{Results - Univariate Analysis}

Of the 36 Ontario public health units invited to participate in the study, 32 have completed the survey $(88.9 \%, \mathrm{~N}=36)$. Not all questions were answered fully by all health units resulting in some analyses being conducted with smaller sample sizes, as noted for each category.

\section{Ontario Health Unit Characteristics}

Table 3.2 Characteristics of Ontario Public Health Units ( $N=36)$

\begin{tabular}{|l|c|c|c|}
\hline \multicolumn{1}{|c|}{ Characteristic } & Median & $\begin{array}{c}\text { Minimum } \\
\text { Value }\end{array}$ & $\begin{array}{c}\text { Maximum } \\
\text { Value }\end{array}$ \\
\hline Size of Region $\left(\mathbf{k m}^{\mathbf{2}}\right)$ & 3,357 & 630 & 266,290 \\
\hline Population & 166,663 & 34,564 & $2,651,717$ \\
\hline Population Density $\left(\mathbf{k m}^{\mathbf{2}}\right)$ & 42 & 0.3 & 4,208 \\
\hline \% Immigrants & 11 & 3.2 & 50 \\
\hline \% Employment Rate & 61 & 52 & 70 \\
\hline \% Post-Secondary Education & 56 & 49 & 72 \\
\hline
\end{tabular}

Source: Ontario Ministry of Health and Long Term Care, 2009.

Table 3.2 presents the qualitative statistical characteristics of Ontario PHUs. These data were obtained from the Ontario Ministry of Health and Long Term Care and they were extracted from 2001 Census (the latest available at the time when the report was produced) using the 2007 health region boundaries. It is expected these statistical characteristics will continue to be representative of the current trends. The province of Ontario is divided into 36 distinctive health regions that vary greatly in size of their geographical area, population they serve, and population density. The geographic area covered by each unit ranges from $630 \mathrm{~km}^{2}$ to $266,290 \mathrm{~km} 2$, with the median size of $3,357 \mathrm{~km}^{2}$. The size of the population served by each health unit ranges from 34,564 to $2,651,717$, with the median being 166,663 . Similarly, the population density varies widely, from 0.3 per $\mathrm{km}^{2}$ to 4,208 per $\mathrm{km}^{2}$. The immigrant population 
served by each health unit ranges from $3.2 \%$ to $50 \%$ with the median value of $11 \%$. The lowest employment rate in a health unit is $52 \%$, with the highest being $70 \%$; the median is $61 \%$. The size of population with a post-secondary education is fairly consistent across the regions, with the minimum of $49 \%$ and maximum of $72 \%$, the median being $56 \%$. Overall, the demographic data indicates the Ontario PHUs display a huge diversity amongst its characteristics between jurisdictions.

\section{Health Units' Involvement in Brownfields}

Table 3.3 PHUs involvement in Activities Related to Brownfields Between 2000 and 2010 (N=32)

Survey Question: Has your health unit been involved ${ }^{1}$ in any activities related to brownfields between 2000 and 2010?

\begin{tabular}{|r|c|c|}
\hline Variable & Frequency & Percent \% \\
\hline Yes & 23 & 71.9 \\
\hline No & 5 & 15.6 \\
\hline DK & 4 & 12.5 \\
\hline Total & 32 & 100 \\
\hline
\end{tabular}

* DK - don't know

Of the 32 PHUs that completed the survey, 23 (71. 9\%) reported being involved in brownfield related activities, while 5 of the 32 PHUs (15.6\%) reported they did not engage in brownfield activities between 2000 and 2010. Of the 32 PHUs (4/32, 12.5\%) did not know whether they engaged in brownfield activities, even though "involved" and "brownfield activities" were clearly defined in the survey immediately following the question. It is theorized that perhaps the PHUs that answered "don't know" were being represented by individuals that have not

\footnotetext{
${ }^{1}$ The questionnaire defined "involved" to include, but not be limited to activities such as: response to brownfields complaints/inquiries, evaluation and interpretation of risk, evaluation of remediation methods, risk communication, etc.
} 
been employed by the health unit between 2000 and 2010, and would not have that knowledge.

Table 3.4 PHUs Change in Involvement in Brownfield Activities Since 2004 ( $N=32$ )

Survey Question: Has your health unit's involvement changed since the introduction of Ontario Brownfields Regulation, O. Reg. 153/04 Record of Site Condition in 2004?

\begin{tabular}{|r|c|c|}
\hline \multicolumn{1}{|c|}{ Variable } & Frequency & Percent \% \\
\hline Yes & 4 & 12.5 \\
\hline No & 24 & 75.0 \\
\hline DK/NR & 4 & 12.5 \\
\hline Total & 32 & 100 \\
\hline *DK/NR - don't know or no response
\end{tabular}

In 2004 the Ontario Government introduced comprehensive brownfields reforms, including the Ontario Brownfields Regulation, O. Reg. 153/04, Record of Site Condition. PHUs were asked to comment on whether their involvement in brownfields has changed since the introduction of the legislation in 2004. Of the 32 PHUs that completed the survey, 24 (75.0\%) reported their involvement has not changed, whereas 4 of the 32 PHUs (12.5\%) reported that it did change. All 4 of the PHUs that reported "change" were larger PHUs with higher population density located in areas of Ontario traditionally associated with higher industrial activity. 3 of the 4 PHUs (75\%) qualitatively reported that their involvement has increased, citing raised awareness of brownfields, and greater need for identification, assessment, and possible remediation of brownfields within their jurisdiction. Only 1 of the 4 PHUs (25.0\%) reported decreased need for involvement citing the MOE absorbing some of the activities that were previously completed by the PHU.

\section{Degree to Which PHUs Become Involved in Brownfield Activities}


Table 3.5 Process for PHUs Involvement in Brownfield Activities ( $\mathrm{N}=32$ )

Survey Question: What is the process for your health unit's involvement in brownfield activities? (please check all that apply)

\begin{tabular}{|c|c|c|c|c|}
\hline Variable & Yes (\%) & No (\%) & NR (\%) & Total (\%) \\
\hline Ad-hoc & $25(78.1)$ & $0(0.0)$ & $7(21.9)$ & $32(100)$ \\
\hline Standards of Practice & $1(3.1)$ & $24(75.0)$ & $7(21.9)$ & $32(100)$ \\
\hline Written Policies & $1(3.1)$ & $24(75.0)$ & $7(21.9)$ & $32(100)$ \\
\hline
\end{tabular}

PHUs were asked about the process for their involvement in brownfield activities. The majority of the PHUs, 25 out of 32 (78.1\%), reported that involvement occurs in an ad-hoc, as needed manner. One PHU out of $32(3.1 \%)$ reported having standards of practice in place, and another PHU reported having written policies in place (1/32, 3.1\%). Although PHUs were asked to check all applicable answers, each PHU that provided a response chose only one answer, with 27 PHUs in total answering this question. Upon further review of the questionnaire data it was determined that the 5 PHUs that did not provide a response to this question are PHUs that have not been involved in brownfield activities between 2000 and 2010.

Table 3.6 Initiation of PHUs Involvement in Brownfield Activities ( $N=32$ )

Survey Question: What typically initiates your health unit's involvement in brownfield activities? (please check all that apply)

\begin{tabular}{|r|c|c|c|c|}
\hline \multicolumn{1}{|c|}{ Variable } & Yes (\%) & No (\%) & NR (\%) & Total (\%) \\
\hline Complaints & $24(75.0)$ & $2(6.3)$ & $6(18.8)$ & $32(100)$ \\
\hline External agency request/referral & $24(75.0)$ & $1(3.1)$ & $7(21.9)$ & $32(100)$ \\
\hline Political office request/referral & $21(65.6)$ & $2(6.3)$ & $9(28.1)$ & $32(100)$ \\
\hline Formal arrangement & $4(12.5)$ & $14(43.8)$ & $14(43.8)$ & $32(100)$ \\
\hline
\end{tabular}

*NR - no response

When asked what typically initiates PHUs involvement in brownfield activities, majority reported demand-driven initiation of involvement. Of the 32 PHUs that completed the survey, $24(75.0 \%)$ reported that involvement was initiated in response to complaints or concerns from 
community, 24 out of 32 (75.0\%) reported responding to requests or referrals from external agencies (e.g. MOE, MOL), and 21 out of 32 (65.6\%) reported responding to requests or referrals from political offices (e.g. City Councillors, MPs/MPPs, council committees). Only 4 out of 32 PHUs (12.5\%) reported having formal arrangements with other city divisions or external agencies to initiate their involvement in brownfields. Several PHUs did not respond to this question. Other than the 5 PHUs that have not been involved in brownfields between 2000 and 2010, it is unknown why some PHUs did not provide a response. The proposed reasons are that available categories did not reflect how the involvement in their PHUs is initiated, or that responders where unaware of how the process is initiated.

In responding to the question, $24 \mathrm{PHUs}$ indicated receiving, or responding to, brownfields related complaints or request from external agencies. However, only 23 PHUs responded they have been involved in brownfields between 2000 and 2010. It is unknown at this time as to why 1 PHU receives complaints or requests, but does not become involved in brownfield. Some of the potential reasons could be: lack of resources or expertise, lack of clear policies or response procedures, or competing program priorities. This is an area to be further explored in future studies.

Table 3.7 Stage at Which PHUs Initiate Involvement in Brownfields ( $N=32$ )

Survey Question: On average, since 2000, at what stage in the brownfield redevelopment process was your health unit's involvement initiated? 


\begin{tabular}{|r|c|c|c|c|c|}
\hline Variable & A/O (\%) & S (\%) & SD/N & NR (\%) & Total (\%) \\
\hline Proactive, during planning stage & $3(9.4)$ & $7(21.9)$ & $13(40.6)$ & $9(28.1)$ & $32(100)$ \\
\hline During remediation & $7(21.9)$ & $5(15.6)$ & $8(25.0)$ & $12(37.5)$ & $32(100)$ \\
\hline Reactively, as health issues arise & $11(34.4)$ & $5(15.6)$ & $8(25.0)$ & $8(25.0)$ & $32(100)$ \\
\hline
\end{tabular}

$*$ A/O - always/often (responses combined from original)

$* S$ - sometimes

* SD/N - seldom/never (responses combined from original)

* NR - no response

Original survey responses in the categories "always" and "often", and "seldom" and "never" were collapsed in order to better understand data distribution and observe for trends. This was considered an important area to explore as proactive involvement at the planning stages allows for public health principles to be incorporated early in the brownfields process (NACCHO, 2000; ATSDR, 2012; TPH, 2011b). Overall, nearly half of all PHUs, 13 out of 32 (40.6\%) reported seldom or never becoming involved proactively, during the planning stage. There was a fairly high number of PHUs that did not respond to this question, even PHUs that reported having involvement in brownfields between 2000 and 2010. It was hypothesized the non-response rate could be associated with the vagueness of the terminology, thus precluding some PHUs from answering this question. Another hypothesis was that categories did not match the PHUs possible responses and the participants were not given the option of choosing "other, please specify". This should be further explored in future studies as this is an important aspect of public health practice on brownfield sites.

Table 3.8 Public Health Units' Activities at Brownfield Sites ( $N=32)$

Survey Question: When participating in brownfield activities, what does your health unit engage in? (multiple responses were allowed in this question) 


\begin{tabular}{|r|c|c|c|c|}
\hline Variable & Yes (\%) & No (\%) & NR (\%) & Total (\%) \\
\hline Review of site's history & $24(75.0)$ & $1(3.1)$ & $7(21.9)$ & $32(100)$ \\
\hline Site visits & $19(59.4)$ & $6(18.8)$ & $7(21.9)$ & $32(100)$ \\
\hline Review of Phase I \& II ESAs & $22(68.8)$ & $3(9.4)$ & $7(21.9)$ & $32(100)$ \\
\hline Review of quantitative RAs & $21(65.6)$ & $3(9.4)$ & $8(25.0)$ & $32(100)$ \\
\hline Risk communication & $19(59.4)$ & $5(15.6)$ & $8(25.0)$ & $32(100)$ \\
\hline Review of monitoring results & $24(75.0)$ & $1(3.1)$ & $7(21.9)$ & $32(100)$ \\
\hline Health impact assessment & $16(50.0)$ & $6(18.8)$ & $10(31.3)$ & $32(100)$ \\
\hline
\end{tabular}

* NR - no response

In this question, original survey responses in the categories "always" and "often", and "seldom" and "never" were once again collapsed in order to better understand data distribution and observe for trends. Based on the survey results, when PHUs do become involved in brownfield sites, they participate in a wide array of activities. Most commonly, 24 out 32 (75.0\%) PHUs review the site history, which is closely followed by the review of Phase I \& II ESAs, and the review of quantitative risk assessments. Surprisingly, only 19 of the 32 PHUs (59.4\%) reported engaging in risk communication, a traditional public health role on contaminated sites. There was number of PHUs that did not answer this question. As some of the terminology (e.g. Phase I and II environmental risk assessments, quantitative risk assessment, health impact assessment) was not defined in the questionnaire, it was theorized that respondents might not have been familiar with it, thus omitting the question.

Table 3.9 Engagement of Community Members in Brownfield Activities ( $N=32$ )

Survey Question: To what extent does your health unit engage community members in brownfield activities?

\footnotetext{
${ }^{2}$ Phase I \& II ESAs are Phase I and Phase II Environmental Site Assessments - standardized approaches for assessment and quantification of environmental contamination

${ }^{3}$ Quantitative RA is quantitative risk assessment - standardized approach for calculating risk. It usually consists of four steps: hazard identification, exposure assessment, dose-response assessment, and risk characterization
} 


\begin{tabular}{|r|c|c|c|c|c|}
\hline Variable & A/O (\%) & S (\%) & SD/N & NR (\%) & Total (\%) \\
\hline Input into all decisions & $2(6.3)$ & $2(6.3)$ & $20(62.5)$ & $8(25.0)$ & $32(100)$ \\
\hline Input into health-related decisions & $6(18.8)$ & $3(9.4)$ & $17(53.1)$ & $6(18.8)$ & $32(100)$ \\
\hline Provide information at key stages & $6(18.8)$ & $2(6.3)$ & $14(43.8)$ & $10(31.3)$ & $32(100)$ \\
\hline Provide information at health related stages & $9(28.1)$ & $3(9.4)$ & $12(37.5)$ & $8(25.0)$ & $32(100)$ \\
\hline Respond to community inquiries & $17(53.1)$ & $4(12.5)$ & $6(18.8)$ & $5(15.6)$ & $32(100)$ \\
\hline
\end{tabular}

* A/O - always/often (responses combined from original)

* S-sometimes

* SD/N - seldom/never (responses combined from original)

* NR - no response

Once again, in this question the original survey responses in the categories "always" and

"often", and "seldom" and "never" were collapsed in order to better understand data

distribution and observe for trends. PHUs were asked about the extent to which they engage

communities when they become involved in brownfield sites. This was deemed to be an

important area to explore as community engagement is recognized as key component of public

health practice on brownfield sites. Once data was re-categorized, it was clear that most PHUs,

20 out of $32(62.5 \%)$ seldom or never engaged the community in the decision-making process,

with only 2 out of $32(6.3 \%)$ indicating they do it always or often. Responding to community

inquiries is also considered to be a critical component of public health practice on

contaminated sites. However, 6 out of 32 PHUs (18.8\%) indicated the do it seldom or never,

where some of them have indicated previously they have been involved in brownfield activities

between 2000 and 2010. Once again, it was speculated this is potentially due to lack of

resources, other competing program priorities, or lack of expertise. This area should be further

explored in future studies.

Ontario PHUs Attitudes, Perception, and Beliefs Regarding Brownfields

Table 3.10 Importance of Brownfields as a Public Health Issue Within PHUs ( $N=32$ )

Survey Question: Within your health unit, are brownfields considered an important public health issue? 


\begin{tabular}{|r|c|c|}
\hline Variable & Frequency & Percent \% \\
\hline Yes & 20 & 62.6 \\
\hline No & 12 & 37.5 \\
\hline Total & 32 & 100 \\
\hline
\end{tabular}

When asked whether brownfields are considered an important public health issue within their jurisdiction, nearly two-thirds of PHUs, 20 out of 32 (62.6\%) responded "yes". Surprisingly, 12 out of 32 PHUs (37.5\%) said "no", which also includes PHUs that have responded that they have been involved in brownfields between 2000 and 2010. This will be further explored in the bivariate analysis section along with variables such as: resources, expertise, need for involvement, etc.

Table 3.11 Importance of Engagement in Brownfield Activities Within PHUs ( $N=32)$ Survey Question: Within your health unit, is engagement in brownfield activities considered important?

\begin{tabular}{|c|c|c|}
\hline Variable & Frequency & Percent \% \\
\hline Yes & 21 & 65.6 \\
\hline No & 10 & 31.3 \\
\hline NR & 1 & 3.1 \\
\hline Total & 32 & 100 \\
\hline
\end{tabular}

* NR - no response

Of the 32 PHUs $(21 / 32,65.6 \%) 21$ reported that within their health unit engagement in brownfield activities is considered to be important. Surprisingly, one PHU that did report brownfields not to be an important public health issue reported that engagement in brownfields was considered important. It was hypothesized this could be due to competing policy priorities. Although currently brownfields might not be considered a priority public health issue, PHUs' involvement in brownfields may be perceived as leading to improvement in the health status in the brownfield communities, and thus be seen as important. This should be 
explored further in future studies, perhaps by utilizing a more qualitative in-depth interview approach.

Table 3.12 Involvement in Brownfields as Part of Current Scope of Work ( $N=32)$

Survey Question: Within your health unit, is involvement in brownfields activities part of your scope of work?

\begin{tabular}{|c|c|c|}
\hline Variable & Frequency & Percent \% \\
\hline Yes & 26 & 81.3 \\
\hline No & 5 & 15.6 \\
\hline $\mathrm{NR}$ & 1 & 3.1 \\
\hline Total & 32 & 100 \\
\hline
\end{tabular}

*NR - no response

The vast majority of PHUs, 26 out of 32 (81.3\%) indicate that involvement in brownfields is currently within their scope of work. As expected, the PHUs that reported that they have not been involved in brownfields between 2000 and 2001, do not have brownfields as part of their scope of work. Interestingly, several PHUs that did not know whether they were involved in brownfields between 2000 and 2010 reported having brownfield sites within their scope of work. Further study is needed to determine whether those PHUs were involved in brownfields, but perhaps outside of the specified time-frame. An alternative hypothesis is that PHUs have involvement in brownfields as part of their scope of work, but there has not been any demand for such involvement.

Table 3.13 Awareness of Brownfields Within PHUs Jurisdictions ( $N=32$ )

Survey Question: Are you aware of brownfield sites located within your health units' jurisdiction?

\begin{tabular}{|c|c|c|}
\hline Variable & Frequency & Percent \% \\
\hline Yes & 21 & 65.6 \\
\hline No & 9 & 28.1 \\
\hline NR & 2 & 6.3 \\
\hline Total & 32 & 100 \\
\hline
\end{tabular}

$*$ NR - no response 
Of 32 PHUs $(21 / 32,65.6 \%)$ 21reported awareness of brownfield sites within their jurisdictions. Surprisingly, 2 PHUs that reported involvement in brownfields between 2000 and 2010 reported not being aware of brownfield sites. It is proposed these PHUs may have policies for involvement in brownfields or have been involved in brownfield activities prior to 2000. 9 out of 32 PHUs (28.1\%) reported not being aware of brownfields within their jurisdiction. As this includes the 5 PHUs that were not involved in brownfields between 2000 and 2010, it could explain why these PHUs lacked involvement during this time frame.

Table 3.14 Need for Involvement in Brownfields Within PHUs Jurisdiction ( $N=32$ )

Survey Question: Within your health unit, is there a need (i.e. complaints/inquiries, community concern, etc.) for public health involvement in brownfield sites?

\begin{tabular}{|c|c|c|}
\hline Variable & Frequency & Percent \% \\
\hline Yes & 25 & 78.1 \\
\hline No & 5 & 15.6 \\
\hline NR & 2 & 6.3 \\
\hline Total & 32 & 100 \\
\hline
\end{tabular}

${ }^{*} \mathrm{NR}-$ no response

25 of the 32 PHUs (78.1\%) reported a "need" for involvement in brownfield sites. In addition to the 23 PHUs that reported involvement between 2000 and 2010, 2 PHUs that previously reported not knowing whether they were involved in brownfields reported a "need" within their jurisdiction. It is unknown at this time whether these PHUs responded to that need and were involved in brownfield response but unaware of it, or if they did not respond due to lack or resources or competing program priorities. This should be further explored in future studies. Not surprisingly, 5 PHUs that were not involved in brownfields between 2000 and 2010 responded there was no "need" for involvement within their jurisdiction. 
Table 3.15 Perceived Benefits Related to PHUs Involvement in Brownfields ( $N=32$ )

Survey Question: Within your health unit, are there benefits to being involved in brownfield activities?

\begin{tabular}{|c|c|c|}
\hline Variable & Frequency & Percent \% \\
\hline Yes & 28 & 87.5 \\
\hline No & 1 & 3.1 \\
\hline NR & 3 & 9.4 \\
\hline Total & 32 & 100 \\
\hline
\end{tabular}

$* \mathrm{NR}-$ no response

Majority of the PHUs, 28 out of 32 (87.5\%), responded there are benefits to being involved in brownfield activities. This includes the 23 PHUs that were involved in brownfields between 2000 and 2010, 4 PHUs that reported no involvement in brownfields, and 1 PHU that did not know whether they were involved in brownfields. It is hypothesized that even though some PHUs may not have a need to be involved, or perhaps do not have the necessary resources or expertise to be involved in brownfields, they believe there are public health benefits associated with PHUs' involvement in brownfields.

Table 3.16 Perceived Benefits Gained from PHUs Involvement in Brownfield Activities ( $\mathrm{N}=28$ )

* Note - the $\mathrm{N}$ changes from 32 to 28 as only the PHUs that answered "yes" in the previous question (Table 13) answered this question

Survey Question: If yes, what benefits could be gained by your health unit's involvement in brownfield activities?

\begin{tabular}{|r|c|c|c|c|}
\hline Variable & Yes (\%) & No (\%) & NR (\%) & Total (\%) \\
\hline Reduction in exposures and health risk & $27(96.4)$ & - & $1(3.6)$ & $28(100)$ \\
\hline Improvement in environmental quality & $24(85.7)$ & $1(3.6)$ & $3(10.7)$ & $28(100)$ \\
\hline Creation of healthy communities & $22(78.6)$ & $1(3.6)$ & $5(15.6)$ & $28(100)$ \\
\hline Economic benefits & $11(39.3)$ & $9(32.1)$ & $8(28.6)$ & $28(100)$ \\
\hline Community empowerment & $15(53.6)$ & $5(15.6)$ & $8(28.6)$ & $28(100)$ \\
\hline
\end{tabular}

${ }^{*} \mathrm{NR}-$ no response

PHUs that answered "yes" in the previous question (Table 3.13) were asked to identify what potential benefits could be gained from PHUs involvement in brownfield sites. Nearly all the 
PHUs, 27 out of $28(96.4 \%)$ identified reduction in exposures and health risks as the priority

benefits. Those were closely followed by improvements in environmental quality (e.g. soil, air quality) and creations of healthy communities (e.g. new parks, exercise areas). As respondents were given a choice between "yes" and "no", it was interesting to see that 9 out of 28 (32.1\%) did not believe PHUs involvement would result in economic benefits, and 5 out 28 (15.6\%) did not believe it would empower the community. These two benefits are closely associated with the incorporation of public health principles into brownfields programs and are important considerations in recognized "best practices" frameworks (ATSDR 2012, NACCHO 2000).

PHUs were asked qualitatively if there are any "other" benefits that could be gained from involvement in brownfields. Three PHUs answered and listed the following: fostering of partnerships with brownfield communities, improvement in working relationship with municipalities and the MOE, gains in expertise.

\section{Capacity Assessment}

Table 3.17 Skills and Expertise Within Ontario Health Units ( $N=32)$

Survey Question: Does your health unit have staff with the following expertise/skills to engage in brownfield-related activities

\begin{tabular}{|r|c|c|c|c|}
\hline Variable & Yes (\%) & No (\%) & DK/NR (\%) & Total (\%) \\
\hline Quantitative risk analysis & $14(43.8)$ & $16(50.0)$ & $2(6.3)$ & $32(100)$ \\
\hline Human toxicology & $10(31.3)$ & $19(59.4)$ & $3(9.4)$ & $32(100)$ \\
\hline Risk communication & $19(59.4)$ & $5(15.6)$ & $8(25.0)$ & $32(100)$ \\
\hline Environmental epidemiology & $20(62.5)$ & $10(31.3)$ & $2(6.3)$ & $32(100)$ \\
\hline Conducting/reviewing ESAs & $16(50.0)$ & $12(37.5)$ & $4(12.5)$ & $32(100)$ \\
\hline Conducting/reviewing remediation & $14(43.8)$ & $16(50.0)$ & $2(6.3)$ & $32(100)$ \\
\hline $\begin{array}{c}\text { Conducting/reviewing } \\
\text { environmental monitoring }\end{array}$ & $17(53.1)$ & $14(43.8)$ & $1(3.1)$ & $32(100)$ \\
\hline *DK/NR - don't know/no response & & & & \\
\hline
\end{tabular}


PHUs were asked about their current level of brownfield related skills and expertise. Although

PHUs reported having skills and expertise in risk communication and environmental epidemiology, considered to be the traditional public health roles on contaminated sites, they reported lacking skills in areas of quantitative risk analysis and toxicology, critical skill sets when providing response on brownfield sites. Interestingly, many PHUs that reported being involved in brownfields and engaging in many of these activities, have also reported lack of skills and expertise in these areas. This will be further explored in the bivariate analysis section.

Table 3.18 Professional Development Opportunities Within PHUs (N=32)

Survey Question: Does your health unit provide staff with professional development activities related to brownfield sites?

\begin{tabular}{|r|c|c|c|c|}
\hline Variable & Yes (\%) & No (\%) & NR (\%) & Total (\%) \\
\hline In-house training sessions & $2(6.3)$ & $27(84.4)$ & $2(6.3)$ & $32(100)$ \\
\hline Provincial training/information sessions & $11(34.4)$ & $18(56.3)$ & $3(9.4)$ & $32(100)$ \\
\hline Federal training/information sessions & $6(18.8)$ & $23(71.9)$ & $3(9.4)$ & $32(100)$ \\
\hline Conferences & $13(40.6)$ & $17(53.10$ & $2(6.3)$ & $32(100)$ \\
\hline Structured courses/seminars & $5(15.6)$ & $23(71.9)$ & $4(12.5)$ & $32(100)$ \\
\hline
\end{tabular}

* NR - no response

When asked about access to professional development and training related to brownfields, relatively few PHUs reported having access to such opportunities. 11 out of 32 PHUs (34.4\%) reported having access to provincial training sessions and 13 out of 32 PHUs (40.6\%) reported having the opportunity to participate in conferences. Only 2 out of 32 PHUs (6.3\%) reported having access to in-house training sessions. 
Table 3.19 Access to Resources Within PHUs $(\mathrm{N}=32)^{4}$

Survey Question: Does your health unit utilize the following resources to engage in brownfield-related activities?

Survey Question: Does your health unit contract out for environmental monitoring services (e.g. environmental media monitoring, sampling, sample analysis)?

\begin{tabular}{|r|c|c|c|c|}
\hline Variable & Yes (\%) & No (\%) & NR (\%) & Total (\%) \\
\hline Environmental monitoring equipment & $1(3.1)$ & $30(93.8)$ & $1(3.1)$ & $32(100)$ \\
\hline Collection of environmental samples & $2(6.3)$ & $28(87.5)$ & $2(6.3)$ & $32(100)$ \\
\hline Laboratory analysis of environmental samples & $3(9.4)$ & $27(84.4)$ & $2(6.3)$ & $32(100)$ \\
\hline Contracting out environmental services & $5(15.6)$ & $24(75.0)$ & $3(9.4)$ & $32(100)$ \\
\hline
\end{tabular}

$* \mathrm{NR}-$ no response

All health units were asked to comment on access to various resources that routinely facilitate their engagement in brownfield-related activities. Of those that responded, only 1 out of 32

PHUs (3.1\%) reported utilizing environmental monitoring equipment, 2 out of 32 PHUs (6.3\%) reported collecting environmental samples, and 3 out 32 PHUs (9.4\%) reported laboratory analysis of environmental samples. This was considered an important area to explore as the public often looks to PHUs for independent sample collection and analysis in order to provide the communities with credible and reliable data and information. 5 out of 29 PHUs (15.6\%) reported contracting out for environmental services such as environmental media monitoring, sampling, and sample analysis.

Table 3.20 Need for Additional Resources and Training ( $N=32)$

Survey Question: Will additional resources and training in the following areas be beneficial in enhancing your health unit's engagement in brownfield activities?

\footnotetext{
${ }^{4}$ Two separate survey questions were combined in this table
} 


\begin{tabular}{|r|c|c|c|c|}
\hline Variable & Yes (\%) & No (\%) & NR (\%) & Total (\%) \\
\hline Risk assessment methods & $28(87.5)$ & - & $4(12.5)$ & $32(100)$ \\
\hline Risk interpretation methods & $28(87.5)$ & - & $4(12.5)$ & $32(100)$ \\
\hline Exposure assessment methods & $28(87.5)$ & - & $4(12.5)$ & $32(100)$ \\
\hline Environmental health surveillance & $25(78.1)$ & $1(3.1)$ & $6(18.8)$ & $32(100)$ \\
\hline Environmental health mapping & $24(75.0)$ & $1(3.1)$ & $7(21.9)$ & $32(100)$ \\
\hline Ontario Brownfields Regulation training & $22(68.8)$ & $4(12.5)$ & $6(18.8)$ & $32(100)$ \\
\hline Interpretation of standards (e.g. soil, air) & $25(78.1)$ & $2(6.3)$ & $5(15.6)$ & $32(100)$ \\
\hline Interpretation of sampling results & $25(78.1)$ & $1(3.1)$ & $6(18.8)$ & $32(100)$ \\
\hline
\end{tabular}

* NR - no response

When asked what additional training and resources that would enhance PHUs' engagement in brownfield activities, majority have identified risk assessment methods, risk interpretation methods, and exposure assessment methods as priorities. This was somewhat expected as these were also the areas in which PHUs reported having limited skills and expertise.

\section{Partnerships and Collaborations}

Table 3.21 Stakeholder Collaboration in Brownfield Activities ( $N=32$ )

Survey Question: When engaging in brownfields activities, which stakeholder is your health unit most likely to collaborate with? (please check all that apply)

\begin{tabular}{|r|c|c|c|c|}
\hline \multicolumn{1}{|c|}{ Variable } & Yes (\%) & No (\%) & NR (\%) & Total (\%) \\
\hline Federal government (e.g. Health Canada) & $12(37.5)$ & $5(15.6)$ & $15(46.9)$ & $32(100)$ \\
\hline Provincial government (e.g. MOE, MOL) & $31(96.9)$ & - & $1(3.1)$ & $32(100)$ \\
\hline Public health agencies (e.g. PHO, OPHA) & $26(81.3)$ & $1(3.1)$ & $5(15.6)$ & $32(100)$ \\
\hline Other health units & $22(68.8)$ & $3(9.4)$ & $7(21.9)$ & $32(100)$ \\
\hline Non-governmental organization & $10(31.3)$ & $10(31.3)$ & $12(37.5)$ & $32(100)$ \\
\hline Other city departments & $26(81.3)$ & $3(9.4)$ & $3(9.4)$ & $32(100)$ \\
\hline Political leaders & $12(37.5)$ & $9(28.1)$ & $11(34.4)$ & $32(100)$ \\
\hline Community groups & $19(59.4)$ & $3(9.4)$ & $10(31.3)$ & $32(100)$ \\
\hline Individual community members & $13(40.6)$ & $9(28.1)$ & $10(31.3)$ & $32(100)$ \\
\hline
\end{tabular}

* NR - no response

When asked about which stakeholders Ontario PHUs are most likely to collaborate with, 31 out of 32 health units $(96.9 \%)$ responded they are most likely to collaborate with the provincial government (e.g. MOE, or MOL). This outcome was somewhat expected as the MOE has the 
primary jurisdictional oversight with respect to brownfield sites in Ontario, and the PHUs often rely to the experience and the expertise of the MOE to evaluate risk at brownfield sites.

Table 3.22 Communication Tools Used by PHUs ( $\mathrm{N}=32)$

Survey Question: What tools does your health unit utilize to communicate information to the public regarding brownfield sites within your jurisdiction?

\begin{tabular}{|r|c|c|c|c|}
\hline \multicolumn{1}{|c|}{ Variable } & Yes (\%) & No (\%) & NR (\%) & Total (\%) \\
\hline One-on-one telephone consultation & $17(53.1)$ & $6(18.8)$ & $9(28.1)$ & $32(100)$ \\
\hline Door to door consultation & $9(28.1)$ & $11(34.4)$ & $12(37.5)$ & $32(100)$ \\
\hline Community meetings & $19(59.4)$ & $8(25.0)$ & $5(15.6)$ & $32(100)$ \\
\hline Site meeting & $8(25.0)$ & $4(12.5)$ & $20(62.5)$ & $32(100)$ \\
\hline Website & $13(40.6)$ & $10(31.3)$ & $9(28.1)$ & $32(100)$ \\
\hline Posters & $6(18.8)$ & $16(50.0)$ & $10(31)$, & $32(100)$ \\
\hline Fact sheets & $16(50.0)$ & $8(25.0)$ & $8(25.0)$ & $32(100)$ \\
\hline
\end{tabular}

* NR - no response

Community engagement is considered to be a cornerstone of public health practice on

brownfield sites. When asked about tools utilized to communicate with the public about

brownfields, most popular tools, as reported by the health units, where: telephone

consultations, community meetings, and fact sheets. Many PHUs did not respond to this

question. It was hypothesized that perhaps the terminology was not well defined or the PHUs

lacked the necessary resources or skills to utilize these public engagement tools when

becoming involved in brownfield sites. 


\subsection{Results - Bivariate Analysis}

Based on the results from the univariate analysis, several variables of interest were chosen for further consideration. Mainly, the "need" for PHUs to become involved in brownfields, attitudes and beliefs about brownfields, and capacity, were shown to be of importance and were explored further in this section.

Table 3.23 The Need for Engagement as Reported by PHU's Involvement in Brownfield Activities ( $\mathrm{N}=\mathbf{2 7}$ )

* Note - the $\mathrm{N}$ changes from 32 to 27 as only the PHUs that answered both questions were considered in the analysis

\begin{tabular}{|l|c|c|c|}
\hline $\begin{array}{l}\text { PHUs Involvement in } \\
\text { Brownfield Activities }\end{array}$ & \multicolumn{2}{|c|}{ Need for Involvement in Brownfield Activities } & Total (\%) \\
\hline & Yes (\%) & No (\%) & \\
\hline Yes (\%) & $21(95.5)$ & $1(4.6)$ & $22(100.0)$ \\
\hline No (\%) & $2(40.0)$ & $3(60.0)$ & $5(100.0)$ \\
\hline Total (\%) & $23(85.2)$ & $4(14.8)$ & $27(100.0)$ \\
\hline
\end{tabular}

PHUs that reported on their involvement in brownfield activities were asked to comment on whether there was a "need" with their jurisdiction to become involved in brownfield activities. For the purpose of the survey, "need" was defined as brownfield-related complaints, inquiries, community concerns, or similar. Predictably, of the 22 PHUs that reported being involved in brownfield activities, 21 , (95.5\%) reported the need for involvement within their jurisdiction.

Of the 5 PHUs that claimed not be involved in brownfields, 2 reported having a demand-driven need for involvement. It was hypothesized this lack of involvement could be due to insufficient resources, lack of expertise, or competing program needs. This should be further examined in future studies. Qualitative tools such as in-depth key informant interviews can be useful in 
exploring these relationships in more detail. The relationship reached statistical significance $(P=0.0128$, Odds ratio: 31.5$)$.

Table 3.24 Awareness of Existing Brownfields within PHU's Jurisdiction and Involvement in Brownfield Activities ( $\mathrm{N}=27$ )

* Note - the $\mathrm{N}$ changes from 32 to 27 as only the PHUs that answered both questions were considered in the analysis

\begin{tabular}{|l|c|c|c|}
\hline $\begin{array}{l}\text { PHUs Involvement in } \\
\text { Brownfield Activities }\end{array}$ & \multicolumn{2}{|c|}{ Awareness of Existing Brownfields } & Total (\%) \\
\hline & Yes (\%) & No (\%) & \\
\hline Yes (\%) & $17(77.3)$ & $5(22.7)$ & $22(100.0)$ \\
\hline No (\%) & $2(40.0)$ & $3(60.0)$ & $5(100.0)$ \\
\hline Total (\%) & $19(70.4)$ & $8(29.6)$ & $27(100.0)$ \\
\hline
\end{tabular}

Empirical evidence, along with the results from the univariate analysis, suggests that PHUs with more brownfields within their jurisdiction tend to have a higher rate of involvement in brownfield activities. Of the PHUs that reported involvement in brownfields, 17 (77.3\%) claimed being aware of brownfield sites within their jurisdiction. Interestingly, of the 5 PHUs that do not become involved in brownfield activities, 2 reported being aware of brownfield sites within their jurisdiction. It was hypothesized this could be due to several reasons: lack of resources or expertise, competing program delivery demands, lack of need for PHUs' involvement, or simply the lack of perception of risk associated with these sites. Due to the limitations of the cross-sectional study design there was no opportunity to explore these hypotheses further, and they should be addressed in future research on this topic. 
Table 3.25 Involvement in Brownfield Activities and Importance of Brownfields as a Public Health Issue ( $\mathrm{N}=28)$

* Note - the $\mathrm{N}$ changes from 32 to 28 as only the PHUs that answered both questions were considered in the analysis

\begin{tabular}{|l|c|c|c|}
\hline $\begin{array}{l}\text { PHUs Involvement in } \\
\text { Brownfield Activities }\end{array}$ & \multicolumn{2}{|c|}{$\begin{array}{c}\text { Importance of Brownfields as a Public Health } \\
\text { Issue }\end{array}$} & Total (\%) \\
\hline & Yes (\%) & No (\%) & \\
\hline Yes (\%) & $16(69.6)$ & $7(30.4)$ & $23(100.0)$ \\
\hline No (\%) & $2(40.0)$ & $3(60.0)$ & $5(100.0)$ \\
\hline Total (\%) & $18(64.3)$ & $10(35.7)$ & $28(100.0)$ \\
\hline
\end{tabular}

Increasingly, public health units have to make difficult resource allocation decisions for competing program delivery within their jurisdictions. Often, resources are allocated based on need, a mandate to deliver the program, or the significance of the health issue at hand. Of the PHUs that reported being involved in brownfield activities, 16 (69.9\%) consider brownfields to be an important public health issue. Interestingly, 2 of the PHUs that do not become involved in brownfield activities reported that brownfields are considered an important public health issue within their jurisdiction. It was hypothesized that perhaps there is lack of need for such involvement within their jurisdiction or lack of necessary resources to become involved.

Table 3.26 Involvement in Brownfield Activities and Benefits from PHUs Involvement on Brownfield Sites ( $\mathrm{N}=\mathbf{2 6}$ )

* Note - the $\mathrm{N}$ changes from 32 to 26 as only the PHUs that answered both questions were considered in the analysis

\begin{tabular}{|l|c|c|c|}
\hline $\begin{array}{l}\text { PHUs Involvement in } \\
\text { Brownfield Activities }\end{array}$ & \multicolumn{2}{|c|}{$\begin{array}{c}\text { Perceived Benefits from PHU's Involvement in } \\
\text { Brownfields }\end{array}$} & Total (\%) \\
\hline & Yes (\%) & No (\%) & \\
\hline Yes (\%) & $21(100.0)$ & - & $21(100.0)$ \\
\hline No (\%) & $4(80.0)$ & $1(20.0)$ & $5(100.0)$ \\
\hline Total (\%) & $25(96.2)$ & $1(3.9)$ & $26(100.0)$ \\
\hline
\end{tabular}


In a climate of an increased evidence-based program delivery, public health units tend to invest in health interventions that produce measurable health outcomes. As such, it was deemed important to examine the relationship between PHUs' involvement in brownfield activities and whether the PHUs believed there were public health benefits associated with being involved in brownfield activities. Of the PHUs that reported being involved in brownfield activities, all have reported there were public health benefits associated with such involvement. Interestingly, 4 of PHUs that do not become involved in brownfields report that within their jurisdictions there were benefits associated with such involvement. It was presumed that perhaps the PHUs did not have a need to engage in brownfield activities but as the same time still recognized that many improvements in health outcomes are associated with PHUs' involvement in brownfields.

Table 3.27 Involvement in Quantitative Risk Analysis on Brownfield Sites and PHUs' Current Expertise in Quantitative Risk Analysis ( $N=23$ )

* Note - the $\mathrm{N}$ changes from 32 to 23 as only the PHUs that answered both questions were considered in the analysis

\begin{tabular}{|l|c|c|c|}
\hline $\begin{array}{c}\text { Involvement in } \\
\text { Quantitative Risk } \\
\text { Analysis }\end{array}$ & \multicolumn{2}{|c|}{ Expertise In Quantitative Risk Analysis } & Total (\%) \\
\hline & Yes (\%) & No (\%) & \\
\hline Yes (\%) & $10(50.0)$ & $10(50 \%)$ & $20(100.0)$ \\
\hline No (\%) & $2(66.7)$ & $1(33.3)$ & $3(100.0)$ \\
\hline Total (\%) & $12(52.2)$ & $11(47.8)$ & $23(100.0)$ \\
\hline
\end{tabular}

Quantitative risk analysis on brownfield sites is an invaluable tool for quantifying exposures and characterizing human health risks from contaminants. PHUs were asked to report on their involvement in quantitative risk analysis on brownfield sites, and also on their expertise in conducting quantitative risk analysis. Out of the PHUs that reported involvement in quantitative risk analysis, only 10 (50.0\%) reported having expertise in this area. Due to the 
cross-sectional nature of the study design, it is unknown at this time whether the PHUs that participate in brownfield activities developed that expertise as a result of their participation, or whether having the risk assessment expertise allows them to be more actively involved in brownfields. This should be further explored in future research on this topic. Qualitative tools such as in-depth interviews can be valuable in evaluating the relationship between these variables in future studies. 


\subsection{Discussion}

\section{Involvement of Ontario Public Health Units in Brownfield Activities}

One of the main objectives of the study was to assess whether Ontario public health units are involved in brownfield related activities. The results of the survey revealed that of the 32 PHUs that participated in the study, the majority reported being involved in brownfield activities. Although 4 PHUs responded that they did not know whether they participated in brownfield activities, and 5 PHUs reported not participating in brownfield activities, most continued with the survey and reported on their brownfield behaviours related to attitudes, beliefs, capacity, and partnerships.

Of the 23 PHUs that do become involved in brownfields, the majority (82.6\%) report to do so in an ad-hoc, as needed manner. Only one health unit reported having written policies and procedures in place that prescribe a systematic approach for involvement in brownfield activities. This outcome was expected as it is consistent with the anecdotal data that were reported by the PHUs at the 2009 Brownfields Consultation meeting between the Ontario Ministry of the Environment and the Greater Toronto Area PHUs (Archbold, 2009). This is considered to be a major barrier to providing an effective response on brownfield sites. Whereas a systematic, proactive engagement of PHUs can enhance community trust, maximize health benefits, and minimize cost overruns and delays, a reactive $a d$-hoc response often leads to delays in assessing risk, reactive crisis management, public mistrust, and media 
sensationalism (NACCHO, 2000; Archbold \& Lachapelle, 2008; Archbold, 2009; Berman, Orr, Forrester, 2009).

All participating health units were asked to provide information on what typically initiates their involvement in brownfield activities. Of the PHUs that do become involved in brownfields, the vast majority (82.6\%) report becoming involved as a result of a complaint or concerns in the community. None of the PHUs reported to always becoming involved proactively during the planning stage, with nearly a third of the PHUs reporting to "always" or "often" becoming involved reactively, as health issue arise. Again, the behaviours gleamed from these data are consistent with the behaviours reported in other questions, and can be interpreted as barriers to an effective response on brownfields sites. Developing proactive response policies and working with brownfield stakeholders to identify opportunities for early PHU involvement in the redevelopment process have been associated with optimization of health benefits and alleviation of public concern on brownfield sites (ATSDR, 2012, NACCHO, 2000).

When Ontario PHUs do become involved in brownfields, they report having participated in a wide range of brownfield related activities. The most common activities include: review of site's history, review of environmental monitoring results, review of Phase I \& II Environmental Site Assessments, and the review of quantitative risk assessments. Results of cross tabulation of these data with specific skills and expertise is however of some concern. It appears that although health units do undertake these activities, they do not always have the necessary skills and expertise required to effectively carry them out. For example, out of the 20 health units 
that engage in quantitative risk analysis on brownfield sites, only $50.0 \%$ report having expertise in quantitative risk analysis (Table 3.27). This skill set is considered essential in quantitatively estimating exposures and characterizing human health risk from site contaminants. Increasing PHUs' capacity through training, education, and access to reliable resources can significantly contribute to the effectiveness of PHUs' participation in brownfield activities.

Health units were also asked to comment on their engagement in environmental monitoring activities such as soil, groundwater, and air monitoring. Of the PHUs that answered the question, very few reported having access to resources such as monitoring equipment, sampling equipment, or the ability to contract out for environmental services (Table 3.19). This is perceived as a significant impediment to an effective response on brownfield sites. Empirical evidence indicates brownfield communities frequently place trust in the local health authorities and due to their mistrust in data gathered by site owners and their consultants, often have an expectation of health units' ability to independently gather and analyze data (NACCHO, 2000;

Blum, 2008). Increasing PHUs' resources to acquire expertise, monitoring equipment, or access to environmental services can substantially reduce barriers to effective public health involvement on brownfield sites. Furthermore, providing public health units with the ability to independently carry out environmental monitoring and analyze data can alleviate concern, and facilitate trust within the affected brownfield communities.

\section{Need for Public Health Units' Engagement in Brownfields}

The need for PHUs' engagement was predicted to be an important variable for determining engagement in brownfield activities. Literature suggests public health agencies 
often have to make difficult decisions about competing priorities for resource allocation (Jain, 2010). As such, informed, evidence-based resource allocation in areas where needs have been identified can result in improved program delivery and ultimately, improved population health outcomes (PHRED, 2008; Scutchfield et al., 2004; Turnock, 2001).

Due to the lack of a comprehensive provincial brownfield inventory, the number and location of brownfields within each health unit is unknown. Due to this limitation, the need for PHUs involvement in brownfield activities was assessed through the use of indicators and selfreported behaviours. Of the 32 health units that responded to the question about "need" to be involved in brownfield activities (in the survey defined as complaints, inquiries, community concern, etc.), the majority (78.1\%) respond there was a need for such involvement within their jurisdiction (Table 3.14). This proved to be a good indicator of whether health units participate in brownfield activities. Of the PHUs that do become involved in brownfields, $91.3 \%$ indicated there is a need for such involvement within their jurisdiction.

It is not clear from the results as to why two health units would identify need for public health involvement within their jurisdiction, but not provide a public health response on brownfield sites. It was hypothesized this was due to the lack of resources or expertise, or simply due to competing program priorities within the health units. PHUs were provided an opportunity to further elaborate on their answers, however, no responses were provided. As PHUs have a legislative mandate to investigate environmental hazards within their jurisdiction, and responding to community needs is a priority in public health practice, this should be further 
explored in future research. The use of qualitative research tools such as in-depth key informant interviews can be useful in further exploring the issue.

Awareness of existing brownfield sites within the public health units' jurisdiction was considered an important variable to explore. The US National Association of County and City Health Officials (NACCHO, 2000) classified the location and distribution of contaminated sites as a traditional public health indicator. Inventory and tracking of brownfield sites allows PHUs to gage the extent of the issue within their jurisdiction, and accordingly, to allocate resources for targeted interventions. Of the PHUs that become involved in brownfields, $17(77.3 \%)$ report being aware of brownfield sites within their jurisdiction (Table 3.24). In contrast, out of all the PHUs that become involved in brownfields $5(22.7 \%)$ report not being aware of any brownfield sites within their jurisdiction. It was hypothesized these PHUs may have policies in place for such involvement, but no actual need. It was further hypothesized that since "need" was not qualified in terms of time, i.e. current, past, or both, PHUs may have underreported their awareness of brownfield sites. Recognizing the many benefits that can be gained from PHUs involvement in brownfield activities, there is much impetus for developing comprehensive brownfield inventories and collaborating with stakeholders to identify such sites.

It was theorized that skills and expertise in brownfield related areas could play a role in how health units perceived the need for involvement within their jurisdiction. It was postulated that health units with higher levels of brownfield-related expertise would be better equipped to recognize health risks associated with brownfields, have established collaborative relationships with other experts in the field, and perhaps have access to more resources, 
resulting in an enhanced ability to engage on brownfield sites. Based on the results, that was deemed to be somewhat true. For example, of the health units that reported the need for PHUs' involvement, $40 \%$ also reported to have expertise in toxicology. That is in contrast with the health units that did not report the need for involvement, of which $80 \%$ reported not having toxicological expertise. Based on the results of the study it was not clear whether it was the expertise and skills that drove the perception of need, or vice versa. This is a significant limitation of a cross-sectional, questionnaire-based study design and should be investigated in more detail in future research. Perhaps the use of qualitative tools such as in-depth key informant interviews can help to further elucidate the issue.

Based on the survey results it became apparent that Ontario health units may lack the necessary capacity to effectively engage in brownfield activities. Consequently, health units reported a strong need for additional training and resources. When asked what additional resources would enhance their health units' engagement in brownfield activities, all PHUs that responded identified risk assessment methods, risk interpretation methods, and exposure assessment methods as priorities. To lesser extent, but also important, was the need for additional resources and training in environmental health surveillance, interpretation of sampling results, environmental health mapping, interpretation of standards, and understanding the Ontario Brownfields Regulation.

The survey results have revealed a high level of need for Ontario public health units to engage in brownfield activities. Furthermore, the results exposed a strong need for information and equipment resources, and additional training. Although the study results are 
largely based on self-reported behaviours and perceptions, the data helped to identify linkages between need, engagement, and capacity. Additionally, the gathered data helped to identify training and resource priorities that can be useful in enhancing PHUs response on brownfield sites.

\section{Capacity of Ontario Public Health Units to Engage in Brownfields}

In general, the survey results revealed a fairly low level of PHU capacity to engage in brownfield activities. Only approximately half of the health units reported having the necessary expertise and skills in areas traditionally associated to be within the scope of public health brownfield activities: assessments and monitoring, surveillance, and interpretation of risk (NACHHO, 2000). For example, of the health units that responded to the question about expertise, less than half reported having skills in the area of quantitative risk analysis, human toxicology, and site remediation. Furthermore, only half of the PHUs reported having skills and expertise in the areas of environmental site assessment and environmental monitoring, just to name a few. This is deemed to be huge barrier to effective public health involvement in brownfields as it precludes the health units from critically evaluating site data, interpreting human health risk, and making appropriate recommendations for risk reduction and management. This is especially of concern as public health units already engage in these activities, often without the necessary skills to do so effectively. The correlation between capacity and performance is strongly linked in empirical evidence. Both Turnock (2004) and Scutchfield et al. (2004) have argued that various capacity variables are associated with public health performance and impact delivery of public health programs. Higher organizational 
capacity has been consistently correlated with higher performance and enhanced public health response, ultimately leading to improved population health outcomes.

Based on the survey results, it is unclear as to why some health units lack the skills in areas such as toxicological and environmental risk analysis, especially as they are considered to be within the realm of the traditional public health role. Currently, the Ontario Public Health Standards (MHLTC, 2008) explicitly prescribe health units to assess environmental health risks, reduce the incidence of adverse health outcomes from exposure to environmental health agents, and reduce the burden of illness from environmental hazards. The above mentioned skills and expertise are necessary to effectively carry out this legislative mandate. One hypothesis advanced to explain this is that some health units may have a larger demand or need for such expertise, resulting in attaining a higher level of such skills. This could be due to more contaminated sites, more industrial pollution point sources, or simply more risk averseness amongst the population. The second hypothesis is that lack of expertise could simply be linked to the lack of available resources. A preliminary qualitative scan of demographic data and the level of health units' expertise suggest that larger, urban health units tend to have more environmental health capacity, although the data are not consistent across all health units. It is, however, consistent with the published literature. Erwin (2008) has noted that local health departments with larger staff, serving populations of more than 50,000 persons, and with higher funding per capita were often higher-performing in all areas of public health delivery. As adequate capacity is critical to effective public health engagement on brownfield sites, more Ontario-specific research is needed to better understand the variables that affect it. 
Two activities through which health units can expand their environmental health capacity are professional development and partnership building. Of the health units that answered the question about brownfield stakeholders and collaborations, only few reported having in-house brownfields related training or attending structured courses or seminars, and less than half reported attending brownfield related conferences. Similarly, with respect to partnerships and collaboration, of the health units that engage in brownfield activities only few had formalized arrangement with provincial agencies such as the MOE or MOL, or formalized arrangements with other municipal or regional departments. Formal relationships with stakeholders are linked to early public health engagement in the redevelopment process and early access to data on hazards and their spatial and temporal distribution, both of which are considered to be instrumental in mitigation of health risks (Chan, 2000). More effort should be made on part of the health units to establish partnerships across jurisdictional lines in order to improve brownfield response capacity. Furthermore, health units need to invest in training and professional development to ensure they have the necessary in-house capacity to provide a meaningful public health response when engaging on brownfield sites.

Expertise, skills, and adequate resources are critical to providing effective public health response on brownfield sites. Empirical evidence indicates that staffing and experienced workforce have consistently been linked with the achievement of public health performance standards and the fulfillment of regulatory mandates (Scutchfield et al., 2004; Erwin, 2008). A CDC (2001) status report on infrastructure notes that the increasing complexity of disease patterns and interventions requires advanced training and competencies to meet the escalating public health standards. However, the limited Canadian data, consistent with the results of this 
study, indicates there is a chronic shortage of people with advanced training in environmental health, preventing delivery of programs and services (Chociolko et al., 2006). In order to ensure a more meaningful public health delivery on brownfield sites, Ontario health units must make a more substantial investment in building their environmental health capacity.

\subsection{Study Limitations}

\section{Study design}

This study utilized a cross-sectional, exploratory study design in order to gather data on Ontario health units' behaviours with respect to brownfields. As there was little existing information on health units' brownfield behaviours, this approach was deemed appropriate in order to gather baseline data. Although the results provide an overview of the current state of health units' brownfield activities and the potential relationships between various variables, the design is not robust enough to determine causal relationships (Aday and Cornelius, 2006). Future research initiatives can benefit from the implementation of more robust approaches such as the longitudinal prospective study designs. By tracking spatial and temporal trends, researches can focus on associations identified through this survey to determine whether they are significant and causal in nature. The more rigorous study design will provide data better aligned with the current evidence-based approach to public health practice.

\section{Population size}

Population size has proven to be a significant limitation in the current research design. As the study population is the 36 Ontario health units, only a maximum of 36 responses could 
be obtained for analysis. Even with a response rate of $88.9 \%(32 / 36)$, the number was too small to carry out any meaningful statistical analysis to test for statistically significant associations or measure the strength of association between variables. When attempting to use chi square to test for significance of association, values were often less than 5 , making the test inappropriate under the current circumstances. Instead, odds ratio and confidence intervals were calculated using the mid p-exact test to correct for small numbers; however, due to the small sample size the observed relationships between variables were mostly not statistically significant. One way to correct for that would be to design a survey at the national scale. Sampling of health units across Canada would encompass a larger population and thus producing a larger sample size. Results could be analyzed for significance and strength of association yielding data that is more statistically robust and defensible.

\section{Self-reporting of behaviours}

Another significant limitation of this study was reliance on self-reporting of behaviours, rather than utilizing a measure of observed behaviours. In survey research, self-reporting of behaviours is often associated with bias and producing data that might not be considered robust (Aday \& Cornelius, 2006; McBurney, 1994). One form of bias can be the social desirability tendency, when respondents perceive one alternative as more socially acceptable than the other (McBurney, 1994). When designing the survey tool, care was taken to formulate the questions so that each alternative appeared to be equally desirable. Furthermore, anonymous modes of data collection were utilized and participants were assured that all attempts will be made to not identify individual health units. It was hypothesized that would 
assure the health units about confidentiality, thus allowing them to answer questions accurately and truthfully.

The second limitation related to self-reporting of behaviours is the recall bias. Many studies have shown that survey respondents often underreport or over report their past behaviours (Aday \& Cornelius, 2006; McBurney, 1994). This limitation can be addressed in future research by not relying on self-reporting of behaviours, and instead, quantitatively accounting for them. For example, when assessing "need", counting the number of actual brownfield related complaints or inquiries would be a more accurate measure of need, as opposed to asking the health units to self-report need. Unfortunately, as such approach would be more time consuming and costly, it was outside the scope of the current study. However, it should be considered for future research as it would generate data that is more defensible and robust. 


\subsection{Integrating Brownfield Redevelopment with Health}

\subsection{Community Design and Health}

In recent years, much of public health research and policy development has been focused on land use planning and its linkages to health (Bergeron, 2009; TPH, 2011b; NCCEH, 2011; OPHA, 2011). The issue is not new. For nearly 100 years it has been recognized that disciplines of urban planning and public health share common goals and perspectives centred around known determinants of health such as environmental quality and socio-economic factors (Kochtitzky et al., 2006; Perdue, Stone, Lawrence, 2003). Many correlations have been made between various aspects of the built environment and health outcomes. For example, in a recent report Healthy City by Design, Toronto Public Health (2011b) highlighted the evidence linking factors such as the natural and built environment, transportation, housing, and neighbourhood design to specific measurable health outcomes such as respiratory ailments, heart disease, diabetes, obesity, and high blood pressure. More so, TPH proposed that building a healthy city requires the reintegration of public health principles into the community design policies, programs, and services in a holistic way that fosters collaboration with other departments and agencies, engages all citizens in the decision-making process, and produces results that are accountable to all stakeholders.

Land use planning policies help to decide where and how communities are built. They also play a crucial role in how impacted sites such as brownfields are revitalized and reintegrated into communities. By introducing public health principles into the brownfield 
revitalization process, it is possible to both regenerate these sites and at the same time achieve improvements in measurable health outcomes.

\subsection{Revitalization of Brownfields and Health}

The revitalization of brownfields is closely connected to public health. The redevelopment of brownfield sites provides a unique opportunity not only for assessing and removing the immediate environmental hazards, but also for revitalizing its host communities with a health focus in mind. Much of the seminal work on this topic was completed by the US National Association of County and City Health Officials in the 1990s (NACCHO, 2000) with input from public health experts, planners, community organizers, and political leaders. They recognized that the community's health was dependant on creating sustainability that relied on integrated policies and planning that moved beyond the technical risk assessment and risk management. NACCHO advocated that to ensure healthy communities, attention must be paid to social justice, equity, building partnerships, and community collaboration.

The traditional role of PHUs regarding brownfield sites has been mainly centred on risk assessment and exposure management. The brownfield redevelopment process usually occurs in four stages: planning and inventory, assessment and investigation, development, and construction (NACCHO, 2000). As evidenced in empirical literature and the survey of Ontario public health units (Chapter 3), engagement of the latter typically occurs during the second stage, assessment and investigation. If at all, this engagement is usually limited to assessing the sites for contamination, and evaluating and limiting potential exposures. Although limited, this 
approach meets the minimal requirements under the current Ontario Public Health Standards that prescribe environmental health hazard investigations and surveillance (MHLTC, 2008).

It is important to re-examine this role. The seminal NACHHO (2000) report concluded that local public health agencies are in a unique position to transcend the traditional role of assessment and testing and transition into addressing quality of life concerns that are closely linked to measurable health outcomes. Inclusion of public health principles in the brownfield revitalization process provides an opportunity for creating healthy cities and healthy communities. This health-focused approach to brownfields is also in line with the current legislative mandate prescribed by the Ontario Public Health Standards. Mainly, the OPHS specifically instruct PHUs to develop and support healthy public policies regarding built

environments within their jurisdiction. Furthermore, the health-based revitalization approach has been tested in several communities across the US with measurable improvements in many health indicators.

\subsection{Best Practices and Health Focused Brownfields Revitalization}

Peer reviewed and grey literature sources were analyzed in order to determine the best practices available for integration of public health principles into the brownfield revitalization process. Only few credible health-based approaches were found, mainly the NACCHO and the Agency for Toxic Substances and Disease Registry (ATSDR) frameworks (NACCHO, 2000; ATSDR, 2012). Both are based on the consideration and integration of broad determinants of health into the brownfield redevelopment process, and both highlight the potential public health benefits such an approach can generate. 
When considering "best practices" on a brownfield site, most of the literature and guidance is focused on the removal of economic and legislative barriers, provision of financial tools, building private-public partnerships, and community engagement (Infrastructure Canada, 2008; NPCR, 2011; The United States Conference of Mayors, 2010). For example, in 2005 the Canadian Housing and Mortgage Corporation (CMHC, 2005) highlighted liability, regulations, finances, technology, and planning, as the most prominent impediments to brownfields redevelopment. As such, most of the current regulations and policies are aimed are reducing these barriers. Only in recent years, the idea of "sustainable development" has been connected to the brownfield redevelopment process (De Sousa, 2008; NPCR, 2011). This new approach is focused on "achieving a broader range of economic, social, and environmental outcomes associated with sustainability" (De Sousa, n.d., pg.1). Public health outcomes are amongst them.

\subsection{Rationale for Choosing the ATSDR Model as Best Practices in Health-Based Brownfield Redevelopment}

Four selection criteria were used to identify best practices within the available health-based brownfield redevelopment frameworks: the approach had to focus on improving health outcomes, it had to be evidence-based, it had to have an evaluation component for measuring health outcomes, and have been successfully tested in brownfield communities. The ATSDR Action Model met all the criteria (ATSDR, 2010). On its website, the ATSDR states that the Brownfields/Land Revitalization Action Model

"creates a framework to assess the impacts of redevelopment on public health, with a goal of achieving positive, sustainable improvements in overall community health" (ATSDR, 2012). The Action Model builds on the public health principles proposed in the seminal work of NACCHO (NACCHO, 2000; ATSDR, 2012). In addition, the ATSDR Action Model has been tested in many development communities across 
the US, where the improvements in health outcomes have been measured across many health indicators (ATSDR, 2010).

\subsection{Overview of the ATSDR Land Reuse Revitalization Process}

Figure 4.1 Steps in Developing a Healthy Community

Organize the

development

community
Evaluate

environment

al and health

Issues
Communicate

risk or health

issues to

development

community
Redesign the

community

with health in

mind
Measure

success:

environment

and health

change

Source: ATSDR, 2010.

1. Organize the development community - Identification of, and collaboration with stakeholders: individuals, groups, agencies, political leaders, and others who have a unique knowledge local sites and environmental issues, and can greatly contribute to the success of the redevelopment process.

2. Evaluate environmental and health issues - Critical assessment of the community living in and around the redevelopment site. The ATSDR proposes four questions that can be used as the basis for this assessment:

- What are the issues in the community? 
- How can redevelopment address these issues?

- What are the community health benefits of the redevelopment?

- What data are needed to measure change?

The table listed below provides examples of indicators that can aid in the evaluation of environmental and health issues in the redevelopment community. 
Table 4.1 Community Health Evaluation Example

\begin{tabular}{|c|c|c|c|c|}
\hline Category & $\begin{array}{l}\text { What are the } \\
\text { community } \\
\text { issues? }\end{array}$ & $\begin{array}{c}\text { How can } \\
\text { redevelopment } \\
\text { address the } \\
\text { issues? }\end{array}$ & $\begin{array}{c}\text { What are the } \\
\text { health benefits? }\end{array}$ & $\begin{array}{c}\text { What data are } \\
\text { needed to } \\
\text { measure } \\
\text { change? }\end{array}$ \\
\hline $\begin{array}{l}\text { Physical and } \\
\text { Mental Health }\end{array}$ & $\begin{array}{l}\text { Lack of parks, } \\
\text { playgrounds and } \\
\text { green spaces }\end{array}$ & $\begin{array}{l}\text { New parks, } \\
\text { community } \\
\text { gardens, walking } \\
\text { trails, bike lanes, } \\
\text { play lots, etc. }\end{array}$ & $\begin{array}{l}\text { Improved mental } \\
\text { illness, } \\
\text { improvements in } \\
\text { physical activity, } \\
\text { reduction in } \\
\text { obesity and } \\
\text { related chronic } \\
\text { diseases }\end{array}$ & $\begin{array}{l}\text { Number of vacant } \\
\text { properties, } \\
\text { number of green } \\
\text { spaces, number of } \\
\text { bike lanes and } \\
\text { trails, number of } \\
\text { recreational } \\
\text { spaces }\end{array}$ \\
\hline $\begin{array}{l}\text { Safety and } \\
\text { Securing }\end{array}$ & $\begin{array}{l}\text { Perceived or } \\
\text { actual high crime } \\
\text { rate; insufficient } \\
\text { lighting }\end{array}$ & $\begin{array}{l}\text { Improved lighting; } \\
\text { broad sidewalks; } \\
\text { community watch } \\
\text { groups }\end{array}$ & $\begin{array}{l}\text { Feel safer and } \\
\text { more secure; } \\
\text { community } \\
\text { ownership and } \\
\text { pride; more } \\
\text { individuals using } \\
\text { the } \\
\text { neighbourhood }\end{array}$ & $\begin{array}{l}\text { Crime rates; } \\
\text { number and types } \\
\text { of sidewalks, } \\
\text { reports from } \\
\text { community watch } \\
\text { groups }\end{array}$ \\
\hline Housing & $\begin{array}{l}\text { Lack of affordable } \\
\text { housing }\end{array}$ & $\begin{array}{l}\text { New or reclaimed } \\
\text { mix-use housing }\end{array}$ & $\begin{array}{l}\text { Avoidance of } \\
\text { gentrification; } \\
\text { increased home } \\
\text { ownership; new } \\
\text { stable rental } \\
\text { homes }\end{array}$ & $\begin{array}{l}\text { Number of } \\
\text { affordable } \\
\text { homes/units; } \\
\text { percent of homes } \\
\text { that are owner } \\
\text { occupied; socio- } \\
\text { economic and } \\
\text { demographic stats }\end{array}$ \\
\hline Education & $\begin{array}{l}\text { Lack of schools; } \\
\text { high drop-out } \\
\text { rates }\end{array}$ & $\begin{array}{l}\text { New schools, } \\
\text { community } \\
\text { centres, and after } \\
\text { school programs }\end{array}$ & $\begin{array}{l}\text { Education \& } \\
\text { community } \\
\text { programs; } \\
\text { increase education } \\
\text { rates }\end{array}$ & $\begin{array}{l}\text { Number of } \\
\text { children/adults } \\
\text { attending schools; } \\
\text { graduation rates, } \\
\text { dropout rates }\end{array}$ \\
\hline Economy & $\begin{array}{l}\text { Vacant properties; } \\
\text { high } \\
\text { unemployment } \\
\text { rates }\end{array}$ & $\begin{array}{l}\text { Recruitment of } \\
\text { new businesses to } \\
\text { the area }\end{array}$ & $\begin{array}{l}\text { Improve economy } \\
\text { in the area }\end{array}$ & $\begin{array}{l}\text { Number of new } \\
\text { businesses, } \\
\text { employment rates }\end{array}$ \\
\hline
\end{tabular}

Source: ATSDR, 2010. 
3. Communicate risk or health issues to the community - Engagement of stakeholders and the community to ensure they support the development goals. Addressing any questions or concerns the community might have. Communication of risks identified in the community.

4. Redesign the community with health in mind - Creation of a redevelopment plan that addresses the health indicators of interest identified during the assessment phase. Consultation with the redevelopment community.

5. Measure the success of environment and health change - Measurement of community health outcomes of interest identified during the assessment phase. Baseline measurements across various indicators can be compared over time during and after the development process.

\subsection{Examples of Development Communities and Improvements in Measurable Health Outcomes}

It has been noted that redevelopment that addresses health and sustainability considerations can produce measurable economic, environmental, health, and social benefits (NACCHO, 2000; De Sousa, 2008; ATSDR, 2010). With many public health programs competing for limited resources, it is important that public health interventions are evidence-based with demonstrated improvements in health outcomes. The ATSDR Action Model has been successfully adopted and deployed by many redevelopment communities throughout the United States. A selection of case studies was chosen to illustrate how the ATSDR approach can be utilized by the development community and to highlight how the approach can help to achieve a variety of health-related goals: increase in recreation and greenspaces, addition of 
affordable housing, improved access to health care, and creation of new jobs and economic

development (ATSDR, 2010).

\section{Table 4.2 Examples of ATSDR Development Communities}

\begin{tabular}{|c|c|c|c|}
\hline $\begin{array}{c}\text { Development } \\
\text { Project }\end{array}$ & Issues & Actions Taken & $\begin{array}{c}\text { Measurable Health } \\
\text { Outcomes }\end{array}$ \\
\hline $\begin{array}{l}\text { The Brass Site, } \\
\text { Kenosha, Wisconsin }\end{array}$ & $\begin{array}{l}\text { - a } 29 \text {-acre former bass } \\
\text { and copper foundry } \\
\text { - PCBs, metals, PAHs, } \\
\text { VOCs impacts } \\
\text { - high crime rates } \\
\text { - high land vacancy } \\
\text { rates } \\
\text { - low employment } \\
\text { rates }\end{array}$ & $\begin{array}{l}\text { - extensive community engagement } \\
\text { - community assessment to ensure the } \\
\text { redevelopment is suitable } \\
\text { - "The Lincoln Neighbourhood } \\
\text { Revitalization Strategy" : promote stability, } \\
\text { increase property values, provide a safe } \\
\text { environment, enhance affordability, } \\
\text { generate employment } \\
\text { - Urban Land Institute produces a new plan: } \\
\text { feasibility of development, revitalization of } \\
\text { community, linkages to other } \\
\text { neighbourhoods } \\
\text { - private/public financing } \\
\text { - health assessment by the Wisconsin } \\
\text { Department of Health Services }\end{array}$ & $\begin{array}{l}\text { - increase in affordable } \\
\text { housing, property values, and } \\
\text { owner-occupancy rates } \\
\text { - lowered crime rate } \\
\text { - increased access to grocery } \\
\text { stores and fresh foods } \\
\text { - reduced exposure to } \\
\text { industrial contaminants } \\
\text { - increase in employment } \\
\text { opportunities }\end{array}$ \\
\hline $\begin{array}{l}\text { Clearwater } \\
\text { Brownfields Area, } \\
\text { Clearwater, Florida }\end{array}$ & $\begin{array}{l}\text { - Clearwater } \\
\text { Brownfields Area (CBA) } \\
\text { with abandoned lands } \\
\text { of former gas stations, } \\
\text { drycleaners, print } \\
\text { shops, and others } \\
\text { - approx. } 220 \\
\text { potentially } \\
\text { contaminated sites } \\
\text { - high unemployment } \\
\text { and poverty rates } \\
\text { - low property values } \\
\end{array}$ & $\begin{array}{l}\text { - extensive community engagement } \\
\text { - "Environmental Justice Plan and Action } \\
\text { Agenda": enhance awareness of } \\
\text { brownfields; improve access to information; } \\
\text { community participation in the decision- } \\
\text { making process; create a healthy and safe } \\
\text { environment; increase the economic base } \\
\text { - EPA assistance grants } \\
\text { - engage the local health department to } \\
\text { assess exposures to contaminants }\end{array}$ & $\begin{array}{l}\text { - access to free health care } \\
\text { for CBA residents } \\
\text { - improved public safety with } \\
\text { a police station, fire station, } \\
\text { an family center } \\
\text { - increase in affordable } \\
\text { housing } \\
\text { - creations of new jobs } \\
\text { - restoration of a polluted } \\
\text { creek }\end{array}$ \\
\hline $\begin{array}{l}\text { Highland Park, } \\
\text { Milwaukee, } \\
\text { Wisconsin }\end{array}$ & $\begin{array}{l}\text { - high density } \\
\text { affordable housing } \\
\text { neighbourhood } \\
\text { - high crime rates and } \\
\text { drug use } \\
\text { - poor living conditions } \\
\text { and disrepair } \\
\text { - lack of connections to } \\
\text { the local community }\end{array}$ & $\begin{array}{l}\text { - extensive community consultation to } \\
\text { identify needs } \\
\text { - demolition of existing structures and } \\
\text { creation of new units with accessibility and } \\
\text { health in mind } \\
\text { - creation of Highland Garden - a 20,000 } \\
\text { square foot green roof }\end{array}$ & $\begin{array}{l}\text { - provision of safe, } \\
\text { affordable "green" housing } \\
\text { - meeting specific needs of } \\
\text { the elderly and disabled } \\
\text { residents } \\
\text { - improvements in } \\
\text { neighbourhood walkability } \\
\text { and access to services }\end{array}$ \\
\hline $\begin{array}{l}\text { Menomonee River } \\
\text { Valley, Milwaukee, } \\
\text { Wisconsin }\end{array}$ & $\begin{array}{l}\text { - a 1,200 acre former } \\
\text { downtown industrial } \\
\text { hub } \\
\text { - } 68 \text { underused or } \\
\text { vacant properties } \\
\text { - high poverty and } \\
\text { unemployment rates } \\
\text { - economic depression } \\
\text { - aging infrastructure }\end{array}$ & $\begin{array}{l}\text { - "Market Study, Engineering, and Land Use } \\
\text { plan for the Menomonee Valley": guide for } \\
\text { managing public investment, creating jobs, } \\
\text { improving environmental conditions, } \\
\text { improvement in health } \\
\text { - extensive community consultation } \\
\text { - EPA grants for environmental assessment } \\
\text { and sustainable development } \\
\text { - } 1999 \text { Sustainable Development Design } \\
\text { Charrette }\end{array}$ & $\begin{array}{l}\text { - addition of greenspace and } \\
\text { recreational space } \\
\text { - creation of jobs and } \\
\text { economic growth } \\
\text { - increase in new businesses } \\
\text { - partnership to collect } \\
\text { baseline health data to track } \\
\text { indicators of community } \\
\text { health over time }\end{array}$ \\
\hline
\end{tabular}


Source: ATSDR, 2010.

As evidenced by the highlighted case studies, the deployment of the ATSDR Action Model on brownfield sites can bring significant improvements in community health as measured across multiple health indicators. However, it should also be noted that successes in the development communities were also dependent on a collaborative approach that relied on access to resources and economic grants, full engagement of communities in the decisionmaking process, and the commitment of local health departments and federal and regional government agencies.

\subsection{Critical Analysis of PHUs Activities on Brownfield Sites in Comparison to the ATSDR Action Model}

By using the data obtained from the province-wide survey, this section will critically examine how Ontario PHUs activities on brownfield sites compare with the best practices set out by the ATSDR Brownfields/Land Revitalization Action Model. The focus is on strengths, gaps, and weaknesses in the Ontario PHUs' current approach. The conclusions will be used to elucidate recommendations for necessary health-based policy and process changes that will be feasible and practical for the Ontario setting.

\section{Organizing the Development Community}

Engaging and organizing the community is a critical first step in a health-based brownfield revitalization process. Meaningful community involvement leads to better acceptance of the redevelopment project, and often greater feelings of trust amongst stakeholders (NACCHO, 2010; ATSDR, 2010). Summarizing literature, Solitare (2005) reported 
that community participation promotes democracy, improves decision quality, educates the public, legitimizes decisions, and promotes community empowerment. In addition, it has been noted that local communities often have knowledge that is specific to the site which may aid the redevelopment process.

When asked about the extent to which Ontario PHUs engage development communities in brownfield related activities, 20 (62.5\%) of PHUs said they seldom or never allow for community input into all brownfield decisions, and only 9 (28.1\%) of PHUs reported that they always or often provide information to communities at health related stages. Furthermore, when PHUs are involved in brownfield activities, only 13 (40.6\%) collaborate with individual community members, 19 (59.4\%) with community groups, 10 (31.3\%) with non-governmental organizations, and 12 (37.5\%) with political leaders. This is perceived as a significant weakness in the current brownfield redevelopment process. As the previous analysis of the ATSDR case studies has shown, community engagement is essential to the effective assessment of community needs, and the overall success of the project.

These results were expected. The Ministry of the Environment indicates that in Ontario, some public consultation for wide-area revitalization projects, such as the Waterfront Toronto initiative, is often undertaken. However, smaller, private-sector driven redevelopment projects rarely involve community engagement (Adams, 2013). In addition, when community engagement does occur, it is usually proponent-driven and it often does not include the local health department. As such, broader, less evident public health issues are often not identified and may not be addressed in the revitalization plan. 


\section{Evaluation of Environmental and Health Issues}

Evaluation of environmental and health issues is yet another critical component of a successful health-based revitalization process. When evaluating environmental and health issues, the ATSDR model proposes moving beyond the traditional roles of environmental monitoring and risk assessment, and to look to broader determinants of community health such as housing, neighbourhood design, safety, employment, access to healthy foods and health care, and education. One credible approach to such assessments is the utilization of the Health Impact Assessment (HIA) tool (TPH, 2005). In its 2005 Board of Health report, the TPH Medical Officer of Health stated that HIA is "combination of procedures, methods, and tools by which a policy, program or project may be judged as to its potential effects on the health of the population, and the distribution of those effects in the population" (TPH, 2005). This approach has been successfully used for the assessment of several North American projects when consideration had to be given to the broader determinants of health (TPH, 2005).

When PHUs were asked to report on the use of the HIA tool on brownfield sites, 16 (50.0\%) reported that they use this approach. The answer was surprising, as only $3(9.4 \%)$ of the health units reported engaging proactively, during the planning stage of the redevelopment process. In order to be effective, HIA must be deployed at the planning stage of a project in order to properly assess and mitigate effects prior to the redevelopment actually taking place.

As 7 (21.9\%) PHUs reported sometimes becoming involved in the planning stage of the redevelopment process, it was hypothesized that the HIA approach might be used on some brownfield sites under specific circumstances. This is a significant weakness in the Ontario 
brownfield practices. Literature indicates that assessment of the community's broader determinants of health has been consistently linked with improvements in health outcomes on brownfield sites. Furthermore, evidence from the ATSDR case studies suggests that it is also closely linked to the success of the project.

Ontario public health units appear to be performing somewhat better when evaluating environmental issues. Approximately three-quarters of all PHUs conduct site visits, review Phase I \& II ESAs, environmental monitoring results, and quantitative risk assessments. However, the quality of that involvement is somewhat questionable. Out of the 20 PHUs that reported involvement in quantitative risk analysis, only 10 (50.0\%) reported having expertise in this area (Table 3.27). In addition, very few PHUs report having the ability to independently conduct environmental monitoring activities or have the resources to externally contract for such services. Once again, this is a serious gap on part of the health units. Significant changes in policy and resource allocation are needed in order to increase PHUs' capacity to successfully carry out these activities.

\section{Communication of Risk and Health Issues to the Community}

The successful communication of risk and health issues is closely integrated with community engagement and organization. As noted in empirical literature, "partnerships are essential for stabilizing a concerned community" (Sly, 2000). Risk communications, and consequently risk management decisions, are effective when communities are engaged early in the process to voice their concerns and provide input into the process. Eiser et al. (2007) noted that shared interests, transparency and openness are the most important factors in predicting 
trust of the local government. On brownfield sites, such qualities are usually fostered when the community is engaged early and meaningfully in the redevelopment process. As previously reported, in Ontario this rarely occurs on brownfield sites (Adams, 2013). Very few PHUs engage the community early in the development process, and only 9 (28.1\%) always or often provide information to the community at critical, health-related stages of the process (Table 3.9).

It is also important to consider how public health units engage the community. Solitare (2005) commented on various factors that limit the extent to which communities participate in brownfields redevelopment. Mainly, she identified awareness of participation, time to participate, and some socio-economic factors as significant indicators of whether development communities participate in the process. In order to be effective, PHUs need to engage communities using a multitude of tools specifically tailored to the demographic and socioeconomic characteristics of the development community.

When asked what tools PHUs used to communicate information regarding brownfield sites within their jurisdiction, approximately half reported holding community meetings, conducting one-on-one consultation, or posting information on their website. This may not be the best approach, as the ability to attend community meetings or having access to the internet is not always feasible for all community members, and engaging in phone consultation is not always practical or efficient. Only $13(18.8 \%)$ of PHUs reported posting posters and 9 (28.1\%) reported conducting door-to-door outreach, tools that are often better tailored to specific community needs. Once again, this is a significant weakness in the current approach and likely 
closely tied to the lack of resources and competing program needs. In order to effectively address this gap, consideration must be given to PHUs brownfield policies and resource allocation.

\section{Redesigning the Community with Health in Mind}

The goal of this step is to create a revitalization plan that is inclusive of the community health, social, and environmental health priorities identified during the health evaluation process. This requires a collaborative approach between the redevelopment community, regulators, health and political leaders, and the developer. Furthermore, this can only be achieved if the community and all the stakeholders are engaged meaningfully and early in the planning process. As the results from the province-wide survey suggest, this rarely occurs in Ontario. Most public health units engage with the communities reactively, as health issues arise, and rarely during the planning stages of the redevelopment process. This is an important gap in the current practice. As demonstrated through the review of the ATSDR case studies, creating successful redevelopment communities is contingent on consultation with the communities to understand and address their specific health needs.

This weakness in the current PHUs process is further highlighted by the lack of appropriate health monitoring near brownfield sites. In order to redesign the community with health in mind, baseline health information is needed to identify relevant issues. In Ontario, relatively few PHUs engage in meaningful Health Impact Assessments when becoming involved in brownfield activities. In contrast, for some time now the US EPA has recognized the importance of monitoring impacts from brownfields, especially in disadvantaged communities 
and among sensitive populations (US EPA, 2006). Through their grant funding for brownfields clean-up, US EPA's current legislation allows grant recipients to spend up to $10 \%$ for "monitoring the health of populations exposed to one or more hazardous substances from brownfield sites" (US EPA, 2006). Generally, these activities include: collecting and linking baseline health and environmental information, monitoring the health of the community, assessing exposure patterns, monitoring the environmental quality during the site clean-up, and conducting Health Impact Assessments. In order for Ontario PHUs to engage meaningfully in health monitoring, it would require regulatory and policy changes aimed at increasing PHUs access to resources and expertise. In order to be effective, these changes will have to be introduced at the federal, provincial, and local levels.

\section{Measuring Success Through Environmental and Health Change}

Perhaps of all the steps in the ATSDR Action Model, this is where the Ontario public health units demonstrate the least activity. Measurable outcomes exhibit PHUs accountability and the success of public health interventions on brownfield sites, increasingly critical when allocating resources and prioritizing program delivery. Although the PHUs were not explicitly asked about measurements of environmental and health indicators, they provided information about factors that are critical to the process.

First, it is important to engage and organize the community and stakeholders early in the redevelopment process. Only when engaged in the meaningful way, can they provide input and identify health priorities within their communities. Early involvement in the planning process is key. Temporal tracking of priority health indicators is most effective when a baseline 
assessment is completed prior to a health intervention taking place. In Ontario, very few PHUs engage proactively in the brownfield planning process, and few engage the community at this stage as well. This is an important weakness in the current approach, as both the development community and the health officials need to be at the table in order to appropriately identify and measure relevant indicators of interest.

Second, in addition to being engaged early, the PHUs need to have the necessary resources and utilize the appropriate tools to effectively measure environmental and health outcomes. In Ontario, that is not always the case. As evidenced by the survey results, relatively few PHUs engage in health impact assessments, some engage in environmental and risk assessments when they might not have the necessary skills to do so, and very few have access to resources and equipment to undertake independent sampling.

Both are significant weaknesses in the current process. Considerable regulatory, policy, and process changes are needed in order to address both issues and to ensure maximization of health benefits on brownfield sites.

\subsection{Conclusions}

To conclude, there is a wealth of empirical knowledge correlating community design with determinants of health. This includes brownfields revitalization and health outcomes. With that in mind, several credible agencies developed brownfield revitalization frameworks to maximize health benefits on brownfield sites. Within that realm, the ATSDR Brownfields/Land Reuse Model represents the "best practices" as the approach is health oriented, evidencebased, focused on measurable outcomes, and successfully tested in communities across the 
United States. When the current Ontario PHUs brownfield practices were compared with the ATSDR model, many gaps and weaknesses were noted across all indicators.

Based on these findings, the next chapter will propose regulatory, policy, and practice recommendations across all levels of government necessary to strengthen brownfield redevelopment and maximize health benefits in affected communities. The recommendations will aim to be feasible, practical, and cost effective. 


\subsection{Recommendations}

This section will propose how to integrate the principles identified within the ATSDR Brownfields/Land Reuse framework into the current Ontario brownfields practice. The recommendations will address actions that can be taken at all levels of government: federal, provincial, and municipal, and will be centered on flexibility, feasibility, and practicality. The goal is to propose an approach that will be appropriate for all public health units in Ontario, be implementable, cost-effective, and health protective.

Verbatim adaptation of the ATSDR model in Ontario is not feasible, nor practical. As it currently exists in the United States, the ATSDR brownfields framework is implemented at the federal level with legislative dedication to funding. First introduced in 1985, the ATSDR was created under the Comprehensive Environmental Response Compensation and Liability Act (CERCLA), also known as the "Superfund Law". Although aligned with other federal bodies such as the US EPA, ATSDR has the specific mandate to address hazardous substances and harmful exposures on brownfield sites throughout the United States (ATSDR, 2011b). In Canada, the responsibility for governing environmental matters falls within the provincial jurisdiction. Through constitutional division of powers, other than on federal lands, each province governs environmental and health matters within their jurisdiction. In each province, the elected parties direct and shape the regulations and policies pertaining to brownfields redevelopment and revitalization. As such, each province has specific brownfields policies that are closely connected to its economic and growth vision and often differ between regions. 
One of the principles for integrating the ATSDR approach into the current Ontario brownfields policies is flexibility. It must be recognized that the ATSDR framework is not static, but rather a collection of steps that might not be sequential and can vary widely in its implementation. That is an important consideration in Ontario. In the current economic climate, public health units are often tasked with delivering more programs and services with fewer resources. As such, each health unit must have the ability to assess the need for brownfield intervention within their jurisdiction and customize their response while adhering to the underlying ATSDR principles.

For example, it is recognized that each brownfield site is unique and the "one-plan-fitsall" approach to redevelopment will likely not work (ATSDR, 2010). Brownfield sites vary in their size, degree of contamination, and the complexity of health issues within the development community. While some sites may provide an opportunity to address a wide breadth of health issues through the redevelopment process, smaller sites may only allow public health practitioners to focus on immediate hazards.

Feasibility is yet another important consideration. It is unlikely that any public health unit or government agency can currently allocate significant resources to establish a new program specifically dedicated to the brownfield issue. In the current economic climate, the emphasis is on the integration of public health principles into the existing governance and policy frameworks. For example, in the Healthy Toronto by Design report, Toronto Public Health (2011) advocated that collaboration between various municipal departments, government institutions, the private sector, and community organizations was crucial to 
creating a city that is healthy and liveable. As such, the feasibility of integrating the ATSDR model into the current PHUs' practices is dependent on recognizing brownfields policies currently in place and enhancing them with public health principles.

Thirdly, the recommendations must be practical. As noted before, the recommendations for Ontario health units must be adoptable and realistic. They must fit within the current governance structure, and meet the mandate of the current Ontario Public Health Standards. They results of these recommendations must be deliverable and measurable.

As such, the proposed recommendations will address gaps regarding brownfields redevelopment practice at three levels of government: federal, provincial, and municipal. It is expected that the implementation of these recommendations will lead to improvements in health outcomes within the development communities.

\subsection{Proposed Federal Initiatives}

The provinces have the primary oversight with respect to the environmental, health, and brownfield regulations and policies within their jurisdiction. Notwithstanding that, the federal government can still play an important leadership role in supporting brownfields redevelopment within each province. Essentially, issues such as brownfields funding and resources can be well addressed at the federal level.

For example, to make the ATSDR program successful in the United States, there is dedicated funding under the Small Business Liability Relief and Brownfields Revitalization Act 
that allows for health-based brownfields revitalization (ATSDR, 2006). To encourage brownfields redevelopment, the Canadian federal government can make funds available for brownfields revitalization within each province. In the Unites States, the Environmental Protection Agency established a financial support system that provides funds for the Environmental Justice Small Grants Program (US EPA, 2009). The purpose of the program is to support initiatives that encourage community, state, and regional efforts to address environmental health issues on brownfield sites. It is critical that similar programs are established in Canada. As many benefits have been associated with brownfields revitalization, federal recognition of these benefits should be tied to establishing grants and financial support for redevelopment process.

\subsection{Provincial Level Support}

\section{Legislative changes}

Currently, the Ontario Brownfields Regulation primarily addresses the end use of the brownfield sites. That is a major public and community health issue. As sites are being redeveloped across Ontario, the effects of the redevelopment are rarely considered. There are no regulatory requirements for environmental monitoring during the remediation or for the assessment of risk in the community. The following recommendations call for strengthening the current brownfields regulation to better address community health issues on brownfield sites:

- Introduce legislative requirement for public health units' involvement at all sites that are either adjacent to sensitive receptors or residential communities. This recommendation 
was first proposed by the Toronto Medical Officer of Health during the recent brownfields consultation (TPH, 2009). The Toronto $\mathrm{MOH}$ acknowledged that brownfield sites may pose a significant health risk to surrounding community. By having health units engaged in the redevelopment process, those risks can be properly assessed and mitigated.

- Introduce requirements to address potential health impacts that may occur during the remediation process. For example, many substances can become disturbed and become dispersed during the remedial process. Especially in densely populated communities, air monitoring might be needed in order to evaluate and mitigate exposure risk in the community.

- Legislate mandatory notification of brownfields communities that redevelopment of the site is being considered. This will allow the redevelopment community to become engaged in the redevelopment process early in the planning state.

- Establish a provincial brownfields inventory. Brownfield inventories are an invaluable tool in providing information on the spatial distribution of brownfield sites.

Furthermore, they usually contain information regarding the contaminants encountered on each site and the level of risk they pose in the community.

The Ministry of the Environment should work collaboratively with the health units to establish partnerships and collaborative approaches that foster heath improvements on brownfield sites. As an example, Toronto Public Health and the MOE have recently worked together on addressing health and environmental issues on a former coal gasification site. This collaboration lead to better assessment and characterization of health risk, better risk 
communication with the community, and improvement in project completion times

(Adams, 2013). The outcome was allowing the project to move forward, have the contamination removed from the site, and address community concerns.

\section{Practices}

Most heath units and the MOE have established relationships that usually vary between the regions (Adams, 2013). Information sharing between the Medical Officer of Health and the Ministry of the Environment is legislated under the Ontario Health Protection and Health Promotion Act. Depending on the "need" within their jurisdiction, some health units may have more defined working relationships with the MOE that lead to better assessment of risk on brownfield sites. In order to maximize the health benefits of this collaboration, the following approaches should be adopted:

- Formalize information sharing regarding the distribution and location of contaminated sites. Most of the MOE district offices have lists of contaminated sites within their jurisdiction and some share that information with their respective health units. By knowing the distribution of brownfields within jurisdiction, public health units can be better positioned to assess risk and respond to community concerns.

- Create a working group to jointly address the issue of brownfields within the jurisdiction - collaborative, proactive approaches between the MOE and PHUs often lead to better risk assessment and risk mitigation on brownfield sites (Adams, 2013). Furthermore, this allows for better information sharing and collaboration between the MOE and the local health unit. 
- Jointly assess and evaluate brownfield redevelopment proposals within the jurisdiction. This will allow the PHU to evaluate potential risks and to communicate the risk to the community. The MOE should notify the local health units regarding redevelopment sites that are abutting residential properties and other sensitive receptors

- Provide assistance to health units with training. The MOE often has opportunities to train on issues regarding risk interpretation, environmental monitoring. For example, in the 2010 training session for vapour intrusion, PHUs were asked to participate. This not only allowed for advanced training for public health practitioners, but also encouraged inter-agency partnership and relationship building. Public health practitioners interacted with the MOE staff to exchange experiences and ideas, and to collaborate.

The Ministry of the Environment and Ontario public health units share a long history of partnership and collaboration. By integrating the proposed changes into the current regulatory framework and policies, this partnership can be enhanced and strengthened. This can lead to improved health outcomes on brownfield sites and measurable improvements across many health indicators.

\section{$\underline{\text { Public Health Ontario }}$}

Public Health Ontario (PHO) was created post-SARS to "protect and promote the health of all Ontarians and to reduce inequalities in health" (PHO, 2011). Within its practice, PHO has a mandate to provide technical assistance to health units on issues of environmental health, including brownfields. In its recent presentation on contaminated sites (PHO, 2012), PHO offered assistance to PHUs with respect to risk interpretation on brownfield sites, review of site 
investigation reports, and brownfield-specific training workshops. That role needs to be strengthened. As the results of the survey have showed, some urban health units have specialized teams dedicated to contaminated site investigations, however, others lack the necessary capacity to address these issues within their jurisdiction. The PHO should take the leadership role in providing training to health units in key priority areas of: risk assessment and interpretation methods, exposure assessment, environmental health surveillance, and interpretation of standards. Furthermore, the PHO should strengthen its capacity to provide assistance and equipment for monitoring and testing. Currently, the equipment available for assistance to health units has limited applicability on brownfield sites and cannot be deployed for extended periods of time in order to properly assess environmental conditions. The PHO can build on that by acquiring additional monitoring equipment and providing grants to health units for contracting out for independent environmental sampling.

\subsection{Changes at the Municipal Level}

Most land use planning decisions are made at the municipal level. Public health units can play an important role in promoting health-based brownfields redevelopment by collaborating with various departments within the municipality and engaging with municipal stakeholders. In addition, municipalities can promote health-based brownfields redevelopment by providing financial incentives to developers and increasing the internal health units' capacity for brownfields response.

\section{Advocacy}


Public health promotion and advocacy are mandated through the current Ontario Public Health Standards and has always been fundamental to public health practice (MHLTC, 2008). For example, in the past, Toronto Public Health has been a strong advocate for the integration of public health principles into the land use planning decision making process (TPH, 2011b). By introducing and promoting the concepts at the Board of Health level, TPH has been successful in collaborating with other municipal divisions to introduce public health principles such as active transportation into the current transportation policies (Toronto, 2013). Public health units can build and expand on these roles. By specifically advocating for the integration of health principles into the brownfields redevelopment process, health units can collaborate with other municipal divisions to ensure public health considerations are addressed early in the planning process.

\section{$\underline{\text { Financial Incentives }}$}

The Ontario government has provided the municipalities with several tools to promote community planning and brownfield redevelopment. For example, under section 28 of the Planning Act, the municipalities can designate Community Improvement Project Areas (CIPA) within their jurisdiction (OMMAH, 2012). By designating an area as CIPA, municipalities can provide financial incentives for community improvement activities within that area. Currently, these incentives include study grants, rehabilitation and remediation grants, tax assistance grants, and development charges exemptions. For example, under the Study Grant Program, municipalities can fund feasibility studies, Phase I and II ESAs, remedial work plans, and risk assessments. To mirror the health-based incentives provided by the US EPA, municipalities can 
require the grant recipients to dedicate a percentage of the grant for health monitoring and health assessment (US EPA, 2006). Furthermore, the municipalities and integrate public health principles into the financial tools they provide by mandating the developers to collaborate with the development community and the local health unit.

\section{Building Capacity}

The health units' ability to effectively engage on brownfield sites is closely correlated with capacity. The survey results have shown that PHUs with greater capacity to become involved in brownfield sites usually do so more proactively and earlier in the brownfields redevelopment process. For example, Toronto Public Health has a dedicated Environmental Response Team (ERT) that is often engaged by municipal and provincial stakeholders to assess health risks on contaminated sites. By having specialized staff that is trained and dedicated to risk assessment and risk mitigation, TPH can effectively engage in the brownfields redevelopment process early in the planning stage. Such involvement leads to enhanced levels of community trust, maximization of public health benefits, and minimization of risk.

The mandate for health units to assess and mitigate environmental health risks in imbedded in the current Ontario Public Health Standards (MHLTC, 2008). The PHUs can build on this mandate by having a staff member specifically trained and dedicated to the assessment of risk and risk mitigation. It is estimated that financial resources required for one full-timeequivalent position will range between $\$ 75,000$ and $\$ 95,000$. As Ontario health units have a $25 \% / 75 \%$ cost sharing arrangement with the province, the actual cost to the municipality will likely be in the $\$ 56,000$ and $\$ 72,000$ ranges. The benefits of such investment within the health 
unit will include enhanced capacity to assess and mitigate risk, and promotion and advocacy for public health on brownfield sites. 


\subsection{Conclusions}

The revitalization of brownfield sites provides many health and community benefits. Redevelopment of historically contaminated lands reduces the public's potential exposure to toxic chemicals and re-introduces sites into active public use. In addition, the revitalization process provides an opportunity for addressing community health issues for the integration of public health principles into community design. It is well established that public health agencies have an important role to play in the redevelopment process (ATSDR, 2010; NACCHO, 2000). In Ontario, public health units often become engaged in the redevelopment process to evaluate health risks and communicate those risks with the impacted communities. The demand for public health units' involvement is often driven by the communities' perception of health agencies as being credible and trustworthy (Sly, 2000; NACCHO, 2000).

A survey of Ontario health units was completed to evaluate the level of PHUs involvement in brownfield activities. The purpose of the survey was to determine the extent to which Ontario PHUs get involved in brownfield activities and to examine key factors that limit or impede that involvement. Health units reported their behaviours with respect to their involvement in brownfield activities, the need for such involvement within their jurisdiction, their attitudes and beliefs regarding brownfields, their capacity, and community engagement. In general, the results indicate that the majority of the Ontario PHUs do become involved in brownfields, however, that involvement is often demand-driven and it usually occurs in a reactive manner. Many health units reported lacking the capacity to respond adequately on 
brownfield sites, and most have indicated that additional training and resources would enhance that response.

The level of Ontario public health units' involvement on brownfield sites was compared to the best practices established by the Agency for Toxic Substances and Disease Registry Brownfields/Land Reuse framework. The ATSDR Model was chosen as the most appropriate for this comparative analysis as the ATSDR approach is health oriented, evidence-based, focused on measurable outcomes, and successfully tested in communities across the United States. When the current Ontario PHUs brownfield practices were compared with the ATSDR model, many gaps and weaknesses were noted across all indicators. Primarily, the PHUs rarely engaged in meaningful community consultation, often failed to adequately evaluate environmental and health issues on brownfield sites, and rarely measured environmental and health changes within the redevelopment communities.

The results of the province-wide survey, combined with the critical analysis of PHUs activities on brownfield sites in comparison to the ATSDR model, allow for the identification of gaps and weaknesses in the current approach. Furthermore, the results also helped to determine what measures are necessary to strengthen PHUs' response on brownfield sites and maximize health benefits within the redevelopment communities. Primarily, recommendations were made for regulatory and policy change at the federal and provincial levels. The issues of advocacy, capacity, and financial tools were addressed at the municipal level.

By adopting the proposed recommendations within their own jurisdiction, and advocating for changes at the federal and provincial level, Ontario public health units can 
enhance public health practice on brownfield sites and maximize health benefits in the redevelopment communities. 


\section{Appendix A}




\title{
KEY INFORMANT QUESTIONNAIRE PUBLIC HEALTH PRACTICE
}

\author{
An Evaluation of Ontario Public Health Units' Practices \\ In the Redevelopment of Brownfields
}

\section{Purpose}

The purpose of this research is to examine the involvement of Ontario Public Health Units in brownfields redevelopment. By utilizing a cross-sectional, hypothesis-generating study design, this research seeks to establish the current level of Ontario Health Units' involvement in brownfields redevelopment, and to identify factors and variables that might modify that involvement.

\section{Definition of brownfields}

"Brownfields are abandoned, idle, or under-utilized industrial and commercial properties where the previous property use caused environmental contamination" (Ontario Ministry of the Environment, 2008).

\section{Background}

The current provincial policies encourage brownfields redevelopment in Ontario. The revitalization of brownfield sites provides opportunities to improve the health of communities by creating jobs, reducing crime, reducing exposures to contaminants, and removing multiple social and physical risks.

It is well established that Public Health Units (PHUs) can play an important role in the redevelopment process. In Ontario, the Ministry of the Environment carries the jurisdictional mandate for site assessment and clean-up. However, anecdotal evidence suggests that public health agencies are often engaged to interpret public health risks and to assess the appropriateness of remedial measures. Such involvement results in enhanced levels of community trust, maximized public health benefits, and minimized risks, cost overruns, and delays. Furthermore, PHU involvement can help to reduce health inequities and foster physically and psychologically healthy, economically and ecologically sustainable communities.

This research will enhance the current knowledge of Ontario Public Health Units' involvement in the brownfields redevelopment process. The results obtained from this study will be significant for public health practice and policy. The gathered data will help to identify needs, gaps, and opportunities in the current approach. Furthermore, the results will aid in establishing best practices and policies aimed at optimizing revitalizations of brownfields across the province. 


\section{PART A. KEY INFORMANT/HEALTH UNIT INFORMATION}

Public Health Unit

Date

$$
\overline{(\mathrm{DD})} / \overline{(\mathrm{MM})} / \overline{(\mathrm{Y}} \overline{\mathrm{YY}} \overline{\mathrm{Y}})
$$

Interviewee(s):

\begin{tabular}{|l|l|l|l|}
\hline POSITION & NAME* & EMAIL ADDRESS* & PHONE NUMBER* \\
\hline & & & \\
\hline & & & \\
\hline & & & \\
\hline & & & \\
\hline
\end{tabular}

* Identifying information, i.e. name, email address, and phone number, is only being collected if follow-up or clarification is needed regarding any of the open-ended questions. Only the principal investigator will have access to your personal information. Personal information will never be shared, revealed, or used in data analysis. All identifying information will be destroyed once it is deemed that the completed survey does not require follow-up.

Please leave the Name, Email Address, and Phone Number boxes blank if you do not wish to share your personal information. 


\section{PART B. DIRECTIONS AND ACRONYMS}

1. Only one survey is requested from each participating PHU.

2. If there are several regional offices within PHU's jurisdiction, staff from different offices should collaborate when completing the questionnaire.

3. Completed questionnaires and signed consent forms should be returned to the attention of the principal investigator by mail, fax, or email (contact information provided below).

Timeframe:

1. Please complete and return the questionnaire by August 5,2011.

2. PHUs that have not completed the questionnaire will be contacted for follow-up.

\section{Contact:}

Please contact the principal investigator if you have any questions or concerns regarding this survey

Principal Investigator: Barbara Lachapelle

Email: blachap@ toronto.ca

Phone: 416 392-7691

Fax: 416 338-1649

Address: 44 Victoria St., $18^{\text {th }}$ Floor, Toronto, ON

\section{List of Acronyms}

MOE Ministry of the Environment

MOL Ministry of Labour

MP Member of Parliament

MPP Member of Provincial Parliament

OAHPP Ontario Agency for Health Protection and Promotion

OPHA Ontario Public Health Association

PHU Public Health Unit 


\title{
PART C. INVOLVEMENT IN BROWNFIELDS
}

\section{Has your health unit been involved in any activities related to brownfields between 2000 and 2010 ?}

\author{
Yes (Y) $\square \quad$ No (N) $\square \quad$ Don't Know (DK)
}

*For the purpose of this survey "involved" includes, but is not limited to: response to complaints/inquiries, evaluation and interpretation or risk, evaluation of remediation methods, risk communication, etc.

\section{Definition of brownfields}

"Brownfields are abandoned, idle, or under-utilized industrial and commercial properties where the previous property use caused environmental contamination" (Ontario Ministry of the Environment, 2008).

* For the purpose of this survey, this definition will include properties that are both vacant and those that are being actively used

* The contamination may be a result of current activities or related to historical use not related to current site uses

* Brownfield sites may include, but are not limited to: former water ports and railway lines, former and current industrial and manufacturing sites, auto-body shops and gas stations, or even neighborhood dry cleaner operations

\section{Has your health unit's involvement changed since the introduction of Ontario Brownfields Regulation, O. Reg. 153/04 Record of Site Condition in 2004?}
a) no, not changed
b) yes, changed
c) don't know

please specify

If your health unit has not been involved in any activities related to Brownfields, please proceed to PART E 


\section{PART D. THE EXTENT OF YOUR HEALTH UNITS' INVOLVEMENT IN BROWNFIELDS ACTIVITIES}

3. What is the process for your health unit's involvement in brownfield activities? (please check all that apply)

a) engagement occurs in an ad hoc/as needed manner

b) standards of practice are in place

c) written policies and procedures are in place

d) other (please specify):

4. What typically initiates your health unit's involvement brownfield activities? (please check all that apply)

a) complaint / concern from the community

b) request / referral from an external agency (e.g. MOE, MOL)

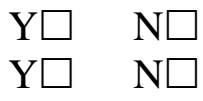

c) request / referral from a political office (e.g. committee referral, councilor request, MP/MPP request)

d) request / referral from another city division (e.g. Parks, Planning)

$\mathrm{Y} \square \quad \mathrm{N} \square$

e) formal arrangement with another city division / external agency

(e.g. Memorandum of Understanding, protocol)

$\mathrm{N} \square \quad \mathrm{Y} \square$

other (please specify):

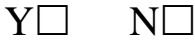

5. On average, since 2000 , at what stage in the brownfield redevelopment process was your health unit's involvement initiated?

\begin{tabular}{|l|l|l|l|l|l|}
\hline & ALWAYS & OFTEN & SOMETIMES & SELDOM & NEVER \\
\hline $\begin{array}{l}\text { Proactively, during the } \\
\text { planning stage }\end{array}$ & & & & & \\
\hline $\begin{array}{l}\text { As remediation activities } \\
\text { are underway }\end{array}$ & & & & & \\
\hline $\begin{array}{l}\text { Reactively, as health- } \\
\text { related issues arise }\end{array}$ & & & & & \\
\hline
\end{tabular}


6. On average, since 2000, what is the extent of your health unit's involvement with brownfield site activities?

\begin{tabular}{|l|l|l|l|l|l|}
\hline & ALWAYS & OFTEN & SOMETIMES & SELDOM & NEVER \\
\hline $\begin{array}{l}\text { Fully engaged in the entire } \\
\text { decision making process }\end{array}$ & & & & & \\
\hline $\begin{array}{l}\text { Provide input during } \\
\text { assessment / clean-up }\end{array}$ & & & & & \\
\hline $\begin{array}{l}\text { Respond to questions from } \\
\text { the public }\end{array}$ & & & & & \\
\hline Other (please specify) & & & & \\
\hline
\end{tabular}

7. What is the number of staff (Full Time Equivalent) involved in brownfield site activities within your health unit?

\begin{tabular}{|l|l|l|}
\hline & Environmental Health Staff & Support Staff \\
\hline Full time & & \\
\hline Part time & & \\
\hline Contract & & \\
\hline Temporary & & \\
\hline
\end{tabular}

8. When participating in brownfield activities, what does your health unit engage in?

a) review of site's history

b) site visits

c) review of Phase I and II environmental site assessments

d) review of quantitative risk assessment

e) risk communication with the public

f) environmental monitoring activities (e.g. soil/groundwater/air)

g) review of monitoring results

h) site cleanup decisions

i) environmental health mapping

j) Health Impact Assessment

k) risk/benefit analysis

1) other (please specify):

$\begin{array}{ll}\mathrm{Y} \square & \mathrm{N} \square \\ \mathrm{Y} \square & \mathrm{N} \square \\ \mathrm{Y} \square & \mathrm{N} \square \\ \mathrm{Y} \square & \mathrm{N} \square \\ \mathrm{Y} \square & \mathrm{N} \square \\ \mathrm{Y} \square & \mathrm{N} \square \\ \mathrm{Y} \square & \mathrm{N} \square \\ \mathrm{Y} \square & \mathrm{N} \square \\ \mathrm{Y} \square & \mathrm{N} \square \\ \mathrm{Y} \square & \mathrm{N} \square \\ \mathrm{Y} \square & \mathrm{N} \square\end{array}$




\section{To what extent does your health unit engage community members in brownfield activities?}

\begin{tabular}{|l|l|l|l|l|l|}
\hline & ALWAYS & OFTEN & SOMETIMES & SELDOM & NEVER \\
\hline $\begin{array}{l}\text { Community input into all } \\
\text { redevelopment decisions }\end{array}$ & & & & & \\
\hline $\begin{array}{l}\text { Community input into } \\
\text { health-related decisions }\end{array}$ & & & & & \\
\hline $\begin{array}{l}\text { Provide community with } \\
\text { information at key stages } \\
\text { of the redevelopment } \\
\text { process }\end{array}$ & & & & & \\
\hline $\begin{array}{l}\text { Provide community with } \\
\text { information at key health- } \\
\text { related stages of the } \\
\text { redevelopment process }\end{array}$ & & & & & \\
\hline $\begin{array}{l}\text { Respond to community } \\
\text { inquiries }\end{array}$ & & & & & \\
\hline Other (please specify) & & & & & \\
& & & & & \\
& & & & & \\
\end{tabular}


10. Within your health unit, are brownfields considered an important public health issue?

$$
\mathrm{Y} \square \quad \mathrm{N} \square
$$

11. Within your health unit, is engagement in brownfield activities considered important?

$$
\mathrm{Y} \square \quad \mathrm{N} \square
$$

12. Within your health unit, is involvement in brownfields activities part of your scope of work?

$$
\mathrm{Y} \square \quad \mathrm{N} \square
$$

13. Are you aware of brownfield sites located within your health unit's jurisdiction?

$$
\mathrm{Y} \square \quad \mathrm{N} \square
$$

14. If yes, please indicate how many:

$$
<5 \square \quad 5-10 \square \quad 11-25 \square \quad 26-50 \square \quad>51
$$

15. Within your health unit, is there a need (i.e. complaints/inquiries, community concern, etc.) for public health involvement in brownfield sites?

$$
\mathrm{Y} \square \mathrm{N} \square
$$

16. If yes, under what circumstances should your health unit become involvement brownfield sites?

Always, brownfields are always an important public health issue Sometimes, only when specific health concerns are raised Never, brownfield sites are already addressed by other legislations Other, (please specify) 
17. Within your health unit, are there benefits to being involved in brownfield activities?

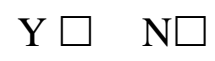

18. If yes, what benefits could be gained by your health unit's involvement in brownfield activities?

a) reduction in exposures and health risks

b) improvement in environmental quality (e.g. soil, air quality)

$\mathrm{Y} \square \quad \mathrm{N} \square$

c) creation of healthy communities (e.g. new parks, exercise areas)

$\mathrm{Y} \square \quad \mathrm{N} \square$

d) economic benefits (e.g. new jobs, bigger tax base)

$\mathrm{Y} \square \quad \mathrm{N} \square$

e) community empowerment

$\mathrm{Y} \square \quad \mathrm{N} \square$

f) other (please specify)

19. Within your health unit, what would be the benefits of enhanced engagement in brownfield activities?

a) improvement in the health of the community

b) promotion of public health

c) prevention of exposures

d) influence on the level of clean-up

e) influence on land planning decisions

f) improved relationships with stakeholders

g) other (please specify)

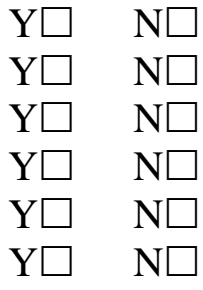




\section{PART F. CAPACITY ASSESSMENT}

20. Does your health unit have staff with the following expertise/skills to engage in brownfield-related activities?
a) quantitative analysis of environmental and human health risks
$\mathrm{Y} \square \quad \mathrm{N} \square \quad \mathrm{DK} \square$
b) human toxicology
$\mathrm{Y} \square \quad \mathrm{N} \square \quad \mathrm{DK} \square$
c) risk communication
$\mathrm{Y} \square \quad \mathrm{N} \square \quad \mathrm{DK} \square$
d) environmental epidemiology
$\mathrm{Y} \square \quad \mathrm{N} \square \quad \mathrm{DK} \square$
e) conducting/ reviewing environmental site assessment
$\mathrm{Y} \square \quad \mathrm{N} \square \quad \mathrm{DK} \square$
f) conducting/reviewing site remediation
$\mathrm{Y} \square \quad \mathrm{N} \square \quad \mathrm{DK} \square$
g) conducting/reviewing environmental monitoring

$\mathrm{Y} \square \quad \mathrm{N} \square \quad \mathrm{DK} \square$

21. Does your health unit provide staff with professional development activities related to brownfields sites?
a) in-house training sessions
b) provincial training / information sessions
c) federal training / information sessions
d) conferences
e) structured courses / seminars
f) other (please specify)

$\begin{array}{ll}\mathrm{Y} \square & \mathrm{N} \square \\ \mathrm{Y} \square & \mathrm{N} \square \\ \mathrm{Y} \square & \mathrm{N} \square \\ \mathrm{Y} \square & \mathrm{N} \square \\ \mathrm{Y} \square & \mathrm{N} \square\end{array}$

22. Does your health unit utilize the following resources to engage in brownfieldrelated activities?

b) environmental monitoring equipment

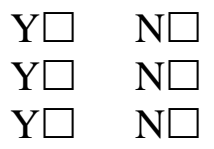

d) laboratory analysis of environmental samples

e) other (please specify) 
23. Does your health unit contract out for environmental monitoring services (e.g. environmental media monitoring, sampling, sample analysis)?

\author{
$\mathrm{Y} \square \quad \mathrm{N} \square$
}

If yes, please specify under what circumstances

24. Are there any information resources that would be helpful in facilitating your health unit's engagement in brownfield activities?
a) provincial Brownfields inventory
b) municipal Brownfields inventory
c) historic land-use database
d) clearinghouse of site-specific environmental data
e) federal environmental monitoring data
f) provincial monitoring data
g) online risk assessment tools
h) online risk interpretation tools
i) online risk communication tool
j) online community engagement tool
i) environmental health surveillance system
j) other (please specify)

$\begin{array}{ll}\mathrm{Y} \square & \mathrm{N} \square \\ \mathrm{Y} \square & \mathrm{N} \square \\ \mathrm{Y} \square & \mathrm{N} \square \\ \mathrm{Y} \square & \mathrm{N} \square \\ \mathrm{Y} \square & \mathrm{N} \square \\ \mathrm{Y} \square & \mathrm{N} \square \\ \mathrm{Y} \square & \mathrm{N} \square \\ \mathrm{Y} \square & \mathrm{N} \square \\ \mathrm{Y} \square & \mathrm{N} \square \\ \mathrm{Y} \square & \mathrm{N} \square \\ \mathrm{Y} \square & \mathrm{N} \square\end{array}$

25. Will additional resources and training in the following areas be beneficial in enhancing your health unit's engagement in brownfield activities?
a) risk assessment methods
b) risk interpretation methods
c) exposure assessment methods
d) environmental health surveillance
e) environmental health mapping
f) Ontario Brownfields Regulation, Record of Site Condition
g) interpretation of standards (e.g. soil, groundwater, air)
i) interpretation of sampling results
j) other (please specify)

\begin{tabular}{ll}
$\mathrm{Y} \square$ & $\mathrm{N} \square$ \\
$\mathrm{Y} \square$ & $\mathrm{N} \square$ \\
$\mathrm{Y} \square$ & $\mathrm{N} \square$ \\
$\mathrm{Y} \square$ & $\mathrm{N} \square$ \\
$\mathrm{Y} \square$ & $\mathrm{N} \square$ \\
$\mathrm{Y} \square$ & $\mathrm{N} \square$ \\
$\mathrm{Y} \square$ & $\mathrm{N} \square$ \\
$\mathrm{Y} \square$ & $\mathrm{N} \square$ \\
\hline
\end{tabular}




\section{PART G. PARTNERSHIPS AND COLLABORATION}

26. When engaging in brownfields activities, which stakeholder is your health unit most likely to collaborate with? (please check all that apply)
a) federal government (e.g. Health Canada)
b) provincial government (e.g. MOE, MOL)
c) public health agencies (e.g. OAHPP, OPHA)
d) other health units
e) non-governmental organizations
f) other city departments (e.g. Planning, Buildings)
g) political leaders (e.g. councilors)
h) community groups
i) individual community members
j) other (please specify)

$\begin{array}{ll}\mathrm{Y} \square & \mathrm{N} \square \\ \mathrm{Y} \square & \mathrm{N} \square \\ \mathrm{Y} \square & \mathrm{N} \square \\ \mathrm{Y} \square & \mathrm{N} \square \\ \mathrm{Y} \square & \mathrm{N} \square \\ \mathrm{Y} \square & \mathrm{N} \square \\ \mathrm{Y} \square & \mathrm{N} \square \\ \mathrm{Y} \square & \mathrm{N} \square \\ \mathrm{Y} \square & \mathrm{N} \square\end{array}$

27. Does your health unit have formalized agreements regarding brownfields (e.g. memorandum of understanding, protocols) with any of the collaborating partners? (please check all that apply)
a) federal government (e.g. Health Canada)
$\mathrm{Y} \square \quad \mathrm{N} \square$
b) provincial government (e.g. Ministry of the Environment, Ministry of Labour)
c) public health agencies (e.g. Ontario Agency for Health Protection and Promotion, Ontario Public Health Association)
d) other health units
e) non-governmental organizations
f) other city departments (e.g. Planning, Buildings)
g) political leaders (e.g. councilors)
h) community groups
i) individual community members
j) other (please specify) 
28. What tools does your health unit utilize to communicate information to the public regarding brownfield sites within your jurisdiction?
a) one-on-one telephone consultation
b) door to door consultation
c) community meetings
d) site meetings
e) website
f) posters
g) fact sheets
h) other (please specify)

$\begin{array}{ll}\mathrm{Y} \square & \mathrm{N} \square \\ \mathrm{Y} \square & \mathrm{N} \square \\ \mathrm{Y} \square & \mathrm{N} \square \\ \mathrm{Y} \square & \mathrm{N} \square \\ \mathrm{Y} \square & \mathrm{N} \square \\ \mathrm{Y} \square & \mathrm{N} \square \\ \mathrm{Y} \square & \mathrm{N} \square\end{array}$


27. Is there any additional information that you feel would be beneficial to this research? please list

Thank you very much for your time! Your input is appreciated. Please feel free to contact me should you have any questions or comments. 


\section{REFERENCES}

Abelsohn, A., Frank, J., Eyles, J. (2009). Environmental Public Health Tracking/ Surveillance in Canada: A Commentary, Healthcare Policy, 4(3), 37-51.

Adams, R. (2013). Personal Conversations with Rod Adams, Manager, Toronto District Office, Ontario Ministry of the Environment, 2012 - 2012.

Aday, L. A., Cornelius, L. J. (2006). Designing And Conducting Health Surveys ( $3^{\text {rd }}$ ed.), San Francisco, CA: John Wiley \& Sons, Inc.

Agency for Toxic Substances and Disease Registry (ATSDR). (2012). Brownfield/Land Reuse Initiative Overview. Last accessed February 24, 2013 http://www.atsdr.cdc.gov/sites/brownfields/overview.html

Agency for Toxic Substances and Disease Registry (ATSDR). (2002). Fiscal Year 2002 Agency Profile and Annual Report, October 1, 2001, to September 30, 2002.

Agency for Toxic Substances and Disease Registry (ATSDR). (2005). Public Health Assessment Guidance Manual. Last accessed July 17, 2011 http://www.atsdr.cdc.gov/hac/PHAManual/toc.html

Agency for Toxic Substances and Disease Registry (ATSDR). (2010). Leading Change For Healthy Communities and Successful Land Reuse.

Agency for Toxic Substances and Disease Registry (ATSDR). (2011). ATSDR: Public Health Resources \& Partnerships for Brownfields and Land Re-Use/Redevelopment. Presentation at the EPA/San Luis Valley CARE, Alamosa, CO. November 30, 2011.

Agency for Toxic Substances and Disease Registry (ATSDR). (2011b). Department of Health and Human Services, Fiscal Year 2011, Justification of Estimates for Appropriation Committees.

Archbold, J. (2009). Personal conversation with Josephine Archbold, Research Consultant, Toronto Public Health, Environmental Protection Office.

Archbold, J. \& Lachapelle, B. (2008). The Changing Role of Public Health in Brownfields Redevelopment. Presentation at the $69^{\text {th }}$ Ontario Branch Canadian Institute of Public Health Inspectors Educational Conference.

Arias-Estevez, M. et al. (2007). The Mobility and Degradation of Pesticides in Soils and the Pollution of Groundwater Resources. Agriculture, Ecosystems and Environment, 123, 247-260. 
Bacot, H. \& O'Dell, C. (2006). Establishing Indicators to Evaluate Brownfield Redevelopment. Economic Development Quarterly, 20(2), 142-161.

Baker, D. \& Nieuwenhuijsen, J. M. (2008). Environmental Epidemiology, Study Methods and Application. Oxford University Press: New York, U.S.

Barron, G., Glad, J., Vukotich, C. (2007). The Use of the National Public Health Performance Standards to Evaluate Change in Capacity to Carry Out the 10 Essential Services. Journal of Environmental Health, 70(1), 29-31.

Bergeron, K. (2009). A Review of the Literature on the Effect of the Built Environment on Five Chronic Disease Factors for Public Health Professionals Interested in Surveillance: A Summary Report. Association of Public Health Epidemiologists in Ontario, Toronto, Ontario

Berman, L., Orr, D., Forrester, T. (2009). Improving Community Health: Brownfields and Health Monitoring. Environmental Practice, 11(3), 190-195.

Blum, E., D. (2008). Love Canal Revisited: Race, Class, and Gender in Environmental Activism. University Press of Kansas,

Boardman, D. J. et al. (2008). Proximate Industrial Activity and Psychological Distress. Population Environment, 30, 3-25.

Boyd, R. D., \& Genuis, J. S. (2007). The Environmental Burden of Disease in Canada: Respiratory Disease, Cardiovascular Disease, Cancer, and Congenital Affliction. Environmental Research, 106, 240-249.

Briggs, D. (2003). Environmental pollution and the global burden of disease. British Medical Bulletin, 68, 1-24.

Buczynska, A. \& Tarkowski, S. (2005). Environmental Exposure and Birth Outcomes. International Journal of Occupational Medicine and Environmental Health, 18(3), 225-232.

Burger, J. (2005). Assessing Environmental Attitudes and Concerns About a Contaminated Site in a Densely Populated Suburban Environment. Environmental Monitoring and Assessment, 101, 147-165.

Canada Mortgage and Housing Corporation, (2005). Brownfield Redevelopment for Housing: Literature Review and Analysis. Socio-economic Series 05-013.

Canadian Institute for Environmental Law and Policy, (2002). $6^{\text {th }}$ Annual Report on 
Ontario's Environment.

Capacity Review Committee. (2006). Revitalizing Ontario's Public Health Capacity The Final Report of the Capacity Review Committee. Ontario Ministry of Health and Long-Term Care.

Carroll, A. (2008). Brownfields: A Local Environmental Health Opportunity. Journal of Environmental Health, 70(9), 59-60.

Centers for Disease Control and Prevention (CDC). (2001). Public Health's Infrastructure A Status Report. Department of Health and Human Services, Prepared for The Appropriations Committee of the United States Senate.

Chan, G. (2000). Historical Land Use and Development Review. Presentation at the $61^{\text {st }}$ Ontario Branch Canadian Institute of Public Health Inspectors Educational Conference.

Chen, C. M., Hong, M. C., Hsu, Y. H. (2007). Administrator Self-Ratings of Organization Capacity and Performance of Healthy Community Development Projects in Taiwan. Public Health Nursing, 24(4), 343-354.

Chociolko, C., Copes, R., Rekart, J. (2006). Needs, Gaps, and Opportunities Assessment For the National Collaborating Centre for Environmental Health. Prepared for: National Collaborating Centre for Environmental Health.

Colten, C. (1990). Historical Hazards: The Geography of Relict Industrial Wastes. Professional Geographer, 42(2), 143-156.

Connecticut Department of Public Health. (2000). Public Health \& Brownfields. Environmental and Occupational Health Assessment.

Creswell, W. J. (1994). Research Design: Qualitative \& Quantitative Approaches. Sage Publications, Inc.

Dean, A.G., Sullivan, K. M., Soe, M. M. OpenEpi: Open Source Epidemiologic Statistics for Public Health, Version www.openepi.com updated 2012/03/21 Last accessed 2013/03/25.

DePass, M. (2006). Brownfields as a Tool for the Rejuvenation of Land and Community, Local Environment, 11(5), 601-606.

De Sousa, C. A. (2006). Unearthing the Benefits of Brownfield to Green Space Projects: An Examination of Project Use and Quality of Life Impacts. Local Environment, 11(5), 577-600. 
De Sousa, C. A. (2002). Brownfield redevelopment in Toronto: an examination of past Trends and future prospects, Land Use Policy, 19(2002), 297-309.

De Sousa, C. A. (nd). Brownfields Research: Findings \& Directions (Presentation). Brownfields Research Consortium, Department of Urban Planning, Geography, \& Urban Studies, University of Wisconsin-Milwaukee.

De Sousa, C. A. (2008). Brownfields Redevelopment and the Quest for Sustainability. London: Elsevier Science/Emerald Group Publishing.

Dixon, T., Raco, M., Catney, P., Lerner, D. N. (2007). Sustainable Brownfield Regeneration: Livable Places From Problem Spaces. Blackwell Publishing.

Dodds, L., Seviour, R. (2001). Congenital Anomalies and Other Birth Outcomes Among Infants Born to Women Living Near a Hazardous Waste Site in Sidney, Nova Scotia, Canadian Journal of Public Health 92(5), 331-334.

Dolk, H. \& Vrijheid, M. (2003). The impact of environmental pollution on congenital anomalies. British Medical Bulletin, 68, 25-45.

ECO Canada. (2007). Who will do the cleanup? Canadian Labour Requirements for Remediation and Reclamation of Contaminated Sites 2006-2009. Environmental Labour Market (ELM) Research, Environmental Careers Organization Canada.

Eiser, J. R., Stafford, T., Henneberry, J., Catney, P. (2007). Risk Perception and Trust in the Context of Urban Brownfields, Environmental Hazards, 7, 150-156.

Ellerbusch, F., Gute, D. M., Desmarais, A. M., Woodin, M. (2006). Community Engagement as a Component of Revitalization: Lessons Learned from the Technical Outreach Services to Communities Programme, Local Environment, $11(5), 515-535$.

Erwin, P.C. (2008). The Performance of Local Health Departments: A Review of the Literature. Journal of Public Health Management Practice, 14(2), E9-E18.

Freund, C.G., Liu, Z. (2000). Local health department capacity and performance in New Jersey. Journal of Public Management Practice, 6:42-50.

Gallagher, D. R. (2009). Advocates for Environmental Justice: the Role of the Champion in Public Participation Implementation. Local Environment, 14(10), 905-916.

Gallagher, D. R. \& Jackson, S. E. (2008). Promoting Community Involvement at Brownfields Sites in Socio-Economically Disadvantaged Neighbourhoods. 
Journal of Environmental Planning and Management, 51(5), 615-630.

Gasana, J. et al. (2006). Blood Lead Levels in Children and Environmental Lead Contamination in Miami Inner City, Florida. International Journal of Environmental Research and Public Health, 3(3), 228-234.

Grant, S., et al. (2011). Facilitated Transport of Dioxins in Soil Following Unintentional Release of Pesticide-Surfactant Formulations. Environmental Science and Technology, 45(2), 406-411.

Great Lakes Commission, (2001). Linking Brownfield Redevelopment and Greenfields Protection for Sustainable Development.

Green Brody, J. et al. (2007). Environmental Pollutants and Breast Cancer: Epidemiologic Studies. Environmental Factors in Breast Cancer: Supplement To Cancer. American Cancer Society.

Greenberg, M. R. (2003). Reversing Urban Decay: Brownfield Redevelopment and Environmental Health. Environmental Health Perspectives, 111(2), A74-A75.

Griffirth, J., Duncan, C. R., Riggan, B. W., Pellom, C. A. (1989). Cancer Mortality in U.S. Counties with Hazardous Waste Sites and Ground Water Pollution. Archives of Environmental Health, 44(2), 69-74.

Gute, D. M. (2006). Sustainable Brownfields Redevelopment and Empowering Communities to Participate More Effectively in Environmental DecisionMaking. Local Environment, 11(5), 473-478.

Gute, D. M. \& Taylor, M. (2006). Revitalizing Neighbourhoods through Sustainable Brownfields Redevelopment: Principles Put into Practice in Bridgeport, CT. Local Environment, 11(5), 537-558.

Hallenbeck, W. H. \& Cunningham, K. M. (1986). Quantitative Risk Assessment for Environmental and Occupational Health. Lewis Publishers Inc.: Michigan, U.S.

Handler, A., Issel, M., Turnock, B. (2001). A Conceptual Framework to Measure Performance of the Public Health System. American Journal of Public Health, 91(8), 1235-1239.

Hanusaik, N., O'Loughlin, L. J., Kishchuk, N., Paradis, G., Cameron, R. (2009). Organizational Capacity for Chronic Disease Prevention: A Survey of Canadian Public Health Organizations. The European Journal of Public Health,

Hayek, M., Arku, G., Gailliland, J. (2010). Assessing London, Ontario's Brownfield 
Redevelopment Effort to Promote Urban Intensification. Local Environment, 15(4), 389-402.

Hazardous Substance Research Centre (HSRC). (nd). The Role of Public Health in Brownfields Redevelopment. Accessed Online July 5, 2009, http://www.hsrc-ssw.org/brownfields/

Health Canada. (2009). Canadian Health Measures Survey: Summary of the Biomonitoring Results and Government Action.

Health Canada. (1996). Human Health Risk Assessment of Chemicals from Contaminated Sites.

Health Protection and Promotion Act, R.S.O. 1990, c. H.7.

Hoar Zahm, S. \& Ward, H. M. (1998). Pesticides and Childhood Cancer. Environmental Health Perspectives, 106(supp.3), 893-908.

Hodge, E., Chung, R. (2012). Contaminated Sites and Public Health. Presentation by Public Health Ontario on July 10, 2012.

Hollander, J. (2010). Private Property Owners and the Remaking of Brownfields. Public Works Management \& Policy, 15(1), 32-56.

Infrastructure Canada, (2008). Study of International Best Practices in Brownfield Management and Redevelopment Policy Discussion Paper, Prepared by ADEC Consultants, Research and Analysis Division, Infrastructure Canada, February 2011

Invest Ontario, Advanced Manufacturing Technologies, www.investontario.com/sectors/am_advancedmanufacturing.asp Accessed November 14, 2009.

Jain, S. (2010). Ontario Public Health Unit Environmental Health Information System Survey. Produced for Association of Local Public Agencies, December 22, 2010.

Johnson, B. (1995). Nature, Extent, and Impact of Superfund Hazardous Waste Sites. Chemosphere, 31(1), 2415-2428.

Kayre, E. W., Hall, I. H., Lybarger, A. J. (1994). Recall Bias in Disease Status Associated With Perceived Exposure to Hazardous Substances. Annals of Epidemiology, 4(5), 393-397.

Kennedy, V.C. (2003). A Study of Local Public Health System Performance in Texas. Journal of Public Health Management Practice, 7:21-29. 
Kochtitzky, C. S., et al. (2006). Urban Planning and Public Health at CDC, Morbidity and Mortality Weekly Report, 55(SUP02); 34-38.

Landrigan, J. P., et al. (2002). Environmental Pollutants and Disease in American Children: Estimates of Morbidity, Mortality, and Costs for Lead Poisoning, Asthma, Cancer, and Developmental Disabilities. Environmental Health Perspectives, 110(7), 721-728.

Leigh, N. G., \& Hise, R. (1997). Community Brownfield Guidebook: Assessing and Resolving Environmental Barriers to Redevelopment, Georgia Tech Research Corporation, Atlanta, Georgia 30332-0415.

Lenaway, D., Halverson, P., Sotnikov, S., Tilson, H., et al. (2006). Public Health Research: Setting a National Agenda. American Journal of Public Health, 96(3), 410-413.

Lichtveld, M., Cioffi, J., Henderson, J., Sage, M., Steele, L. (2003). People Protected Public Health Prepared Through a Competent Workforce. Journal of Public Health Management Practice, 9(5), 340-343.

Litt, S. J. \& Burke, A. T. (2002). Uncovering the Historic Environmental Hazards of Urban Brownfields. Journal of Urban Health: Bulletin of the New York Academy of Medicine, 79(4), 464-481.

Litt, S. J., Tran, L. N., Burke, A. T. (2002). Examining Urban Brownfields through the Public Health "Macroscope". Environmental Health Perspectives, 110(Sup2), 183-193.

Lorenzana, M. R., et al. (2003). Lead Intervention and Pediatric Blood Levels at Hazardous Waste Sites. Journal of Toxicology and Environmental Health, Part A, 66, 871-893.

Macey, G. P., \& Cannon, J. Z. (2007). Reclaiming the Land: Rethinking Superfund Institutions, Methods and Practices. Springer.

McBurney, D. H. (1994). Research Methods. Brooks/Cole Publishing Company, A Division of Wadsworth, Inc. Pacific Grove: California.

McGeehin, M. A., Qualters, J. R., Niskar, A. S. (2004). National Environmental Public Tracking Program: Bridging the Information Gap. Environmental Health Perspectives, 112(14), 1409-1413.

McKinney, D. J. (1981). Environmental Health Chemistry: The Chemistry of Environmental Agents as Potential Human Hazards. Ann Arbor Science Publishers Inc/The Butterworth Group: Ann Arbor, Michigan. 
McLaughlin Centre for Population Health Risk Assessment. (2007). Environmental Burden of Disease Workshop Summary. University of Ottawa, Ottawa, Ontario, Canada, February $12^{\text {th }}, 2007$.

Miller, A. C., Moore, K. S., Richards, T. B., McKaig, C. (1994). A Screening Survey to Assess Local Public Health Performance. Public Health Reports, 109(5), 659-664.

Miller, J. F., Davidson, C. I., Lange, D. A., Meyer Grelli, M. L. (2011). Brownfields and Environmental Justice: Income, Education, and Race. Environmental Justice, 4(2), 121-124.

Mostafa, G. A., El-Shahawi, H. H., Mokhtar, A. (2009). Blood Lead Levels in Egyptian Children from High and Low Lead-Polluted Areas: Impact on Cognitive Function. Acta Neurologica Scandinavica, 120, 30-37.

National Association of County \& City Health Officials (NACCHO). (2000). Community Revitalization and Public Health: Issues, Roles and Relationships For Local Public Health Agencies. NACHHO: Washington, DC.

National Collaborating Centre for Environmental Health (NCCEH). (2011). Community Planning with a Health Equity Lens: Promising Directions and Strategies, August 2011.

National Collaborating Centre for Environmental Health (NCCEH). (2006). Needs, Gaps, and Opportunities Assessment for the National Collaborating Centre for Environmental Health, September 2006.

National Research Council (U.S.). (1991). Environmental Epidemiology Public Health And Hazardous Wastes. Committee on Environmental Epidemiology, Board on Environmental Studies and Toxicology, Commission on Life Sciences, National Academy Press: 1991.

New Partnership for Community Revitalization Inc. (NPCR). (2011). Smart Growth Outlook 2011: Challenges and Opportunities in Brownfields, Area-Wide Planning \& Implementation, January 2011.

Northeast Midwest Institute (NEMW). (2008). Brownfields Redevelopment Toolbox For Disadvantaged Communities. Northeast-Midwest Institute Center for Policy Initiatives.

Ofungwu, J., Eget, S. (2005). Brownfields and Health Risks-Air Dispersion Modeling and Health Risk Assessment at Landfill Redevelopment Sites. Integrated 
Environmental Assessment and Management, 2(3), 253-261.

Ontario Brownfields Advisory Panel. (2000). Brownfields Policy Review Summary of Advice from the Brownfields Advisory Panel. Ontario Government Documents Collection.

Ontario Ministry of the Environment. (2011). Brownfields Environmental Site Registry. http://www.environet.ene.gov.on.ca/besr-public/generalSearch.do?action=display Last accessed October 22, 2011.

Ontario Ministry of the Environment. (2008). Brownfields Redevelopment. http://www.ene.gov.on.ca/envision/land/decomm/brownfields.htm Retrieved: September 22, 2009.

Ontario Ministry of the Environment. (2011a). Pesticides. http://www.ene.gov.on.ca/environment/en/category/pesticides/index.htm Last accessed October 24, 2011.

Ontario Ministry of the Environment. (2011). Protocol for Analytical Methods Used in The Assessment of Properties under Part XV.1 of the Environmental Protection Act, Laboratory Services Branch, March 9, 2004, amended as of July 1, 2011.

Ontario Ministry of the Environment. (2009). Rationale for the Development of Soil and Groundwater Standards for Use at Contaminated Sites in Ontario, Standards Development Branch.

Ontario Ministry of Health and Long-Term Care. (2009). Initial Report on Public Health. Public Health Division.

Ontario Ministry of Health and Long-Term Care (MHLTC). (2008). Ontario Public Health Standards 2008.

Ontario Ministry of Municipal Affairs and Housing (OMMAH). (2012). Municipal Financial Incentives for Brownfield Redevelopment: Trends Among Ontario Municipalities, Office of the Provincial Brownfields Coordinator.

Ontario Ministry of Public Infrastructure Renewal, (2006). Growth Plan for the Greater Golden Horseshoe. Queen's Printer for Ontario, Ontario.

Ontario Ministry of Public Infrastructure Renewal, (2008). Size and Location of Urban Growth Centres in the Greater Golden Horseshoe. Queen's Printer for Ontario, Ontario.

Ontario Public Health Association (OPHA). (2011). Highlights: Weaving Health into 
The Land Use Planning Process.

Ontario Public Health Research, Education \& Development Program (PHRED). (2007a). Public Health Data and Information Management Capacity Survey Tool.

Ontario Public Health Research, Education \& Development Program (PHRED). (2007b, 2007b). Public Health Data and Information Management Capacity Survey Tool. User's Guide.

Ontario Public Health Research, Education \& Development Program (PHRED). (2008). Public Health Data and Information Management Tool, User's Guide. June 2007, Revised October 2008.

Ott, W. R., Steinemann, A. C., Wallace, L. A. (ed). (2007). Exposure Analysis. Taylor \& Francis: Boca Raton, Fl.

Perdue, W. C., Stone, L. A., Gostin, L. O. (2003). The Built Environment and Its Relationship to the Public's Health: The Legal Framework. American Journal of Public Health, 93 (9), 1390-1394.

Resnick, B. et al. (2007). Enhancing the Maryland Environmental Public Health Workforce: A Collaborative Approach. Journal of Environmental Health, 70 (1), 32-36.

Public Health Ontario (PHO). (2012). Presentation on Contaminated Sites and Public Health, presented by Erin Hodge and Rena Chung, July 10, 2012.

Public Health Ontario (PHO). (2011). About Us. http://www.oahpp.ca/about/index.html Last accessed on April 3, 2013.

Russi, B. M., Borak, B. J., Cullen, R. M. (2008). An Examination of Cancer Epidemiology Studies Among Populations Living Close to Toxic Waste Sites. Environmental Health, 7(32).

Ryerson University. (2012). Ryerson University Library \& Archives. Locating Environmental Studies Articles. Last accessed February 12, 2012 http://www.ryerson.ca/library/subjects/envir2.html

Ryerson University. (2012b). Ryerson University Library \& Archives. Last accessed February 17, 2012. http://journals1.scholarsportal.info.ezproxy.lib.ryerson.ca/searchadvanced.xqy

Scutchfield, F. D., Knight, A. E., Kelly, A. V., Bhandari, W. M., Vasilescu, I. P. (2004). Local Public Health Agency Capacity and its Relationship to Public Health 
Systems Performance. Journal of Public Health Management Practice, 10(3), 204-215.

Sever, L. E. (1998). Environmental Contamination and Health Effects: What is the Evidence? Journal of Clean Technology, Environmental Toxicology, and Occupational Medicine, 7(3), 313-329.

Sly, T. (2000). The Perception and Communication of Risk: A Guide for the Local Health Agency. Canadian Journal of Public Health, 91(2), 153-156.

Smith, R. K., Corvalan, F. C., Kjellstrom, T. (1999). How Much Global III Health Is Attributable to Environmental Factors? Epidemiology, 10(5), 573-584.

Solitare, L. (2005). Prerequisite Conditions for Meaningful Participation in Brownfields Redevelopment. Journal of Environmental Planning and Management, 48(6), 917-935.

Swickard, T. J. (2008). Regulatory Incentives to Promote Private Sector Brownfield Remediation and Reuse. Soil \& Sediment Contamination, 17, 121-136.

Syms, P. (1999). Desk Reference Guide to Potentially Contaminative Land Uses. ISVA, London.

Syms, P. (2004). Previously Developed Land Industrial Activities and Contamination. Blackwell Publishing: Great Britain.

The Cancer and the Environment Stakeholder Group. (2007). Cancer and the Environment in Ontario: Gap Analysis on the Reduction of Environmental Carcinogens. July 20, 2007.

The City of Toronto (Toronto). (2013). Memorandum to Fiona Chapman, Manager, Pedestrian Projects and Monica Campbell, Director, Healthy Public Policy, from Stephen Schijns, Manager, Infrastructure Planning, Re: Inclusion of Health and Public Realm Principles and Evaluation Criteria in Eglinton Planning Study Environmental Assessment (EA) Alternatives Analysis, dated February 12, 2013

The United States Conference of Mayors. (2010). Brownfields Redevelopment: Reclaiming Land, Revitalizing Communities, A Compendium of Best Practices, Volume 5, November 2010.

Tomas, C. D. (2009). Statistical Methods in Environmental Epidemiology. Oxford University Press: New York, U.S. 
Tong, S., von Schirnding, E. Y., Prapamontol, T. (2000). Environmental Lead Exposure: a Public Health Problem of Global Dimensions. Bulletin of the World Health Organization, 78(9), 1068-1077.

Toronto Public Health (TPH). (2005). Toronto Staff Report to The Board of Health From Dr. McKeown, Medical Officer of Health Re: Health Impact Assessment, November, 14, 2005.

Toronto Public Health (TPH). (2009). Letter from the Medical Officer of Health to Susan Howard, Senior Policy Analyst, Ontario Ministry of the Environment re: Comments on EBR posting: 010-4642 Proposal for Amending Ontario Regulation 153/04, Brownfields Record for Site Condition.

Toronto Public Health (TPH). (2011). Assessing Urban Impacted Soil for Urban Gardening: Decision Support Tool - Technical Report and Rationale. Toronto: City of Toronto, May 2011.

Toronto Public Health (TPH). (2011b). Healthy City by Design. Toronto, Ontario. October 2011.

Turnock, B., J. (2001). Public Health What It Is and How It Works. Sudbury, Massachusetts : Jones and Bartlett Publishers.

Tyshenko, G. M. et al. (2007). Regulatory and Nonregulatory Strategies for Improving Children's Environmental Health in Canada. Journal of Toxicology and Environmental Health, Part B, 10, 143-156.

United Nations Development Programme (UNDP). (1997). General Guidelines for Capacity Assessment And Development. Version 1.

United States Agency for Environmental Protection (US EPA). (2009). Risk Assessment Guidance for Superfund Volume I: Human Health Evaluation Manual (Part F, Supplemental Guidance for Inhalation Risk Assessment). Office of Superfund Remediation and Technology Innovation Environmental Protection Agency, Washington, D.C.

United States Agency for Environmental Protection (US EPA). (2006). Brownfields Public Health and Health Monitoring. Solid Waste and Emergency Responses (5105T0, EPA-560-F-06-210, July 2006.

Vandermoere, F. (2008). Psychosocial Health of Residents Exposed to Soil Pollution in a Flemish Neighbourhood. Social Science and Medicine, 66, 1646-1657.

Vrijheid, M. (2000). Health Effects of Residence Near Hazardous Waste Landfill Sites: 
A Review of Epidemiological Literature. Environmental Health Perspectives, 108 (Suppl 1), 101-112.

Weir, E., D’Entremont, N., Stalker, S., Kurji, K., Robinson, V. (2009). Applying the Balanced Scorecard to Local Public Health Performance Measurement:

Deliberations and Decisions. BMC Public Health, 9(127).

Wild, P., Bourgkard, E., Paris, C. (2009). Lung Cancer and Exposure to Metals: The Epidemiological Evidence. Methods in Molecular Biology, Cancer Epidemiology, vol. 472, Humana Press: NJ.

World Health Organization. (2000). Methodology for Assessment of Environmental Burden of disease. ISEE Session on the Environmental Burden of Disease, Buffalo, 22 August 2000, WHO Consultation, Buffalo, 23-24 August 2000.

World Health Organization. (2006). Preventing Disease Through Healthy Environments. Towards an estimate of the environmental burden of disease. WHO Press: Switzerland. 